\title{
Development of microorganisms with improved transport and biosurfactant activity for enhanced oil recovery Annual Report
}

\author{
Report Start Date: June 1, 2002 \\ Report End Date: May 31, 2003 \\ M.J. McInerney, R.M. Knapp, D. P. Nagle, Jr., Kathleen Duncan, \\ N. Youssef, M. J. Folmsbee, S. Maudgakya
}

Date of Report: June 26, 2003

DE-FC-02NT15321

\author{
Department of Botany and Microbiology \\ University of Oklahoma \\ 770 Van Vleet Oval \\ Norman, OK 73019-0245
}




\section{Disclaimer}

This report was prepared as an account of work sponsored by an agency of the United States Government. Neither the United States Government nor any agency thereof, nor any of their employees, makes any warranty, express or implied, or assumes any legal liability or responsibility for the accuracy, completeness, or usefulness of any information, apparatus, product or process disclosed, or represents that its use would not infringe privately owned rights. Reference herein to any specific commercial product, process, or service by trade name, trademark, manufacturer, or otherwise does not necessarily constitute or imply its endorsement, recommendation, or favoring by the United States Government or any agency thereof. The views and opinions of authors expressed herein do not necessarily state or reflect those of the United States Government or any agency thereof. 


\section{Table of Contents}

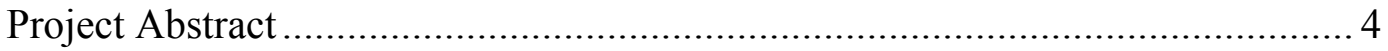

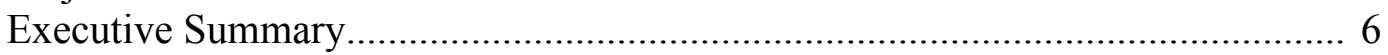

Chapter 1. Subsurface hydrocarbon mobilization using biosurfactants requires viscosity control and a low molecular weight alcohol...................................................... 9

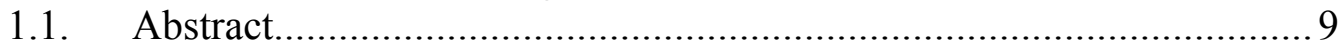

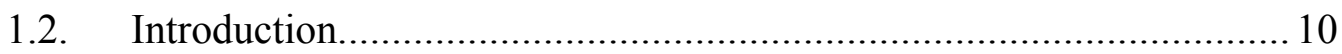

1.3. Experimental methods.................................................................. 12

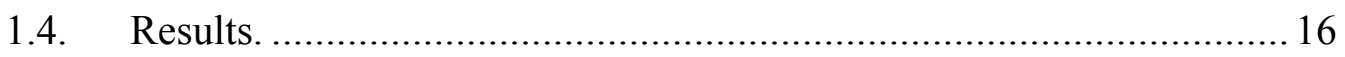

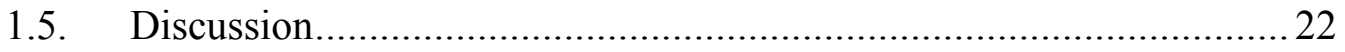

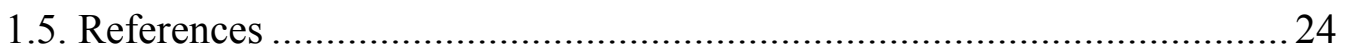

Chapter 2. Anaerobic growth of and biosurfactant production by Bacillus

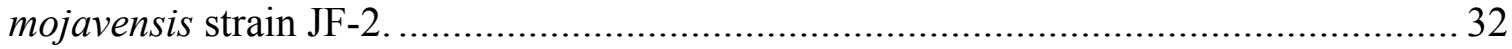

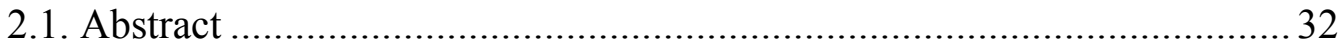

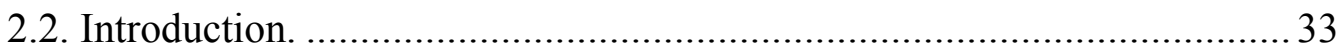

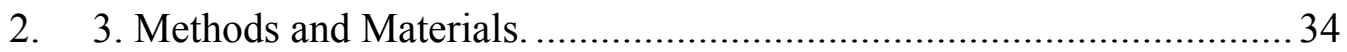

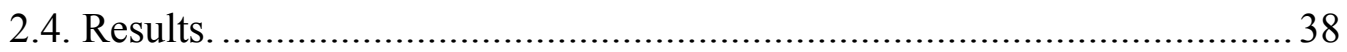

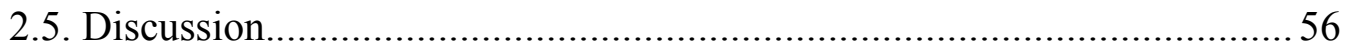

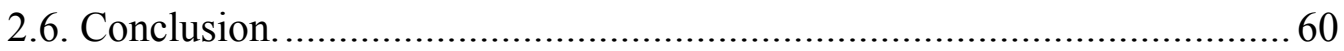

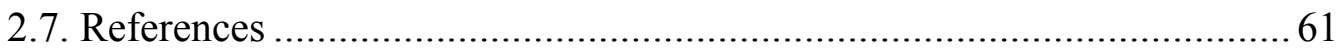

Chapter 3. Screening, selection, and genetic manipulation of biosurfactant-

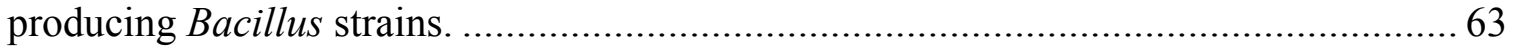

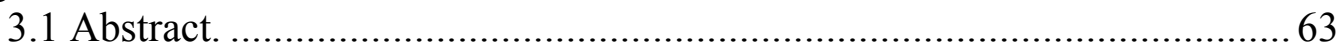

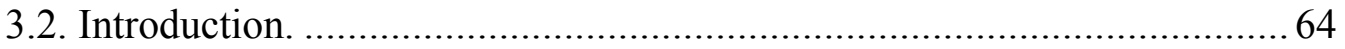

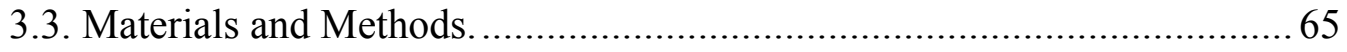

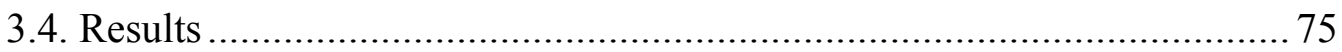


Chapter 4. Interfacial Tension Measurements ............................................. 103

4.1 Abstract .............................................................................. 103

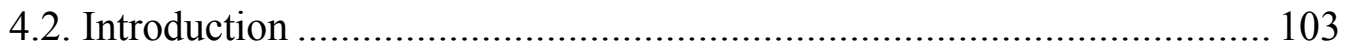

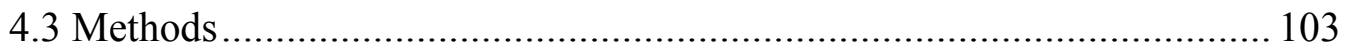

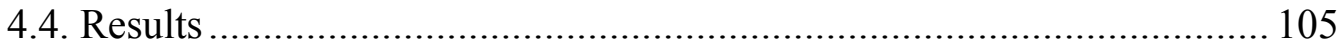

4.5. Discussion.............................................................................. 110

4.6. Conclusions: ...................................................................... 110

4.7 List of references ................................................................... 111

\section{Project Abstract}

Biosurfactants enhance hydrocarbon biodegradation by increasing apparent aqueous solubility or affecting the association of the cell with poorly soluble hydrocarbon. Here, we show that a lipopeptide biosurfactant produced by Bacillus mojavensis strain JF-2 mobilized substantial amounts of residual hydrocarbon from sandpacked columns when a viscosifying agent and a low molecular weight alcohol were present. The amount of residual hydrocarbon mobilized depended on the biosurfactant concentration. One pore volume of cell-free culture fluid with $900 \mathrm{mg} / \mathrm{l}$ of the biosurfactant, $10 \mathrm{mM}$ 2,3-butanediol and $1000 \mathrm{mg} / \mathrm{l}$ of partially hydrolyzed polyacrylamide polymer mobilized $82 \%$ of the residual hydrocarbon. Consistent with the high residual oil recoveries, we found that the bio-surfactant lowered the interfacial tension (IFT) between oil and water by nearly 2 orders of magnitude compared to typical IFT values of 28-29 $\mathrm{mN} / \mathrm{m}$. Increasing the salinity increased the IFT with or without 2,3butanediol present. The lowest interfacial tension observed was $0.1 \mathrm{mN} / \mathrm{m}$. The lipopeptide biosurfactant system may be effective in removing hydrocarbon contamination sources in soils and aquifers and for the recovery of entrapped oil from low production oil reservoirs.

Previously, we reported that Proteose peptone was necessary for anaerobic growth and biosurfactant production by $B$. mojavensis JF-2. The data gathered from crude purification of the growth-enhancing factor in Proteose peptone suggested that it consisted of nucleic acids; however, nucleic acid bases, nucleotides or nucleosides did not replace the requirement for Proteose Peptone. Further studies revealed that salmon 
sperm DNA, herring sperm DNA, Echerichia coli DNA and synthetic DNA replaced the requirement for Proteose peptone. In addition to DNA, amino acids and nitrate were required for anaerobic growth and vitamins further improved growth. We now have a defined medium that can be used to manipulate growth and biosurfactant production.

As an initial step in the search for a better biosurfactant-producing microorganism, 157 bacterial strains were screened for biosurfactant production under both aerobic and anaerobic conditions. A hundred and forty seven strains produced either equal or higher amounts of biosurfactant compared to B. mojavensis JF-2 and the 10 best strains were chosen for further study. In an attempt to increase biosurfactant production, a genetic recombination experiment was conducted by mixing germinating spores of four of the best strains with $B$. mojavensis JF-2. Biosurfactant production was higher with the mixed spore culture than in the cocultures containing B. mojavensis JF-2 and each of the other 4 strains or in a mixed culture containing all five strains that had not undergone genetic exchange. Four isolates were obtained from the mixed spores culture that gave higher biosurfactant production than any of the original strains. Repetitive sequencebased polymerase chain reaction analysis showed differences in the band pattern for these strains compared to the parent strains, suggesting the occurrence of genetic recombination. We have a large collection of biosurfactant-producing microorganisms and a natural mechanism to improve biosurfactant production in these organisms. 


\section{Executive Summary}

Current technology recovers only one-third to one-half of the oil that is originally present in an oil reservoir. Since almost all regions of the world have been intensively explored for oil and the discovery of large new oil resources is unlikely, the exploitation of oil resources in existing reservoirs will be essential in the future. In order to exploit this untapped resource, technology must be developed to increase the mobility of oil in existing reservoirs. Microorganisms produce a variety of compounds capable of generating the low interfacial tensions between the hydrocarbon and the aqueous phases required to mobilize residual hydrocarbon. In particular, the lipopeptide biosurfactant produced by Bacillus mojavensis JF-2 reduces the interfacial tension between hydrocarbon and aqueous phases to very low levels $(<0.016 \mathrm{mN} / \mathrm{m})$.

Biosurfactants are a diverse group of surface-active chemical compounds produced by a wide variety of microorganisms. They are amphiphilic molecules with both hydrophilic and hydrophobic domains, which allow them to partition at the interface of two fluids with differing polarities such as oil-water or water-air interfaces. They are thus capable of reducing the interfacial and/or surface tension. Such properties make them good candidates for enhanced oil recovery.

Biosurfactants have been investigated as replacements for synthetic surfactants since they are environmentally friendly and biodegradable. They are less sensitive to extreme conditions of temperature, salt concentration, and pressure than synthetic surfactants. Since biosurfactants have very low critical micelle concentration $(\mathrm{mg} / \mathrm{l})$, they are considered to be more economical to use than synthetic surfactants.

Most research on biosurfactants has focused on bioremediation of fuelcontaminated sites where they are thought to enhance hydrocarbon mobilization by increasing the apparent aqueous solubility. Here, we show that a lipopeptide biosurfactant produced by $B$. mojavensis JF-2 mobilizes substantial amounts of residual hydrocarbon from sand-packed columns when a viscosifying agent and a low molecular weight alcohol are present. The amount of residual hydrocarbon mobilized depends on the biosurfactant concentration. One pore volume of cell-free culture fluid with $900 \mathrm{mg} / \mathrm{l}$ of the biosurfactant, $10 \mathrm{mM}$ 2,3-butanediol and $1000 \mathrm{mg} / 1$ of partially hydrolyzed polyacrylamide polymer mobilized $82 \%$ of the residual hydrocarbon. Even low biosurfactant concentrations $(16 \mathrm{mg} / \mathrm{l})$ mobilized substantial amounts of residual hydrocarbon (29\%). The biosurfactant concentrations effective for residual oil recovery are substantially lower than that required for synthetic surfactants, suggesting that biosurfactant-mediated oil recovery will be an economically feasible process.

The recovery of residual oil depends on the generation of low interfacial tensions in other to release oil that is entrapped in small pores. The data above suggest that the JF2 biosurfactant could significantly lower the interfacial tension (IFT). Studies were conducted to test directly whether the B. mojavensis JF-2 biosurfactant generates low 
interfacial tensions. The presence of a co-surfactant, 2,3-butanediol was shown to improve oil recoveries possibly by changing the optimal salinity concentration of the formulation. For this reason, we also tested the effect of 2,3-butanediol and salinity on interfacial tension. The biosurfactant lowered IFT by nearly 2 orders of magnitude compared to typical values of $28-29 \mathrm{mN} / \mathrm{m}$. Increasing the salinity increased the IFT with or without 2,3-butanediol present. However, the presence of 2,3-butanediol partially counteracted the effects of salinity since the IFT at high salinity was lower in the presence of 2,3-butanediol than in its absence. The lowest interfacial tension observed was $0.1 \mathrm{mN} / \mathrm{m}$.

B. mojavensis JF-2 is the only strain known to grow and produce an effective biosurfactant anaerobically. Thus, this strain is the only one that can be used for in situ applications. However, anaerobic growth in the original medium was inconsistent and little biosurfactant was produced. The in situ growth and biosurfactant production of $B$. mojavensis JF-2 in sandstone cores resulted in inconsistent oil recoveries probably due to its inconsistent growth under anaerobic conditions. For this reason, it was necessary to improve growth and control biosurfactant production by manipulating the medium components.

Improved anaerobic growth and biosurfactant production was accomplished with the addition of Proteose peptone to the medium, but the resulting medium was much too complex to allow a proper understanding of the nutritional controls of biosurfactant production. Consequently, it was necessary to elucidate the nature of the growthenhancing factor found in Proteose peptone and identify any other growth factor requirement(s).

Previously, we reported that Proteose peptone was necessary for anaerobic growth and biosurfactant production by B. mojavensis JF-2. Preliminary data suggested that the growth-enhancing factor consisted of nucleic acids; however, nucleic acid bases, nucleotides or nucleosides did not replace the requirement for Proteose Peptone. Further studies revealed that salmon sperm DNA, herring sperm DNA, Echerichia coli DNA and synthetic DNA replaced the requirement for Proteose peptone. In addition to DNA, amino acids and nitrate were required for anaerobic growth and vitamins further improved growth. These results indicate that Proteose peptone is not necessary for in situ growth of B. mojavensis JF-2 and can be replaced by DNA, amino acids and vitamins. Since small amounts of DNA, amino acids and vitamins maybe naturally present in the environment or by cross-feeding from other microorganisms, only a carbon/energy source would need to be added to stimulate in situ growth and biosurfactant production.

Since genetic recombination is known to occur between mixed germinating spores of Bacillus species, we hypothesized that Bacillus strains with improved biosurfactant producing ability could be obtained by mixing germinating spores of JF-2 and those of other Bacillus species. Our aim is to obtain strains that produce higher amount of biosurfactants than JF-2, are able to grow anaerobically with minimal nutrient requirements, and can maintain their biosurfactant activity over long periods of time. We screened a large number of Bacillus strains for anaerobic growth and biosurfactant production, selected the most promising strains, and attempted to increase biosurfactant production through genetic recombination. 
We screened 157 bacterial strains for biosurfactant production under both aerobic and anaerobic conditions. These data were compared to the amount of biosurfactant produced by $B$. mojavensis JF-2. A 147 strains produced either equal or higher amounts of biosurfactant compared to JF-2 and the 10 best strains were chosen for further study. In an attempt to increase biosurfactant production, a genetic recombination experiment was conducted by mixing germinating spores of four of the best strains with JF-2. Biosurfactant production was higher with the mixed spore culture than in the co-cultures containing JF-2 and each of the other 4 strains or in a mixed culture containing all five strains that had not undergone genetic exchange. Four isolates were obtained from the mixed spores culture that gave higher biosurfactant production than any of the original strains. Repetitive sequence-based polymerase chain reaction analysis showed differences in the band pattern for these strains compared to the parent strains, suggesting the occurrence of genetic recombination.

We achieved all of the milestones that were proposed for this project during the first year. Also, we accomplished on task that was proposed for year 2 (oil recovery studies). We know the chemical nature of the growth-enhancing factor for B. mojavensis strain JF-2 (Task 1.1). We completed our screening for biosurfactant-producing strains and developed an natural genetic process to improve biosurfactant production (Task 1.2). We found that the transport of spores through porous material is highly efficient (Task 2). The JF-2 biosurfactant lowers interfacial tension between brine and oil by two orders of magnitude (Task 3.1) and effectively mobilizes large amounts of residual oil from model porous systems (Task 3.2, year 2).

In addition to meeting and exceeding our goals for the first year, this project also has had broader impacts on science and the infrastructure of science. The discovery of the DNA requirement for growth is a novel one and may help explain why so few microorganisms present in most environments can be cultivated in the laboratory. We anticipate that this discovery will be an important step in understanding the biological diversity on Earth. Second, we provided hands-on research experience for a large number of undergraduates. Fourteen students did their capstone project in microbiology on various aspects of this project. In addition, we had four undergraduates involved in independent research projects on this project and we are happy to report that one female undergraduate that worked on this project has recently entered our graduate microbiology program. Thus, the project has resulted in a more scientifically literate workforce and has increased the diversity of students pursuing graduate training the science. 


\section{Chapter 1. Subsurface hydrocarbon mobilization using biosurfactants requires viscosity control and a low molecular weight}

\section{alcohol.}

\subsection{Abstract.}

Biosurfactants enhance hydrocarbon biodegradation by increasing the apparent aqueous solubility or affecting the association of the cell with the poorly soluble hydrocarbon. Here, we show that a lipopeptide biosurfactant produced by Bacillus mojavensis strain JF-2 mobilized substantial amounts of residual hydrocarbon from sandpacked columns when a viscosifying agent and a low molecular weight alcohol are present. The amount of residual hydrocarbon mobilized depended on the biosurfactant concentration. One pore volume of cell-free culture fluid with $900 \mathrm{mg}^{-1}$ of the biosurfactant, $10 \mathrm{mM} \mathrm{2,3-butanediol} \mathrm{and} 1000 \mathrm{mg} \mathrm{l}^{-1}$ of partially hydrolyzed polyacrylamide polymer mobilized $82 \%$ of the residual hydrocarbon. Even low biosurfactant concentrations $\left(16 \mathrm{mg}^{-1}\right)$ mobilized substantial amounts of residual hydrocarbon (29\%). The lipopeptide biosurfactant system may be an effective in removing hydrocarbon contamination sources in soils and aquifers and for the recovery of entrapped oil from low production oil reservoirs. 


\subsection{Introduction.}

The widespread use of petroleum hydrocarbons has resulted in the contamination of valuable groundwater resources. Petroleum hydrocarbons may exist in the vadose and saturated zones as a free liquid or ganglia of residual hydrocarbon $(8,20,53)$. Even if the free liquid hydrocarbon can be removed, substantial amounts of residual hydrocarbon remain entrapped by capillary forces and represent a long-term source of contamination (20). Entrapment of petroleum hydrocarbons by capillary forces is also a major factor that limits oil recovery $(3,34,38)$. Current technology recovers only one-third to one-half of the oil that is originally present in an oil reservoir (1). Since almost all regions of the world have been intensively explored for oil, the discovery of large new oil resources is unlikely and the exploitation of oil resources in existing reservoirs will be essential in the future (1).

Surfactants of synthetic or biological origin enhance hydrocarbon biodegradation by increasing the apparent aqueous solubility of the hydrocarbon $(14,16-18,23,25,29$, $35-37,39,40,47,49,50,52,56,57)$ or by enhancing the interaction of the microbial cell with the hydrocarbon $(2,7,39)$. Alternately, bulk hydrocarbon displacement can occur if the capillary forces that entrap the hydrocarbon are reduced $(42,45)$. Interfacial tension between the hydrocarbon and aqueous phases is largely responsible for trapping the hydrocarbon in the porous matrix and ultra-low values (several orders of magnitude reduction) are needed for hydrocarbon mobilization $(3,10,11,38,53)$. To achieve ultralow interfacial tensions, surfactant concentrations significantly above that needed to form micelles (e.g., the critical micelle concentration) are required $(8,43)$. Optimized 
surfactant formulations recover almost all of the residual hydrocarbon present in laboratory test systems $(3,5,14,42,45)$ and have been shown to be effective in removing hydrocarbon contamination in aquifers $(41,42)$. However, the large concentrations of surfactants required for mobilization necessitate recycling and reusing the surfactants and treating only small portions of the contaminated zone at a time (26). High chemical and low crude oil prices have prevented the widespread use of surfactants for enhanced oil recovery.

Microorganisms produce a variety of biosurfactants (13), several of which generate the low interfacial tensions between the hydrocarbon and the aqueous phases required to mobilize residual hydrocarbon $(13,19,28)$. In particular, the lipopeptide biosurfactant produced by Bacillus mojavensis strain JF-2 reduces the interfacial tension between oleic and aqueous phases to very low levels $(<0.016 \mathrm{mN} / \mathrm{m})(28,32)$. The critical micelle concentration is $20 \mathrm{mg} / \mathrm{l}$, indicating that the biosurfactant is effective even at very low concentrations (28). The use of biosurfactants to mobilize residual hydrocarbon has met with mixed results. From 20 to $90 \%$ of hydrocarbons present in contaminated soils or oil shale cuttings were removed in the presence of biousrfactants $(23,51)$. The rhamnolipid biosurfactant produced by certain strains of Pseudomonas was 20 times more effective in solubilizing hexadecane than some synthetic surfactants (47) and mobilized up to $75 \%$ of the residual hexadecane from sand-packed columns $(21,22)$. However, the number of pore volumes required (40 to 70) was large. Residual oil is recovered when a biosurfactant-producing bacterium and the nutrients needed to support growth are introduced into sandstone cores $(31,48,54)$, but residual hydrocarbon 
recoveries were often low (5 to $20 \%$ ) and required multiple pore volumes of recovery fluid $(31,48)$.

Here, we show that substantial mobilization of residual hydrocarbon from a model porous system does occur at biosurfactant concentrations made naturally by $B$. mojavensis strain JF-1. Effective mobilization with a minimal volume of recovery fluid requires three components, a biosurfactant, a polymer and 2,3-butanediol.

\subsection{Experimental methods.}

Cultivation. Bacillus mojavensis strain JF-2 (ATCC) was grown in a phosphatebuffered, mineral salts medium (medium E)(24) with (in $\mathrm{g}^{-1}$ ) 1 g yeast extract, $1 \mathrm{~g}$ $\mathrm{NaNO}_{3}$ and 30 g Proteose Peptone \#3 (Difco Laboratories, Inc., Detroit, MI). B. mojavensis strain JF-2 was streaked onto agar plates of the above medium with $15 \mathrm{~g} \mathrm{l}^{-1}$ agar and colonies were used to inoculate 100-ml liquid cultures of the above medium. The 100 -ml cultures were incubated without shaking at $37^{\circ} \mathrm{C}$ for 24 hours and used to inoculate a 1-liter culture of the same medium. The 1-liter culture was incubated aerobically at room temperature until stationary phase was reached (about $48 \mathrm{~h}$ ) with stirring provided by a magnetic stirrer and a stir bar.

Anaerobically prepared medium contained $0.025 \%$ cysteine $\bullet \mathrm{HC}$ and was boiled and dispensed under $\mathrm{O}_{2}$-free $100 \%$ nitrogen gas phase(6). Additions to and transfers from sterile, anaerobic media were done by using sterile syringes and needles degassed with $\mathrm{O}_{2}$-free, $100 \%$ nitrogen prior to use(6).

Cell-free culture fluid preparation: After incubation, the cells from aerobically

grown cultures were removed by centrifugation $\left(10,000 \times g ; 4^{\circ} \mathrm{C} ; 20 \mathrm{~min}\right)$. The cell-free 
culture fluid was divided into two portions and 2,3-butanediol was added to one portion to give a final concentration of $10 \mathrm{mM}$. Each portion then received sufficient partiallyhydrolyzed polyacrylamide to give a final concentration of $1 \mathrm{~g} \mathrm{l}^{-1}$. Uninoculated medium received the same concentrations of polymer and butanediol.

Preparation of cell-free culture fluid without biosurfactant. B. mojavensis strain JF-2 was grown anaerobically in the above medium in one-liter volumes using 2liter bottles. After growth ceased, the cells were removed by centrifugation as above and the $\mathrm{pH}$ of the cell-free medium was reduced to less that 2 by the addition of $50 \% \mathrm{HCl}$. The acidified, cell-free medium was left at $4^{\circ} \mathrm{C}$ overnight to precipitate the biosurfactant(12). The precipitated material was removed by centrifugation as described above. The $\mathrm{pH}$ of the biosurfactant-free, cell-free medium was adjusted to 7.0 by the addition of $\mathrm{NaOH}$ pellets.

Biosurfactant preparation. Large amounts of the biosurfactant were obtained by growing $B$. mojavensis strain JF-2 aerobically in carboys containing 8 liters medium without Proteose peptone. After growth ceased, the $\mathrm{pH}$ of the medium was adjusted to less than 2 by the addition of concentrated $\mathrm{HCl}$. The acidified medium was kept overnight at $4^{\circ} \mathrm{C}$ to precipitate the biosurfactant. The medium was centrifuged as described above. The supernate was discarded and the pellet was dissolved in $200 \mathrm{ml}$ of methanol. The methanol solution was centrifuged as above to remove particulate material. The concentration of the biosurfactant in methanol was measured by highpressure liquid chromatography (HPLC). An appropriate volume of the methanolic, biosurfactant solution was added to the neutralized, biosurfactant-free, cell-free medium to give the biosurfactant concentrations shown in Table 1. 
Biosurfactant quantification: The biosurfactant from a 20-ml sample of cell-free culture fluid was collected by acid precipitation and centrifugation as described above. The pellet containing the biosurfactant was extracted with $2 \mathrm{ml}$ of methanol for $1 \mathrm{~min}$ with agitation. The insoluble material was removed by centrifugation as above. The biosurfactant was then quantified by a HPLC equipped with a $\mathrm{C}_{18}$ column and an ultraviolet detector set at $210 \mathrm{~nm}(27)$. The mobile phase was $70 \%$ methanol and $30 \%$ of a $10 \mathrm{mM}$ phosphate buffer ( $\mathrm{pH}$ of 6.8$)$. The flow rate was $1 \mathrm{ml} / \mathrm{min}$ and the injection volume was $20 \mu 1$. Surfactin (Sigma Chemical Co. St. Louis, MO) was used as the standard. The amount of biosurfactant present in cultures was corrected for the percent recovery of known amounts of surfactin added to sterile medium after acid precipitation and methanol extraction.

Preparation of sand-packed columns. Plexiglas columns were approximately $4.5 \mathrm{~cm}$ (inside diameter) by $40 \mathrm{~cm}$ long and packed with quartz sand (approximately 100 mesh grain size). Each end had a plate had an O-ring to prevent leaks which had a fitting sealed with a rubber septum. Connections to sources of vacuum, gas and liquids were made with a syringe needle attached to nylon tubing that was inserted into this septum. The weight of the sand was calculated from the difference in weight before and after packing with sand. Air was removed from the column by placing the column under vacuum for 10 minutes. The column was then saturated with a $5 \% \mathrm{NaCl}$ brine solution by positive displacement. Once the brine reached the top of the column, a syringe needle was inserted into the top septum to allow the solution to exit the column. After one pore volume of the solution passed through the column, the flow rate was measured with a stopwatch and a graduated cylinder. The injection pressure was measured by using a 
pressure gauge attached between the fluid reservoir and the column and used to calculate the permeability of the column to the brine solution according to Darcy's law. The column was then weighed and the volume of brine inside the column (pore volume) was calculated from the difference in the wet and dry weight of the column and the brine density.

The column was then saturated with oil by positive displacement by keeping the oil reservoir pressurized with nitrogen gas. The displaced water was collected in a graduated cylinder to measure the volume. After only oil was displaced from the column, the flow rate and injection pressure were determined as described above. These data were used to calculate the effective permeability of the column to oil at residual water saturation. The amount of residual water present in the column was calculated from the amount of water displaced from the column during oil flooding and the amount of water present after brine saturation. The column was then flooded to residual oil saturation by injecting the brine solution into the column until no more oil was displaced from the column. The amount oil displaced from the column was determined volumetrically and used to calculate the residual oil saturation from difference in oil volume before and after brine flooding. After water breakthrough, the flow rate of brine and the injection pressure were determined as described above and used to calculate the effective permeability of the column to brine at residual oil saturation. At least six pore volumes of brine were injected through the column to ensure that it was at residual oil saturation.

Biosurfactant treatments. The column was flooded with a biosurfactant solution as described above for brine flooding. Unless otherwise indicated, each column was flooded with $200 \mathrm{ml}$ of the biosurfactant solution, approximately 2 pore volumes. 
Effluent from the columns was collected in 50-ml syringes held in a vertical position to allow the measurement of oil and brine volumes. Duplicate columns were used for each treatment. When the biosurfactant solution contained partially hydrolyzed polyacrylamide (PHPA) $\left(1 \mathrm{~g} \mathrm{l}^{-1}\right), 5 \mathrm{ml}$ of the PHPA $\left(1 \mathrm{~g} \mathrm{l}^{-1}\right)$ in $2.5 \% \mathrm{NaCl}$ was injected into the column prior to injection of biosurfactant-containing solution. After the biosurfactant-containing solution passed through the column, $25 \mathrm{ml}$ of $1 \mathrm{~g} \mathrm{l}^{-1}$ of PHPA in $2.5 \% \mathrm{NaCl}$ followed by $25 \mathrm{ml}$ of $0.7 \mathrm{~g} \mathrm{l}^{-1}$ of PHPA in $2.5 \% \mathrm{NaCl}$ were injected into the column. Each column was then flooded with $150 \mathrm{ml}$ of $2.5 \% \mathrm{NaCl}$.

Petrophysical data. The sand packs had the following properties (mean \pm standard deviation): porosity, $31.9 \pm 1.2 \%$; pore volume, $90.3 \pm 6.9 \mathrm{ml}$; permeability, 2.0 \pm 0.1 Darcies; and residual oil saturation, $21.9 \pm 3.0 \%$. The crude oil had a density of $0.825 \mathrm{~g} \mathrm{~cm}^{-3}$. An average molecular weight for crude oil of 320 to $330 \mathrm{~g} \mathrm{~mol}^{-1}$ was estimated from the crude oil composition of an Oklahoma crude oil by using the method of Waston, Nelson and Murphy(9). The molar solubility ratio was estimated from the slope of the line in Figure 1, the crude oil density and an assumed average molecular weight 320 to $330 \mathrm{~g}$ mol-1 (8).

\subsection{Results.}

Effect of the biosurfactant alone. Since surfactant-enhanced remediation processes use surfactant concentrations far above the critical micelle concentration(8), we tested whether increasing the biosurfactant concentration would result in substantial mobilization of residual hydrocarbon. The amount of oil recovered when the biosurfactant-free culture fluid was used alone or with the addition of up to $1.7 \mathrm{~g}^{-1}$ of the 
partially purified biosurfactant was very low and similar to the $5 \% \mathrm{NaCl}$ control (Table

1).

Table 1. Oil recovery with different concentrations of the biosurfactant ${ }^{\mathrm{a}}$.

\begin{tabular}{lllllll}
\hline $\begin{array}{l}\text { Type of Fluid } \\
\text { Injected }\end{array}$ & $\begin{array}{l}\text { Polymer } \\
\text { Present }\end{array}$ & $\begin{array}{l}\text { Biosurfactant } \\
\text { Concentration } \\
\left(\mathrm{mg} \mathrm{l}^{-1}\right)\end{array}$ & $\begin{array}{l}\text { Volume } \\
\text { Injected } \\
(\mathrm{ml})\end{array}$ & $\begin{array}{l}\text { Residual } \\
\text { Oil } \\
\text { Saturation } \\
(\%)^{\mathrm{b}}\end{array}$ & $\begin{array}{l}\text { Volume } \\
\text { of Oil } \\
\text { Recovered } \\
(\mathrm{ml})^{\mathrm{b}}\end{array}$ & $\begin{array}{l}\text { Percent } \\
\text { Residual } \\
\text { Oil } \\
\text { Recovery } \\
\mathrm{b}\end{array}$ \\
\hline $5 \% \mathrm{NaCl}$ & - & 0 & 200 & $20(10)$ & $0.2(0)$ & $1.3(0.6)$ \\
$2.5 \% \mathrm{NaCl}$ & + & 0 & 150 & $8.4(7.1)$ & $\mathrm{ND}^{\mathrm{c}}$ & $\mathrm{ND}^{\mathrm{c}}$ \\
$\begin{array}{l}\text { Biosurfactant-free } \\
\text { culture fluid }\end{array}$ & - & 0 & 200 & $25(4)$ & $0.2(0.5)$ & $<0.1$ \\
& - & 100 & 100 & $13(8)$ & $0.1(0)$ & $1.1(0.9)$ \\
& - & 175 & 100 & $16(4)$ & $0.4(0.1)$ & $2.2(0.5)$ \\
& - & 300 & 100 & $17(10)$ & $0.4(0.3)$ & $2.3(1.6)$ \\
& - & 1700 & 200 & $27(10)$ & $0.4(0.1)$ & $1.6(0.1)$ \\
& - & 12300 & 200 & $22(3.4)$ & $0.9(0.7)$ & $4.9(3.1)$ \\
& + & 12300 & 60 & $13(7.2)$ & $2.6(0.1)^{\mathrm{d}}$ & $\begin{array}{l}23.6 \\
(13.9)^{\mathrm{d}}\end{array}$ \\
\hline
\end{tabular}

${ }^{a}$ Biosurfactant-free culture fluid was prepared by removing cells from an anaerobically grown culture by centrifugation and then removing any biosurfactant that may have been present in the culture by acid precipitation. The $\mathrm{pH}$ of the medium was then adjusted to 7.0 and the indicated concentration of the partially purified biosurfactant was added. The concentration of partially hydrolyzed polyacryalmide was $1 \mathrm{~g} \mathrm{l}^{-1}$.

${ }^{\mathrm{b}}$ Mean of duplicate determinations with the range shown in parentheses.

${ }^{\mathrm{c}} \mathrm{ND}$, not determined.

${ }^{\mathrm{d}}$ Analysis of variance and Tukey test showed that these means were significantly different from the means of the other treatments $(\mathrm{P}<0.05)$.Even at a very high biosurfactant concentration $\left(12.3 \mathrm{~g}^{-1}\right)$, similar to that used in surfactant-based enhanced oil recovery or groundwater remediation technologies $(15,42)$, the recovery of residual hydrocarbon was poor and not statistically significant different from that obtained with lower biosurfactant concentrations.

When the concentration of the biosurfactant used was $1.7 \mathrm{~g} \mathrm{l}^{-1}$ or less, no visible oil bank was formed. A few sand packs had places where clean sand was visible 
indicating that some oil had been mobilized. A visible oil bank formed when the concentration of the biosurfactant was $12.3 \mathrm{~g} \mathrm{l}^{-1}$. However, the oil bank dissipated by the time it reached the middle of the sand pack, suggesting that substantial oil could be produced if a mechanism to stabilize the oil bank could be developed.

Effect of polymer. The addition of partially-hydrolyzed polyacrylamide $\left(1 \mathrm{~g} \mathrm{l}^{-1}\right)$ to cell-free culture fluid that contained $12.3 \mathrm{~g} \mathrm{l}^{-1}$ of the biosurfactant significantly improved residual hydrocarbon recovery (Table 1). As these polymer-biosurfactanttreated packs were eluted, an oil-bank formed that grew in thickness as it migrated through the sand pack. The same concentration of the polymer alone in $2.5 \% \mathrm{NaCl}$ did not lead to the formation of an oil-bank, nor was residual hydrocarbon recovered (Table 1).

\section{Components needed for significant residual hydrocarbon recovery.}

Surfactant-based oil or contaminant recovery technologies use a small molecular weight alcohol in addition to the viscosifying agent and the surfactant $(4,5,43)$. We tested whether the addition of 2, 3-butanediol, an alcohol commonly made by Bacillus species during anaerobic growth(44) along with partially-hydrolyzed polyacrylamide would recover residual hydrocarbon at biosurfactant concentrations made naturally by $B$. mojavensis strain JF-1. When both partially-hydrolyzed polyacrylamide and 2,3butanediol were added to cell-free culture fluid that contained the $16 \pm 2.5 \mathrm{mg} \mathrm{l}^{-1}$ (mean with the range) of the biosurfactant, $4.4 \pm 3.4 \mathrm{ml}$ of oil representing about $29 \%$ of the hydrocarbon remaining in the sand pack was recovered (Table 2). Very little oil was recovered when partially-hydrolyzed polyacrylamide and 2,3-butanediol were added to sterile medium in the absence of the biosurfactant. Some oil was recovered when cell-free 
culture fluid with $16 \mathrm{mg}^{-1}$ of biosurfactant was used alone or when supplemented with either partially-hydrolyzed polyacrylamide or 2,3-butanediol. However, these values

Table 2. Effect of biosurfactant concentration and the addition of partially hydrolyzed polyacrylamide and 2,3-butanediol on oil recovery by cell-free spent medium of $B$. mojavensis strain JF-2.

\begin{tabular}{llllll}
\hline $\begin{array}{l}\text { Injected } \\
\text { solution }\end{array}$ & Additions & $\begin{array}{l}\text { Number of } \\
\text { Replicates }\end{array}$ & $\begin{array}{l}\text { Residual Oil } \\
\text { Saturation } \\
(\%)^{\mathrm{b}}\end{array}$ & $\begin{array}{l}\text { Volume of } \\
\text { Oil } \\
\text { Recovered } \\
(\mathrm{ml})^{\mathrm{b}}\end{array}$ & $\begin{array}{l}\text { Percent } \\
\text { Residual Oil } \\
\text { Recovery }^{\mathrm{b}}\end{array}$ \\
\hline $\begin{array}{l}\text { Sterile } \\
\text { medium }\end{array}$ & None & 2 & $14.6(2.5)$ & $<0.1$ & $\mathrm{NA}^{\mathrm{c}}$ \\
& $\begin{array}{l}\text { Butanediol + } \\
\text { Polymer }\end{array}$ & 2 & $24.2(5)$ & $0.2(0.1)^{*}$ & $1.1(0.2)^{*}$ \\
& None & 4 & $14.6(6.5)$ & $1.8(0.6)^{* *}$ & $10.6(7)^{* *}$ \\
$\begin{array}{l}\text { Spent } \\
\text { medium }\end{array}$ & Butanediol & 2 & $19.2(5.7)$ & $1.9(0.6)^{* *}$ & $15.2(0.6)^{* *}$ \\
& $\begin{array}{l}\text { Polymer } \\
\text { Butanediol }+\end{array}$ & 2 & $16.3(0.7)$ & $2.4(0.1)^{* *}$ & $15.2(0.6)^{* *}$ \\
& Polymer & $15.8(5.6)$ & $4.4(3.4)^{* * *}$ & 29.3 \\
& & & & $(15.6)^{* * *}$ \\
\hline
\end{tabular}

${ }^{a}$ Spent medium was prepared by removing the cells by centrifugation from an aerobically grown culture of $B$. mojavensis strain JF-2 that contained the $16 \pm 2.5 \mathrm{mg} \mathrm{l}^{-1}$ of the biosurfactant. Sterile and spent media were amended with $1 \mathrm{~g} \mathrm{l}^{-1}$ of partially purified polyacrylamide and $10 \mathrm{mM}$ 2,3-butanediol as indicated.

${ }^{\mathrm{b}}$ Mean value with the range shown in parentheses. Means with different number of* were significantly different from each other by analysis of variance and a Tukey test $(\mathrm{P}<$ $0.05)$.

${ }^{\mathrm{N}} \mathrm{NA}$, not applicable.

were significantly less than the treatment that contained the biosurfactant, butanediol and polymer. 
Analysis of variance coupled with a Tukey test (55) showed that increasing the biosurfactant concentration significantly increased the amount of residual hydrocarbon recovered $(\mathrm{P}<0.05)$. About $15.5 \mathrm{ml}$ of oil representing about $81.6 \%$ of the residual hydrocarbon was recovered when $1 \mathrm{~g} \mathrm{l}^{-1}$ of partially-hydrolyzed polyacrylamide and 10 $\mathrm{mM}$ 2,3-butanediol were added to cell-free culture fluid containing $914 \mathrm{mg} \mathrm{l}^{-1}$ of the biosurfactant. The relationship between residual hydrocarbon recovery and the amount of biosurfactant was linear (Figure 1). The molar solubility ratio was about 290 to 300 .

Figure 1. The relationship between oil recovery and the amount of biosurfactant injected into the sand packs.

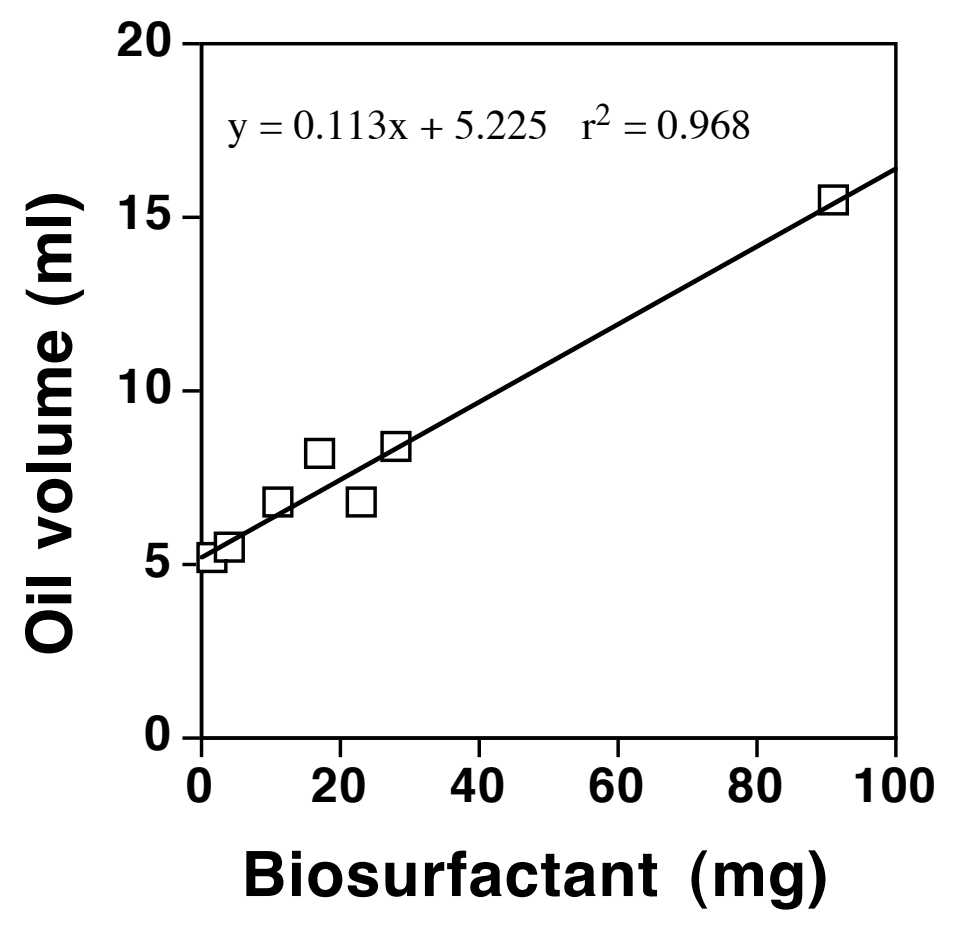


Optimization of the injection protocol. Surfactant-based recovery technologies usually inject a small volume of the polymer before injection of the surfactant-alcoholpolymer mixture $(3,5)$. We found that there was a significant improvement in the volume of oil recovered $(15.5 \mathrm{ml})$ when $5 \mathrm{ml}$ of $1 \mathrm{~g} \mathrm{l}^{-1}$ of partially purified polyacrylamide dissolved in $2.5 \% \mathrm{NaCl}$ was injected immediately before the biosurfactant-containing recovery fluid compared to the amount of oil recovered without the polymer pre-injection (13.1 ml). The biosurfactant and 2,3-butanediol concentrations in this experiment were $914 \mathrm{mg} \mathrm{l}^{-1}$ and $10 \mathrm{mM}$, respectively. In another experiment, large amounts of oil were recovered even when less than one pore volume of the recovery fluid was injected into the sand packs (Table 3).

Table 3. Oil recovery when different volumes of recovery fluid were injected into sand packs. $^{\text {a }}$

\begin{tabular}{llll}
\hline $\begin{array}{l}\text { Volume of } \\
\text { Recovery Fluid } \\
\text { (Pore Volume) }\end{array}$ & $\begin{array}{l}\text { Residual Oil } \\
\text { Recovery }\end{array}$ & $\begin{array}{l}\text { Volume of Oil } \\
\text { Recovered }(\mathrm{ml})^{\mathrm{b}}\end{array}$ & $\begin{array}{l}\text { Percent } \\
\text { Residual Oil }^{\mathrm{b}} \\
\text { Recovery }^{\mathrm{b}}\end{array}$ \\
\hline 1.1 & $16.2(0.9)^{\mathrm{b}}$ & $8.4(0.9)^{\mathrm{y}}$ & $50.4(4.6)^{*}$ \\
0.87 & $21.1(3.4)$ & $6.8(0.5)^{\mathrm{y}}$ & $32.9(0.4)^{* *}$ \\
0.66 & $20.8(0.1)$ & $8.2(1.4)^{\mathrm{y}}$ & $38.4(4.5)^{* *}$ \\
0.46 & $24.6(3.9)$ & $6.8(0.9)^{\mathrm{y}}$ & $30.2(0.3)^{* *}$ \\
\hline
\end{tabular}

${ }^{\mathrm{a}}$ Cells from an aerobically grown culture of $B$. mojavensis strain JF-2 that contained the $283 \mathrm{mg} \mathrm{l}^{-1}$ of the biosurfactant were removed by centrifugation and $1 \mathrm{~g} \mathrm{l}^{-1}$ of partially purified polyacrylamide and $10 \mathrm{mM}$ 2,3-butanediol were added.

${ }^{\mathrm{b}}$ Mean of duplicate sand packs with the range shown in parentheses. Means with different number of * were shown to be significantly different from each other by analysis of variance and a Tukey test $(\mathrm{P}<0.05)$. 


\subsection{Discussion}

Our data show that the lipopeptide biosurfactant produced by B. mojavensis strain JF-2 mobilized large amounts of residual hydrocarbon from sand-packed columns at concentrations about 10 to 100 -fold lower than typically used for surfactant-enhanced remediation process $(3,26,43,45,46)$. Consistent with these findings, we found that the molar solubility ratio (MRS) for the JF-2 biosurfactant was 100 times greater than that of synthetic surfactants (8). The rhamnolipid biosurfactant was also shown to have a MSR 20 times greater than alkyl benzyl sulfonate surfactants(47). Thanamani and Shreve (47) argued that the rhamnolipid structure results in a large volume, low-density micelle that accommodates more hydrocarbon than alkyl benzyl sulfonate micelles. However, in our work, an oil bank formed, which suggests that once mobilized, the oil formed a separate phase that may not have required large amounts of biosurfactants to maintain.

Much anecdotal evidence implicates the need for a variety of products such as acids, gases, solvents, polymers, emulsifiers and/or biosurfactants or a combination of microorganisms that collectively make these products to recover residual oil from low production oil reservoirs (33). However, it is not clear whether these products are effective alone or if combinations of products are needed. The use of a mutant strain of $B$. mojavensis strain JF-2 defective in biosurfactant production clearly showed importance of biosurfactant production for residual oil recovery (30). Here, we found that a small molecular weight alcohol, 2,3-butanediol, and a vsicosifying agent, PHPA, are also required. Thus, the belief that microbially enhanced oil recovery requires multiple microbial species or products may be due to the need to form the three components we define here as necessary for residual hydrocarbon mobilization. 
We observed that an oil-bank formed is formed dissipated before it reached the effluent end of the pack. Compared to oil, water moves rapidly through the porous material. This results in an irregular front with water pushing through the oil and reaching the production well first. To prevent this, polymers such as xanthan gum and polyacrylamide are often added to chemical surfactant floods to increase the viscosity of the water phase (3). The role of 2,3-butanediol is less clear. Mobilization of residual oil requires middle-phase microemulsions where the surfactant is equally soluble in the water and oil phases and the prevention of mesophases (e.g., liquid crystals)(43). Alcohols are usually added to prevent surfactant liquid crystal formation and act to increase the effective surfactant concentration. Whether 2,3-butanediol serves such a role is unclear. In actual in situ applications, the addition of 2,3-butanediol may not be required since it is a common fermentative product of Bacillus species (44). We found that B. mojavensis strain JF-1 consistently produces between 5 to $10 \mathrm{mM} 2,3$-butanediol when grown anaerobically in our medium (unpublished data).

Our data indicate that the injection of biosurfactant-containing culture fluids with 2,3-butanediol and polyacrylamide will result in substantial recovery of residual hydrocarbon. The in situ biosurfactant production would be more difficult. The distribution of biosurfactant bacteria in aquifers and oil reservoirs is not known so it is not clear whether such organisms would have to be added. Once they are in the reservoir, a process that selectively stimulates the growth of biosurfactant-producing bacteria is needed. Preliminary results indicate that 15 to $90 \%$ of the total culturable population in groundwater samples contained the genes for the lipopeptide biosurfactant when the supplemented with proteose peptone and nitrate (unpublished data). Thus, it may be 
possible to enhance the growth of biosurfactant-producing bacteria by selective nutrient additions.

\subsection{References}

1. 1999. Energy Statistics Sourcebook. Fourteenth Edition. Penn Well Publishing Co., Tulsa OK.

2. Al-Tahhan, R. A., T. R. Sandrin, A. A. Bodour, and R. M. Maier. 2000. Rhamnolipid-induced removal of lipopolysaccharide from Pseudomonas aeruginosa: effect on cell surface properties and interaction with hydrophobic substrates. Appl. Environ. Microbiol. 66:3262-3268.

3. Austad, T., and K. Taugbøl. 1995. Chemical flooding of oil reservoirs 1. Low tension polymer flood using a polymer gradient in three-phase region. Colloids and Surfaces A: Physicochemical and Engineering Aspects 101:87-97.

4. Austad, T., and K. Taugbøl. 1995. Chemical flooding of oil reservoirs 1. Low tension polymer flood using a polymer gradient in three-phase region. Colloids and Surfaces A: Physicochem. Eng. Aspects 101:87-97.

5. Austad, T., and K. Taugbøl. 1995. Chemical flooding of oil reservoirs 2. Dissociative surfactant-polymer interaction with negative effect on oil recovery. Colloids and Surfaces A: Physicochemical and Engineering Aspects 103:73-81.

6. Balch, W. E., and R. S. Wolfe. 1976. New approach to the cultivation of methanogenic bacteria: 2-mercaptoethanesulfonic acid (HS-CoM)-dependent growth of Methanobacterium ruminantium in pressurized atmosphere. Appl. Environ. Microbiol. 32:781-791. 
7. Bouchez-Naïtali, M., D. Blanchet, V. Bardin, and J. P. Vandecasteele. 2001. Evidence for interfacial uptake in hexadecane degradation by Rhodococcus equi: the importance of cell flocculation. Microbiology 147:2537-43.

8. Brusseau, M. L., D. A. Sabatini, J. S. Gierke, and M. D. Annable. 1999. Surfactant selection criteria for enhanced subsurface remediation. Adv. Chem. Series 725:8-23.

9. Buthod, P. 1987. Chapter 21, Crude Oil Properties and Condensate Properties and Correlations., p. 21-3--21-5. In H. B. Bradley (ed.), Petroleum Engineering Handbook. Society of Petroleum Engineers, Richardson, TX.

10. Cassidy, D. P., and A. J. Hudak. 2001. Microorganism selection and biosurfactant production in a continuously and periodically operated bioslurry reactor. J. Hazard. Mater. 84:253-64.

11. Chiu, Y. C., and P. R. Kuo. 1999. An empirical correlation between low interfacial tension and micellar size and solubilization for petroleum sulfonates in enhanced oil recovery. Colloids Surfaces A: Physiochem. Eng. Aspects 152:235244.

12. Cooper, D. G., S. R. MacDonald, S. J. B. Duff, and N. Kosaric. 1981. Enhanced production of surfactin from Bacillus subtilis by continuous product removal and metal cation additions. Appl. Environ. Microbiol. 42:408-412.

13. Desai, J., and I. M. Banat. 1997. Microbial production of surfactants and their commercial potential. Microbiol. Mol. Biol. Rev. 61:47-64.

14. Deshpande, S., B. J. Shiau, D. Wade, D. A. Sabatini, and J. H. Harwell. 1999. Surfactant selection for enhancing ex situ soil washing. Wat. Res. 33:351-360. 
15. Deshpande, S., L. Wesson, D. Wade, D. A. Sabatini, and J. H. Harwell. 2000. Dowfax surfactant components for enhancing contaminant solubilization. Wat. Res. 34:1030-1036.

16. Diallo, M. S., L. M. Abriola, and J. Weber, W. J. 1994. Solubilization of nonaqueous phase liquid hydrocarbons in micellar solutions of dodecyl alcohol ethoxylates. Environ. Sci. Technol. 28:1829-1837.

17. Edwards, D. A., R. G. Luthy, and Z. Liu. 1991. Solubilization of polycyclic aromatic hydrocarbons in micellar nonionic surfactant solutions. Environ. Sci. Technol. 25:127-133.

18. García-Junco, M., E. De Olmedo, and J. J. Ortega-Calvo. 2001. Bioavailability of solid and non-aqueous phase liquid (NAPL)-dissolved phenanthrene to the biosurfactant-producing bacterium Pseudomonas aeruginosa 19SJ. Environ. Microbiol. 3:561-9.

19. Georgiou, G., S.-C. Lin, and M. M. Sharma. 1992. Surface-active compounds from microorganisms. Biotechnology (N Y) 10:60-65.

20. Harwell, J. H., D. A. Sabatini, and R. C. Knox. 1999. Surfactants for ground water remediation. Colloids and Surfaces A: Physicochem. Eng. Aspects 151:255-268.

21. Herman, D. C., R. J. Lenhard, and R. M. Miller. 1997. Formation and removal of hydrocarbon residual in porous media: effects of attached bacteria and biosurfactants. Environ. Sci. Technol. 31:1290-1294. 
22. Herman, D. C., Y. Zhang, and R. M. Miller. 1997. Rhamnolipid (biosurfactant) effects on cell aggregation and biodegradation of residual hexadecane under saturated flow conditions. Appl. Environ. Microbiol. 63:3622-3627.

23. Ivshina, I. B., M. S. Kuyukina, and N. Christofi. 1998. Oil desorption from mineral and organic materials using biosurfactant complexes produced by Rhodococcus species. World J. Microbiol. Biotechnol. 14:711-717.

24. Jenneman, G. E., R. M. Knapp, M. J. McInerney, D. E. Menzie, and D. E. Revus. 1984. Experimental studies of in-situ microbial enhanced oil recovery. Soc. Pet. Eng. J. 24:33-7.

25. Jones, W. R. 1997. Biosurfactants, bioavailability and bioremediation. Global Environ. Biotechnol.:379-390.

26. Krebs-Yuill, B., J. H. Harwell, D. A. Sabatini, and R. C. Knox. 1995. Presented at the ACS Symposium Series.

27. Lin, S.-C., K.-G. Lin, C. C. Lo, and Y.-M. Lin. 1998. Enhanced biosurfactant production by a Bacillus licheniformis mutant. Enzym. Microbiol. Technol. 23:267-273.

28. Lin, S.-C., M. A. Minton, M. M. Sharma, and G. Georgiou. 1994. Structural and immulogical characterization of a biosurfactant produced by Bacillus licheniformis JF-2. Appl. Environ. Microbiol. 60:31-38.

29. Maier, R. M., and G. Soberon-Chavez. 2000. Pseudomonas aeruginosa rhamnolipids: biosynthesis and potential applications. Appl. Microbiol. Biotechnol. 54:625-633. 
30. Marsh, T. L., X. Zhang, R. M. Knapp, M. J. McInerney, P. K. Sharma, and B. E. Jackson. 1995. Presented at the The Fifth International Conference on Microbial Enhanced Oil Recovery and Related Problems for Solving Environmental Problems.

31. Marsh, T. L., X. Zhang, R. M. Knapp, M. J. McInerney, P. K. Sharma, and B. E. Jackson. 1995. Mechanisms of microbial oil recovery by Clostridium acetobutylicum and Bacillus strain JF-2., p. 593-610. In K. L. Sublette (ed.), The Fifth International Conference on Microbial Enhanced Oil Recovery and Related Problems for Solving Environmental Problems. Office of Scientific and Technical Information, CONF-9509173.

32. McInerney, M. J., M. Javaheri, and D. P. Nagle. 1990. Properties of the biosurfactant produced by Bacillus licheniformis strain JF-2. J. Indust. Microbiol. 5:95-102.

33. McInerney, M. J., and D. W. S. Westlake. 1990. Microbial enhanced oil recovery, p. 409-445. In C. Brierly (ed.), Microbial Mineral Recovery. MacMillian Publishing Co., New York.

34. Miller, D. J., S.-P. von Halasz, M. Schmidt, and G. Pusch. 1991. Dual surfactant systems for enhanced oil recovery at high salinities. J. Petr. Sci. Engineer. 6:63-72.

35. Morán, A. C., N. Olivera, M. Commendatore, J. L. Esteves, and F. Siñeriz. 2000. Enhancement of hydrocarbon waste biodegradation by addition of a biosurfactant from Bacillus subtilis O9. Biodegradation 11:65-71. 
36. Pennell, K. D., L. M. Adriola, and J. Weber, W. J. 1993. Surfactant-enhanced solubilization of residual dodecane in soil columns. 1. Experimental investigation. Environ. Sci. Technol. 27:2332-2340.

37. Pennell, K. D., L. M. Adriola, and J. Weber, W. J. 1993. Surfactant-enhanced solubilization of residual dodecane in soil columns. 2. Mathematical modeling. Environ. Sci. Technol. 27:2341-2351.

38. Reed, R. L., and R. N. Healy. 1977. Some physicochemical aspects of microemulsion flooding: a review., p. 383-437. In R. S. Schechter (ed.), Improved Oil Recovery by Surfactant and Polymer Flooding. Academic Press, Inc., Orlando, FL.

39. Ron, E. Z., and E. Rosenberg. 2001. Natural roles of biosurfactants. Environ. Microbiol. 3:229-236.

40. Rouse, J. D., D. A. Sabatini, J. M. Suflita, and J. H. Harwell. 1994. Influence of surfactants on microbial degradation of organic compounds. Crit. Rev. Environ. Sci. Technol. 24:325-370.

41. Sabatini, D. A., J. H. Harwell, M. Hasegawa, and R. Knox. 1998. Membrane processes and surfactant-enhanced subsurface remediation: results of a field demonstration. J. Memb. Sci. 151:87-98.

42. Sabatini, D. A., R. C. Knox, J. H. Harwell, and B. Wu. 2000. Integrated design of surfactant enhanced DNAPL remediation. Efficient supersolubilization and gradient systems. J. Contam. Hydrol. 45:99-121.

43. Salager, J.-L. 1999. Microemulsions, p. 253-302. In G. Broze (ed.), Handbook of Detergents. Part A. Properties. Marcel Dekker, Inc., New York. 
44. Shariati, P., W. J. Mitchell, A. Boyd, and F. G. Priest. 1995. Anaerobic metabolism in Bacillus licheniformis NCIB 6346. Microbiology 141:1117-1124.

45. Shiau, B. J., D. A. Sabatini, and J. H. Harwell. 2000. Removal of chlorinated solvents in subsurface media using edible surfactants: column studies. J. Environ. Engineer. ASCE 126:611-621.

46. Smith, S. A., B.-J. Shiau, J. H. Harwell, J. F. Scamehorn, and D. A. Sabatini. 1996. Performance and chemical stability of a new class of ethoxylated sulfate surfacfants in a subsurface remediation application. Colloids Surfaces A: Physiochem. Eng. Aspects 116:225-239.

47. Thangamani, S., and G. S. Shreve. 1993. Effect of anionic biosurfactant on hexadecane partitioning in multiphase systems. Environ. Sci. Technol. 28:19932000.

48. Thomas, C. P., G. A. Bala, and M. L. Duvall. 1993. Surfactant-based enhanced oil recovery mediated by naturally occurring microorganisms. Soc. Petrol. Eng. Reservoir Eng. 11:285-291.

49. Tiehm, A. 1994. Degradation of polycyclic aromatic hydrocarbons in the presence of synthetic surfactants. Appl. Environ. Microbiol. 60:258-263.

50. Toren, A., E. Z. Ron, R. Bekerman, and E. Rosenberg. 2002. Solubilization of polyaromatic hydrocarbons by recombinant bioemulsifier AlnA. Appl. Microbiol. Biotechnol. 59:580-584.

51. Van Dyke, M. I., P. Couture, M. Brauer, H. Lee, and J. T. Trevors. 1993. Pseudomonas aeruginosa UG2 rhamnolipid biosurfactants: structural 
characterization and their use in removing hydrophobic compounds from soil. Can. J. Microbiol. 39:1071-1078.

52. Volkering, F., A. M. Breure, J. G. van Andel, and W. H. Rulkens. 1995. Influence of nonionic surfactants on bioavailability and biodegradation of polycyclic aromatic hydrocarbons. Appl. Environ. Microbiol. 61:1699-1705.

53. West, C. C., and J. H. Harwell. 1992. Surfactants and subsurface remediation. Environ. Sci. Technol. 26:2324-2330.

54. Yakimov, M. M., M. Amro, M. Bock, K. Boseker, H. L. Fredrickson, D. G. Kessel, and K. N. Timmis. 1997. The potential of Bacillus licheniformis strains for in stiu enhanced oil recovery. J. Petr. Sci. Engineer. 18:147-160.

55. Zar, J. H. 1999. Biostatistical Analysis. Fourth Ed. Prentice Hall, Upper Saddle River, N. J.

56. Zhang, Y., W. J. Maier, and R. M. Miller. 1997. Effect of rhamnolipids on the dissolution, bioavailability, and biodegradation of phenanthrene. Environ. Sci. Technol. 31:2211-2217.

57. Zhang, Y., and R. M. Miller. 1992. Enhanced octadecane dispersion and biodegradation by a Pseudomonas rhamnolipid surfactant (biosurfactant). Appl. Environ. Microbiol. 58:3276-3282. 


\section{Chapter 2. Anaerobic growth of and biosurfactant production by \\ Bacillus mojavensis strain JF-2}

\subsection{Abstract}

Previously, we reported that Proteose peptone was necessary for anaerobic growth and biosurfactant production by Bacillus mojavensis JF-2. The growth-enhancing factor in Proteose peptone was methanol insoluble, had an average molecular weight of 3900 Da, was retained by an anion exchange column, was acid and base stable, was low in protein, and absorbed at about $260 \mathrm{~nm}$. These data suggested that the growth-enhancing factor consisted of or contained a nucleic acid; however, nucleic acid bases, nucleotides or nucleosides did not replace the requirement for Proteose Peptone. Further studies revealed that salmon sperm DNA, herring sperm DNA, Echerichia coli DNA and synthetic DNA replaced the requirement for Proteose peptone. As little as $20 \mathrm{mg} / \mathrm{l}$ of $E$. coli DNA was sufficient to increase growth from an absorbance of 0.08 to about 0.25 . In addition to DNA, amino acids were required for anaerobic growth and vitamins further improved growth from an absorbance of $0.4-0.6$ to about 0.8 . A small amount of nitrate was required for anaerobic growth although not in stochiometric amounts relative to the amount of sucrose present. These results indicate that Proteose peptone is not necessary for in situ growth of $B$. mojavensis JF-2 and can be replaced by DNA, amino acids and vitamins. Since small amounts of DNA, amino acids and vitamins maybe naturally present in the environment or by cross-feeding from other microorganisms, only a carbon/energy source would need to be added to stimulate in situ growth and biosurfactant production. 


\subsection{Introduction.}

Javahari et al., (4) reported both the successful anaerobic growth of and biosurfactant production by Bacillus mojavensis strain JF-2. This biosurfactant effectively reduces both surface tension and interfacial tension and is potentially useful in enhanced oil recovery $(6,10)$. B. mojavensis JF-2 is the only strain known to grow and produce an effective biosurfactant anaerobically. Thus, this strain is the only one that can be used for in situ applications. However, anaerobic growth in the original medium described by Javahari et al. (3) was inconsistent and little biosurfactant was produced. In situ growth and biosurfactant production of B. mojavensis JF-2 in sandstone cores resulted in inconsistent oil recoveries probably due to its inconsistent growth under anaerobic conditions (8) (13). For this reason, it was necessary to improve growth and control biosurfactant production by manipulating the medium components.

Improved anaerobic growth and biosurfactant production was accomplished with the addition of Proteose peptone to the medium (9) but the resulting medium was much too complex to allow a proper understanding of the nutritional controls of biosurfactant production. Consequently, it was necessary to elucidate the composition of the growthenhancing factor found in Proteose peptone and identify any other growth factor requirement(s). A thorough understanding of the exact nutritional requirements for anaerobic growth will allow for the subsequent manipulation of these requirements to maximize biosurfactant production. 


\section{3. Methods and Materials.}

Medium: Medium E contained the following components per liter (g): TES buffer (N-tris(hydroxymethyl)methyl-2- aminoethansulfonic acid); sodium chloride (50); sucrose (10); yeast extract (1); sodium nitrate (1); dibasic potassium phosphate (1.0); ammonium sulfate (1); magnesium sulfate $(0.25)$ and $10 \mathrm{ml}$ of a metal solution. The metal solution was a modification of Wolin's (3) metal solution and contained the following components per liter: Ethyldiaminetetraacetate (EDTA) (1); $\mathrm{MnSO}_{4} \bullet \mathrm{H}_{2} \mathrm{O}$ (3); $\mathrm{FeSO}_{4} \cdot 7 \mathrm{H}_{2} \mathrm{O}(0.1) ; \mathrm{CaCl}_{2} \cdot 2 \mathrm{H}_{2} \mathrm{O}(0.1) ; \mathrm{CoCl}_{2} \cdot 2 \mathrm{H}_{2} \mathrm{O}(0.1) ; \mathrm{ZnSO}_{4} \cdot 7 \mathrm{H}_{2} \mathrm{O}$ (0.1); $\mathrm{CuSO}_{4} \bullet 7 \mathrm{H}_{2} \mathrm{O}(0.01) ; \mathrm{H}_{3} \mathrm{BO}_{4}(0.01) ; \mathrm{Na}_{2} \mathrm{MO}_{4} \cdot 2 \mathrm{H}_{2} \mathrm{O}(0.01) ; \mathrm{AlK}\left(\mathrm{SO}_{4}\right)_{2}$ (0.01). Cysteine hydrochloride was added in the concentration of $0.25 \mathrm{~g} / 1$.

For some experiments, medium E was supplemented with pools of amino acids, nucleic acid bases, vitamins and fatty acids that were prepared as described by Tanner $e t$ al., (12). The nucleic acid base stock solution was prepared as follows. Adenine, cytosine, guanine, thymine and uracil were combined in a single stock solution at 1 gram each per $100 \mathrm{ml}$ of nanopure water. This stock solution was 10 times the final concentration of $0.1 \mathrm{~g} / 1$ each base. Both the nucleotide and the nucleoside stock solutions were made in the same manner, at the same concentrations for each component. Adenosine, cytosine, guanosine, and thymididine were combined for the nucleotide stock solution and adenosine monophosphate, cytosine monophosphate, guanosine monophosphate, and thymididine monophosphate were combined for the nucleoside stock solution. Salmon sperm DNA, herring sperm DNA, and Echerichia coli DNA and RNA were added directly to the media at the concentration of $1 \mathrm{~g} / 1$ unless otherwise indicated. When the concentration of the DNA was varied, stock solutions were prepared 
in nanopure water at 10X the final concentration. Salmon sperm DNA was only used in the initial DNA experiment, E. coli DNA was used only where specified. All other experiments using DNA contained herring sperm DNA. All additions to the medium were added prior to autoclaving unless other wise indicated.

The vitamin stock solution was prepared $100 \mathrm{X}$ the final concentration and consisted of $2 \mathrm{mg} / \mathrm{l}$ each of biotin and folic acid; $10 \mathrm{mg} / \mathrm{l}$ pyridoxine- $\mathrm{HCl} ; 5 \mathrm{mg} / \mathrm{l}$ each of thiamine- $\mathrm{HCl}$, riboflavin, nicotinic acid, calcium pantothenate, paraminobenzoic acid, and lipoic acid; and $0.1 \mathrm{mg} / 1$ of vitamin $\mathrm{B}_{12}$. Anaerobic media and solutions were prepared by the procedure of Balch and Wolfe (1).

Inoculation Protocol: A serum bottle with $100 \mathrm{ml}$ of anaerobic Medium E was inoculated directly from a well-isolated colony of B. mojavensis strain JF-2 on a Medium E agar plate that had been incubated for $24 \mathrm{hr}$.. The serum bottle was incubated for 24 to 48 hours at $37^{\circ} \mathrm{C}$ and then used as an inoculum for experimentation. A $1 \%$ inoculum was used. All experiments were performed in serum tubes with 10 of medium and a nitrogen headspace. When the medium contained E. coli DNA or synthetic DNA, the serum tubes contained only two milliliters of medium.

Growth conditions All tubes and serum bottles were incubated at $37^{\circ} \mathrm{C}$. Growth was measured as absorbance at $600 \mathrm{~nm}$.

Biosurfactant Quantification: The JF-2 biosurfactant was quantified by highpressure liquid chromatography (HPLC). A $\mathrm{C}_{18}$ column was used with a mobile phase of $73 \%$ methanol and $27 \% 10 \mathrm{mM}$ phosphate buffer at a $\mathrm{pH}$ of 6.5 . The HPLC was run at a flow rate of $1 \mathrm{ml} / \mathrm{min}$ and the injection volume was $20 \square 1$. A UV detector was used with the wavelength set at $210 \mathrm{~nm}$. 
Samples for HPLC analysis were prepared in the following manner. First, a $10-\mathrm{ml}$ sample was centrifuged to remove the cells. The cells were discarded and the supernatant was acidified by the addition of $0.25 \mathrm{ml}$ of $50 \% \mathrm{HCl}$. The sample was frozen until analyzed. Later, the sample was thawed, centrifuged and the supernatant was discarded. The remaining pellet was vortexed with $2 \mathrm{ml}$ of methanol for 1 minute, then centrifuged in a microfuge for $5 \mathrm{~min}$. The supernatant was poured off and $20 \square 1$ of it was injected into the HPLC.

Bacterial DNA extraction DNA was purified by using the Marmur procedure (7).

Agarose Gel electrophoresis: The size of E. coli and herring sperm DNA fragments was determined by agarose gel electrophoresis. To make the gel, $0.3 \mathrm{~g}$ of agarose was dissolved in $30 \mathrm{mls}$ of nanopure water by heating the water to boiling. After cooling a few minutes, $2 \square 1$ of ethidium bromide was added. This gel was then poured into a $7.1 \mathrm{X} 10 \mathrm{~cm}$ tray () with a comb for eight $20 \square 1$ wells and allowed to solidify. A 5 $\square 1$ sample size was used. The gel was run 30 minutes at 96 volts. Polymerase chain reaction (PCR) size markers from 50 to 1000 nucleotide base pairs in length, were used as standards (Promega). The gel was viewed under UV light and an image of the gel was recorded by using a Nucleocam photographic system (Nucleotech Imaging, San Mateo, $\mathrm{Ca})$.

Synthetic DNA: A random sequence of 50 nucleotide bases was generated and then tested for hairpin turns and self-annealing sequences with the oligonucleotides properties calculator found at www.basic.nwu.edu/biotools/oligocalc.html. Selected bases were changed until a sequence was generated that did not contain hairpin turns, or self-annealing areas, and was about 50\% GC. The final sequence, named JF-2 SS, was 
TGG CGA AGG ATG CTG GCT ACA CTG CAG TTA TCT CTC ACC GTT CTG GCG AA. A DNA sequence that was complementary to JF-2 SS, named JF-2 COM was also generated and tested. Both sequences of DNA were obtained from Integrated DNA Technologies (IDT). To determine if single stranded or double stranded DNA supported anaerobic growth, three tubes of Medium E with $0.05 \%$ each of JF-2 SS, JF-2 COM and JF-2 SS plus JF-2 COM were inoculated as described above. An uninoculated control and an unamended control were used for each of the above treatments. 


\subsection{Results.}

Requirement for DNA: It was previously shown that B. mojavensis strain JF-2 required Proteose peptone for anaerobic growth and biosurfactant production (8). $B$. mojavensis grew anaerobically to an absorbance 600 of about 0.8 when $30 \mathrm{~g} / 1$ of Proteose peptone was added to Medium E or to the complete medium (e. g., Medium E supplemented with nucleic acid bases, amino acids, vitamins and fatty acids), (Figure 2.1). Anaerobic growth of B. mojavensis JF-2 did not occur in medium E, or in the complete medium in the absence of Proteose peptone (Figure 2.1).

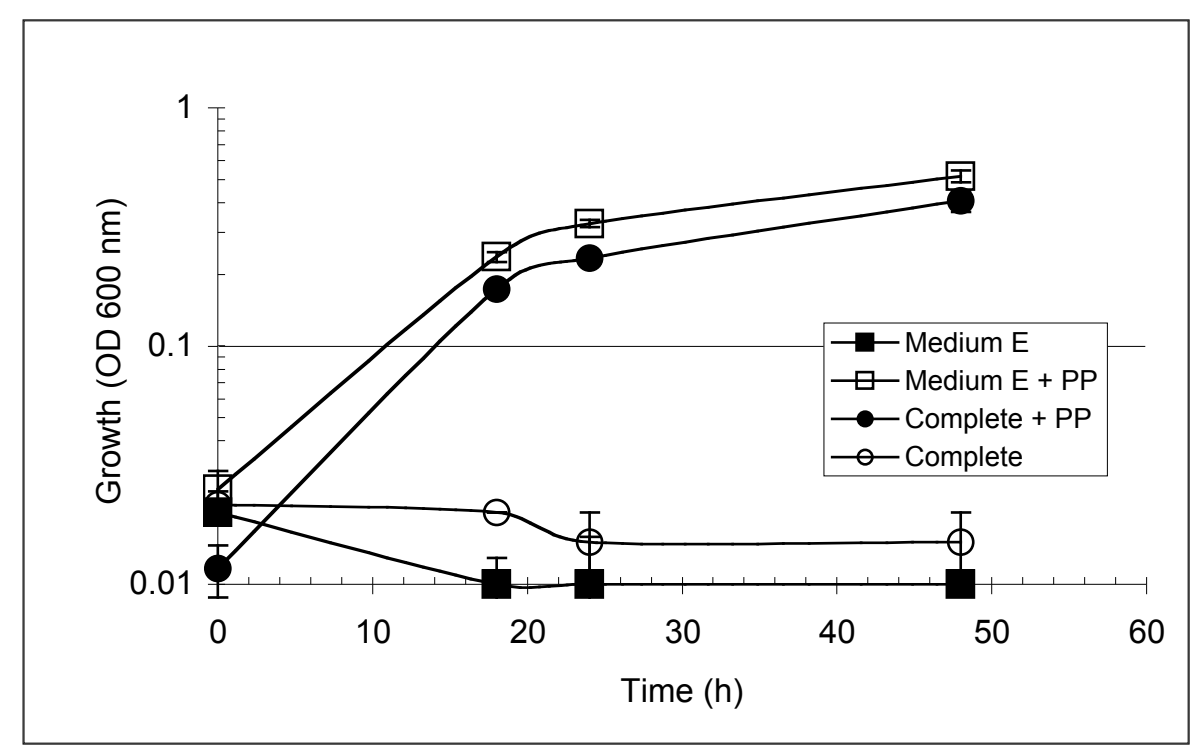

Figure 2.1. The effect of Proteose peptone on anaerobic growth of B. mojavensis JF-2 in Medium E and in Complete medium. Abbreviation: PP, addition of Proteose peptone.

Anaerobic production of the biosurfactant by B. mojavensis JF-2 also required Proteose peptone (Figure 2.2). If Proteose peptone was absent from both the inoculating culture medium and the experimental medium then only $1 \mathrm{mg} / \mathrm{l}$ or less of the JF-2 biosurfactant was produced. If an inoculum containing $1 \%$ Proteose peptone was used to 
inoculate experimental Medium E (resulting in $<1 \mathrm{~g} / \mathrm{l}$ in the experimental medium), then biosurfactant production increased to about $12 \mathrm{mg} / \mathrm{l}$. Further increasing the concentration of Proteose peptone from $5 \mathrm{~g} / 1$ to $30 \mathrm{~g} / 1$ only slightly improved biosurfactant production. The presence of Proteose peptone in the inoculating medium did not influence biosurfactant production in the experimental medium if the experimental medium contained $5 \mathrm{~g} / 1$ Proteose peptone or more.

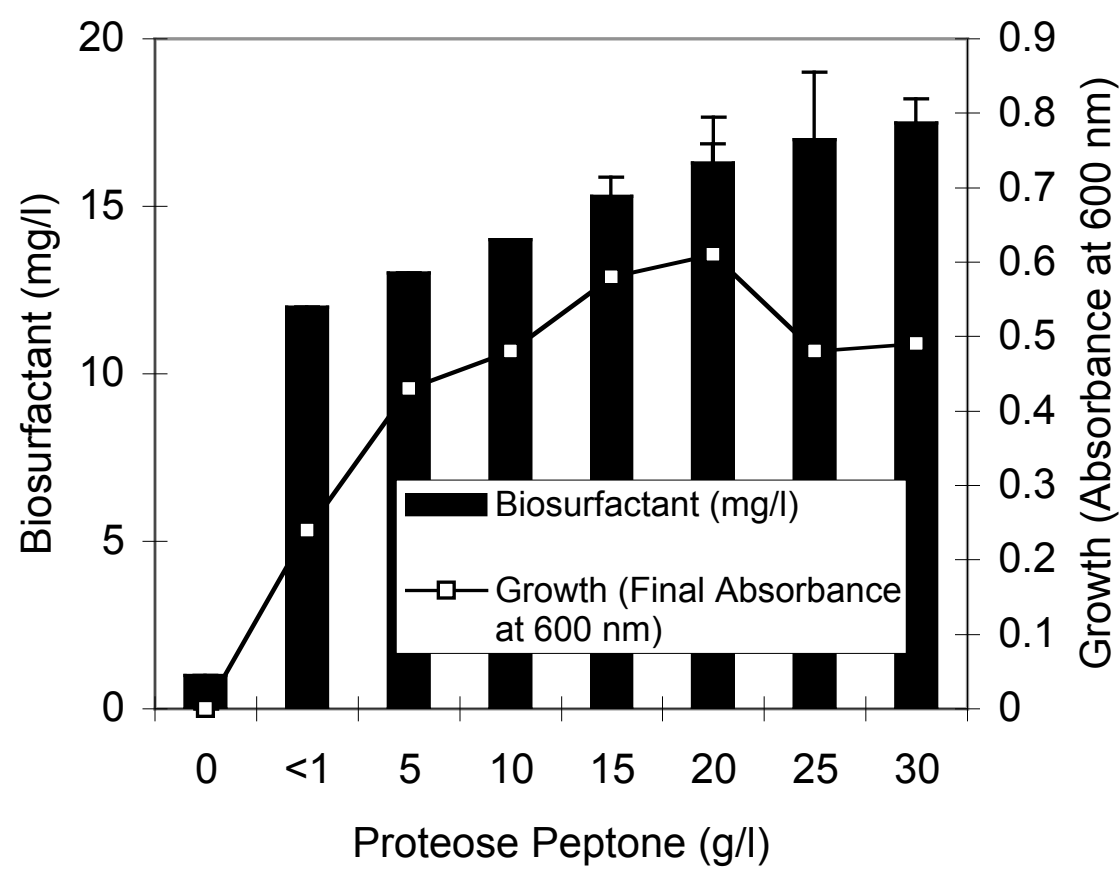

Figure 2.2. The effect of Proteose peptone on biosurfactant production and growth of $B$. mojavensis strain JF-2.

The next step was to identify the growth-enhancing factor. It was initially assumed that the growth factor consisted of an amino acid or peptide since Proteose peptone is an enzymatic digest of protein. Individual amino acids such as glutamate, glutamine, phenylalanine, tyrosine, tryptophan and methionine and poly amino acids, 
such as polyglutamate, polyglutamine, polytyrosine, polytryptophane and polymethionine were each individually added to Medium E, but none replaced the requirement for Proteose Peptone (data not shown).

Subsequent crude purification of the growth-enhancing factor found in Proteose peptone revealed that it was methanol insoluble, had an average molecular weight of $3900 \mathrm{Da}$, was retained by an anion exchange column, was acid and base stable, was low in protein content, and exhibited a maximum absorbance at $260 \mathrm{~nm}$ (data not shown).

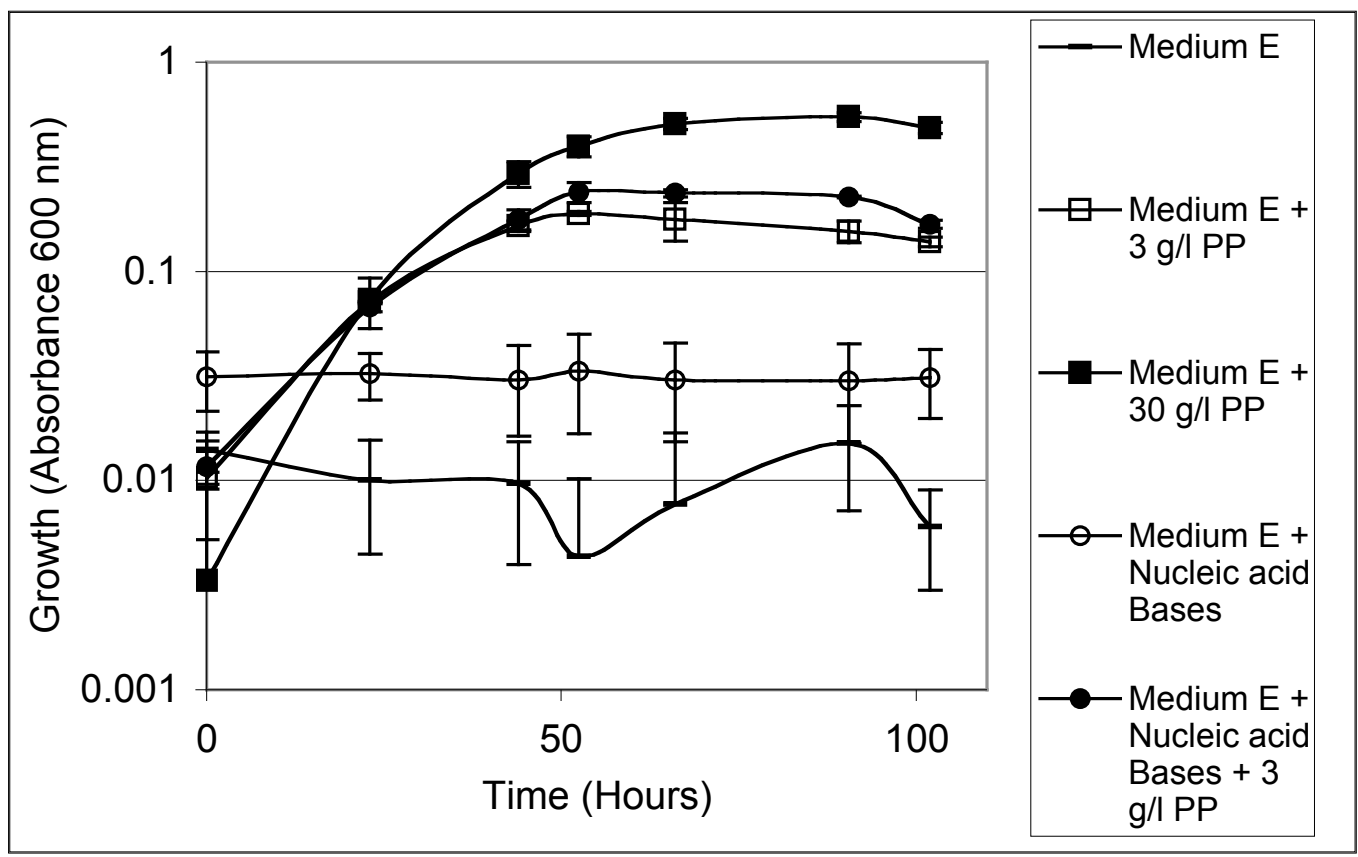

Figure 2.3. The effect of nucleic acid bases combined with $3 \mathrm{~g} / 1$ Proteose peptone on the anaerobic growth of B. mojavensis strain JF-2 in medium E.

These results suggested that the growth-enhancing factor consisted of or contained nucleic acids or the components of nucleic acids. It was possible that Proteose peptone supplied both amino acids in the form of peptides and nucleic acids. Thus, we tested whether nucleic acid bases combined with a small amount of Proteose peptone could replace the requirement of Bacillus mojavensis JF-2 for a large amount of Proteose 
peptone for anaerobic growth. We found that the addition of nucleic acid bases to Medium E combined with $3 \mathrm{~g} / 1$ Proteose peptone did not improve growth compared to that in Medium E with just $3 \mathrm{~g} / \mathrm{l}$ Proteose peptone and did not replace the requirement for 20 to $30 \mathrm{~g} / \mathrm{l}$ of Proteose peptone for anaerobic growth (Figure 2.3).

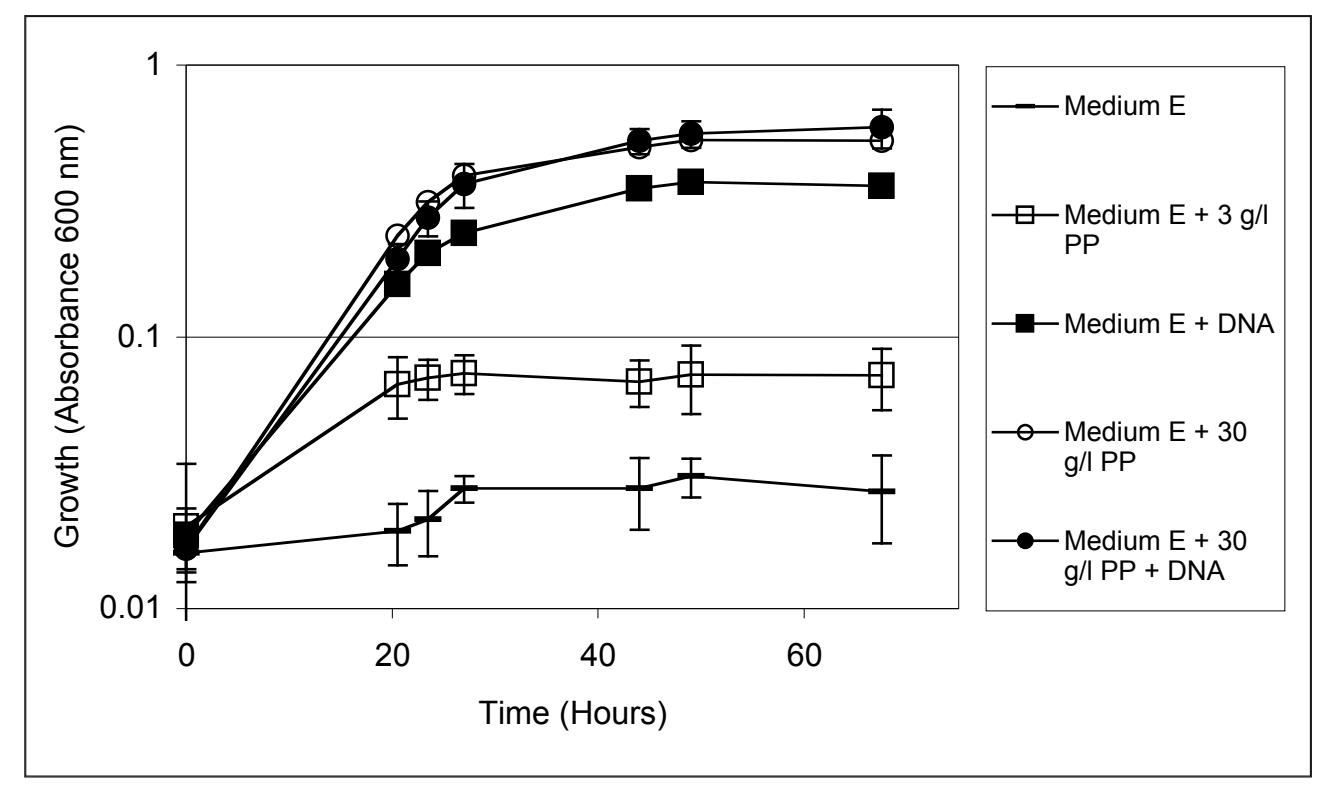

Figure 2.4. The effect of salmon sperm DNA on anaerobic growth of Bacillus mojavensis JF-2.

As stated earlier, since crude purification of the growth-enhancing factor suggested that it consisted of or contained nucleic acids, but the addition of nucleic acid bases to medium E did not replace the requirement for Proteose peptone, we tested whether nucleic acids could replace the Proteose peptone requirement. Salmon sperm DNA supported anaerobic growth of B. mojavensis strain JF-2 (Figure 2.4), as did herring sperm DNA (Figure 2.5). Initially, salmon sperm and herring sperm DNA were used at the concentrations of $1 \mathrm{~g} / \mathrm{l}$, but it was also found that even $0.5 \mathrm{~g} / 1$ herring sperm DNA supported anaerobic growth in medium E (Figure 2.6). 


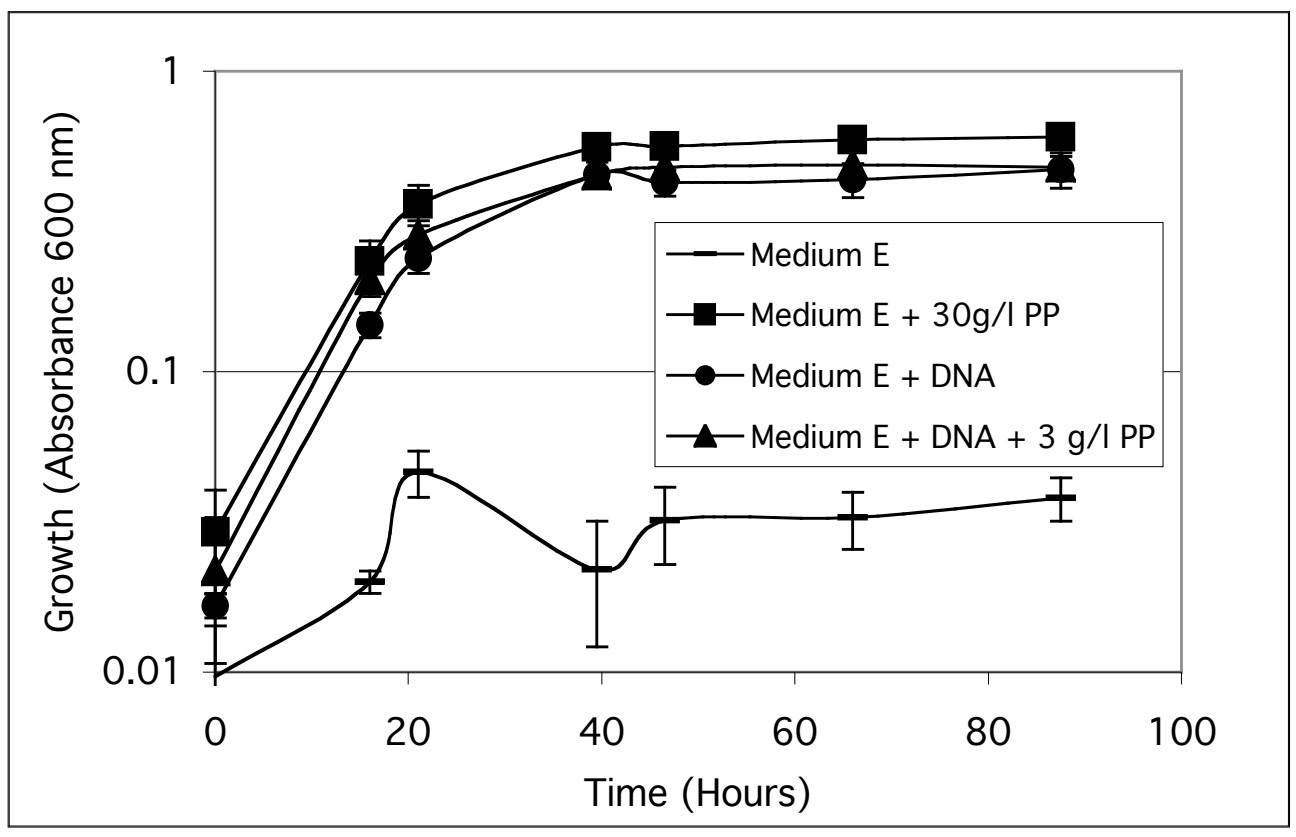

Figure 2.5. The effect of herring sperm DNA on anaerobic growth of Bacillus mojavensis JF-2.

RNA and ribonucleosides were then added to the medium to see if the growth enhancing effect of DNA could be replaced with other sources of nucleic acids or precursors to nucleic acids. From Figures 2.7 and 2.8, it is apparent that neither RNA nor ribonucleosides supported anaerobic growth of B. mojavensis strain JF-2 while growth was observed in medium supplemented with DNA. The presence of RNA or ribonucleosides was not inhibitory to the growth of B. mojavensis strain JF-2 in medium E with DNA. It is interesting to note that the presence of ribonucleosides in medium with DNA caused an extended lag phase. 


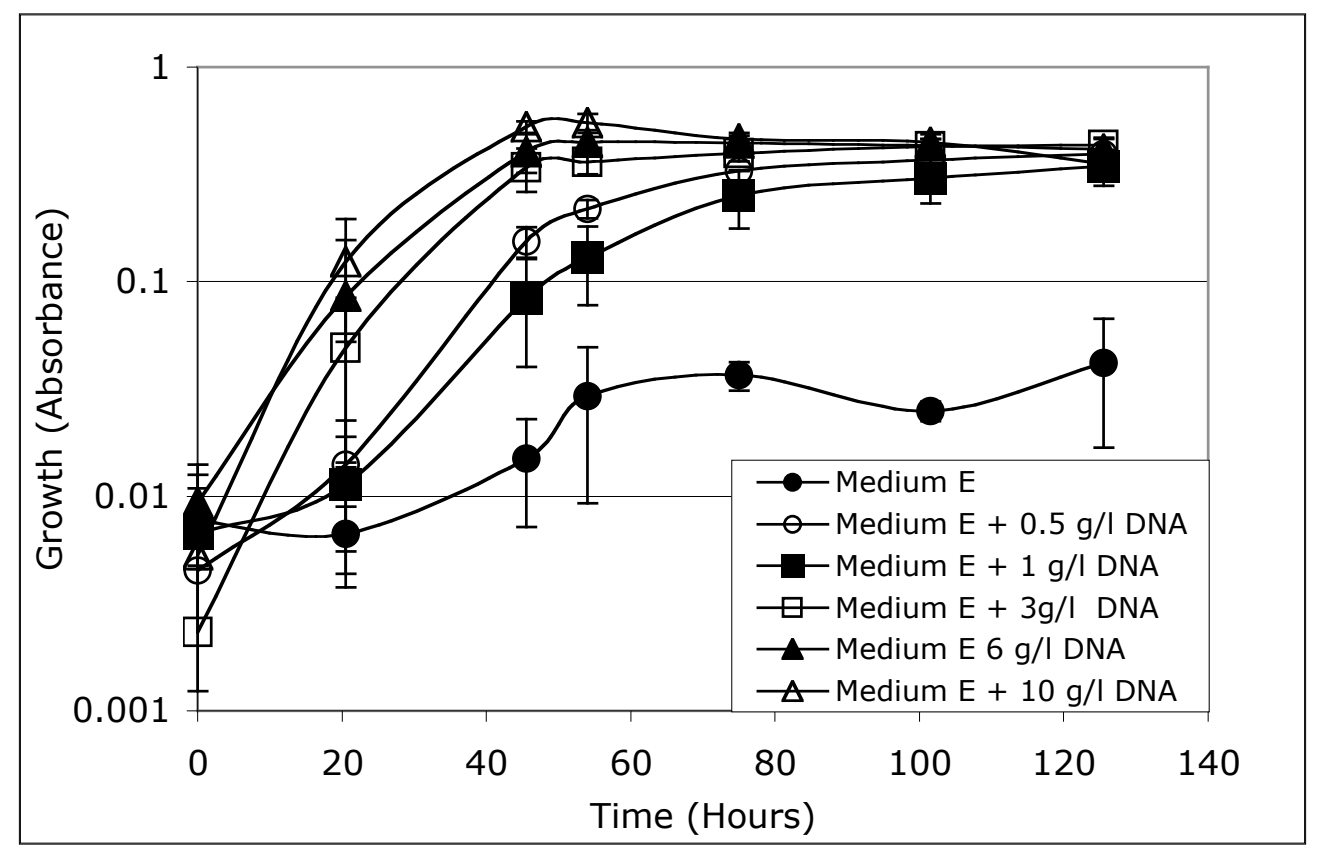

Figure 2.6. The effect of various concentrations of herring sperm DNA on anaerobic growth of B. mojavensis JF-2.

Initially, RNA and ribonucleosides were added prior to autoclaving the medium. Since these some of these components may have been altered during autoclaving, this experiment was repeated with filter sterilized RNA, ribonucleosides and also included filter sterilized ribonucleotides. From Figures 2.9, 2.10, and 2.11, it is apparent that the addition of filter sterilized RNA, ribonucleotides or ribonucleosides did not replace the requirement for DNA. Again, the addition of ribonucleosides to medium with DNA resulted in an extended lag phase.

One important difference between RNA and DNA is that RNA contains a ribose sugar while DNA contains a deoxyribose sugar. Since RNA did not support anaerobic growth of B. mojavensis JF-2, it was possible that the deoxyribose sugar found in DNA was the actual growth factor. However, the addition of $1 \mathrm{~g} / 1$ 2-deoxyribose to Medium $\mathrm{E}$ did not replace the growth-enhancing effect of DNA (data not shown). 


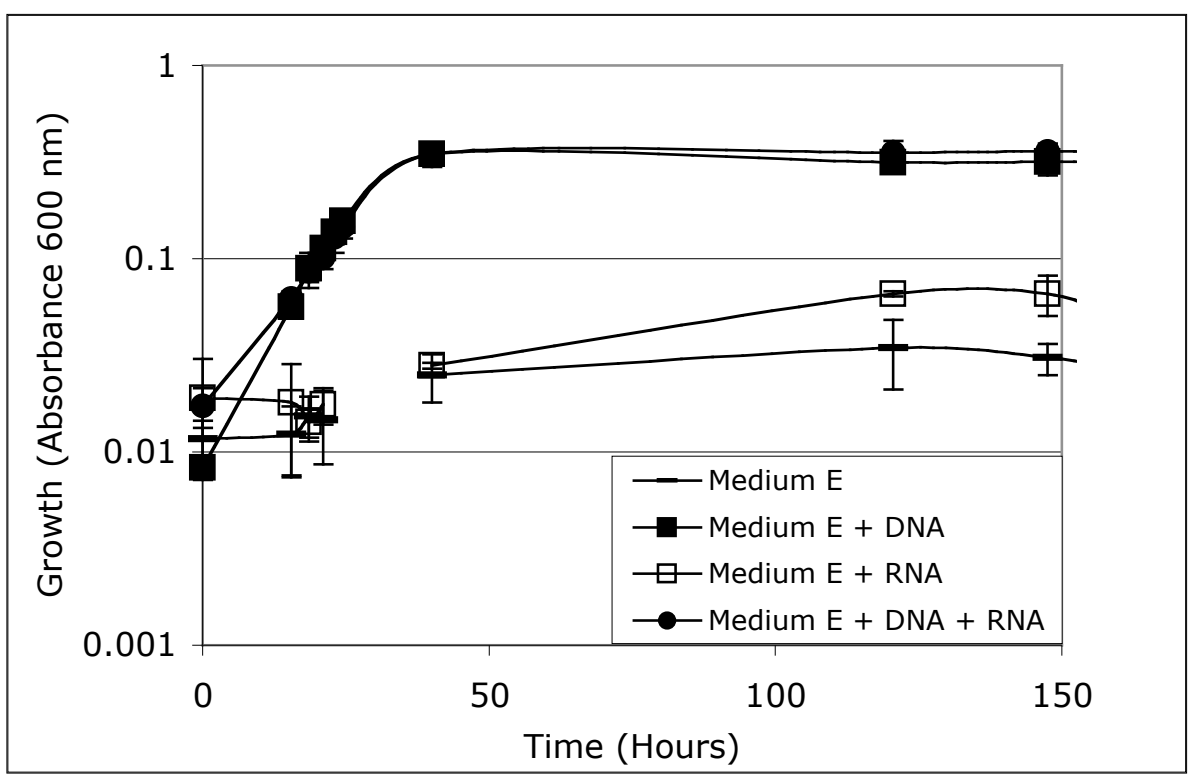

Figure 2.7. The effect of RNA on anaerobic growth of Bacillus mojavensis JF-2.

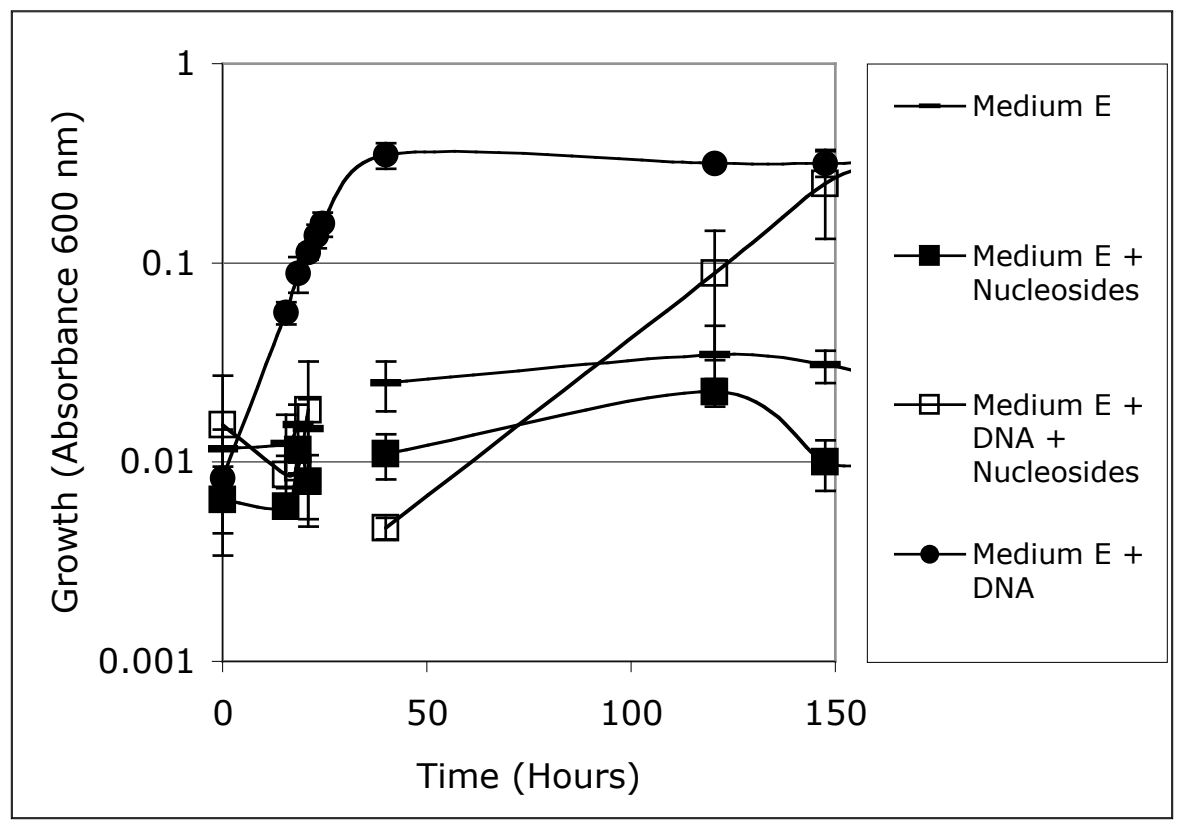

Figure 2.8. The effect of ribonucleosides on anaerobic growth of Bacillus mojavensis JF2. 


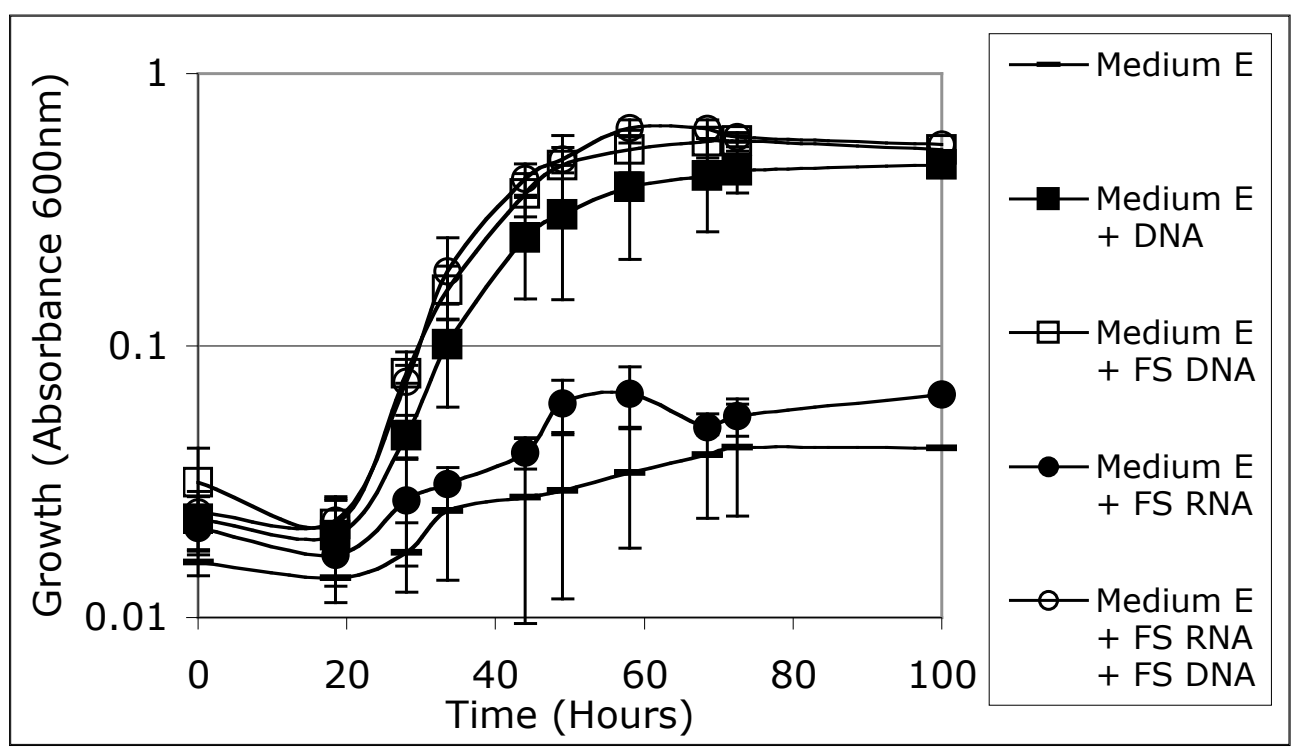

Figure 2.9. The effect of filter sterilized (FS) RNA on anaerobic growth of Bacillus mojavensis JF-2.

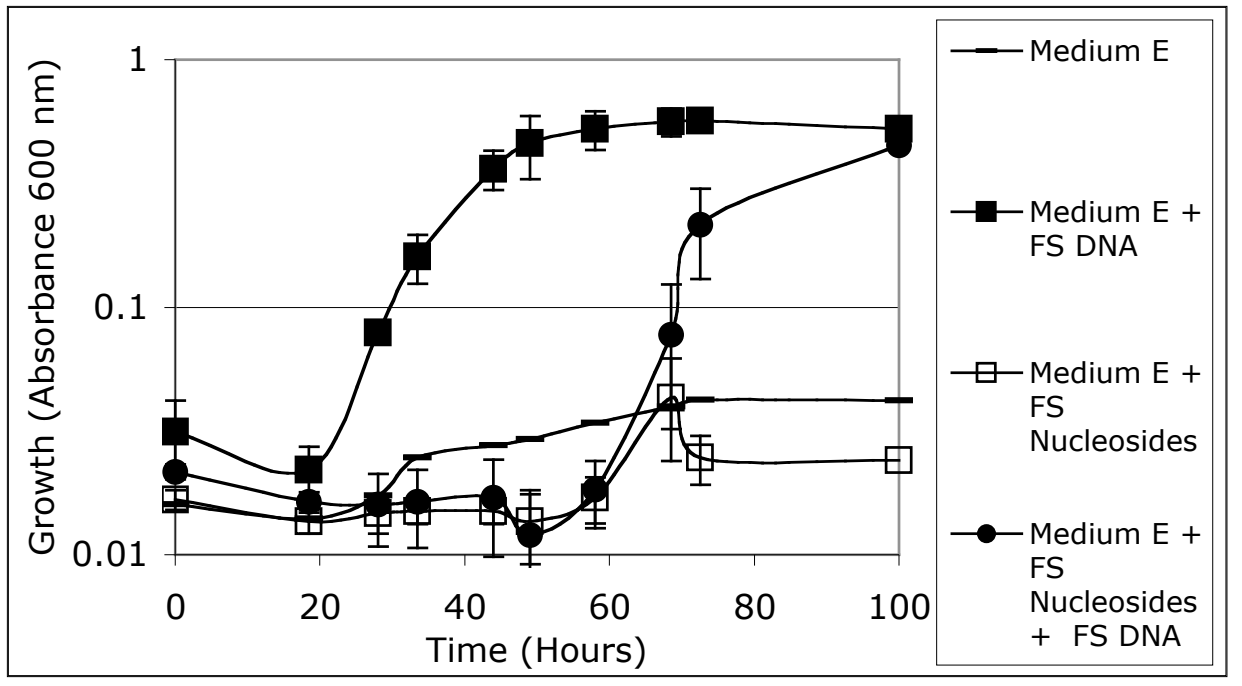

Figure 2.10. The effect of filter sterilized (FS) ribonucleosides on anaerobic growth of Bacillus mojavensis JF-2.

The above experiments used eukaryotic DNA since this form of DNA is readily available. We also tested the ability of prokaryotic DNA to replace Proteose peptone by extracting and purifying DNA from Escherichia coli. It was found that DNA from E. coli replaced herring sperm DNA (Figure 2.12) and as little as $20 \mathrm{mg} / \mathrm{l}$ of E. coli DNA was sufficient to support evidence of anaerobic growth of $B$. mojavensis strain JF-2, 
resulting in an increase in absorbance of the culture from an absorbance of 0.08 to 0.25 (Figure 2.13).

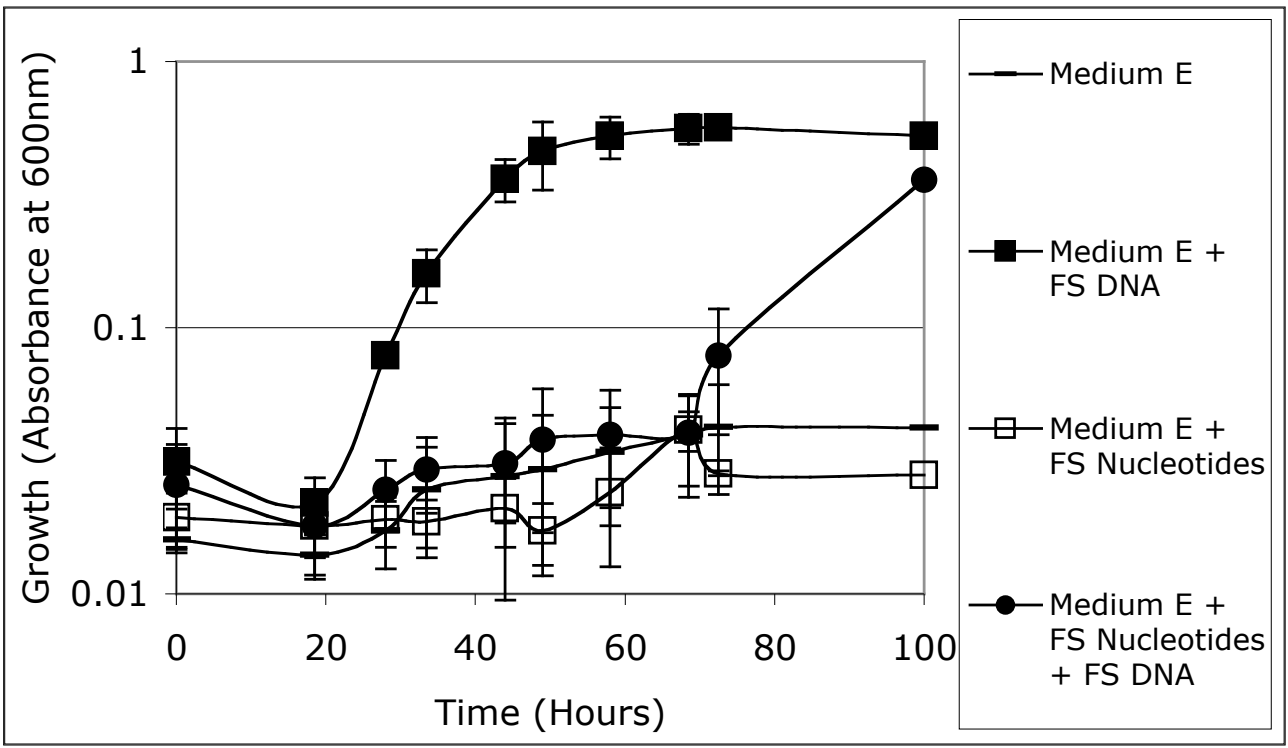

Figure 2.11. The effect of filter sterilized (FS) ribonucleotides on anaerobic growth of Bacillus mojavensis JF-2.

However, from Figure 2.13, it is also apparent that herring sperm DNA was more effective as a growth supplement than the E. coli DNA when tested at the same concentration. Growth was faster and resulted in a higher final absorbance when $1 \mathrm{~g} / 1$ herring sperm DNA was added to the growth medium compared to medium with $1 \mathrm{~g} / 1 \mathrm{E}$. coli DNA.

As a result of the different responses to the two different DNA sources, the size of the DNA fragments of each of the two sources of DNA was determined by agarose gel electrophoresis. Herring sperm DNA consisted of smaller DNA fragments (about 50 base pairs) than did the E. coli DNA (about 1000 to 300 base pair fragments) (Figure 2.14), 
suggesting that smaller molecular weight fragments of DNA were more effectively utilized by B. mojavensis strain JF-2 than larger DNA fragments.

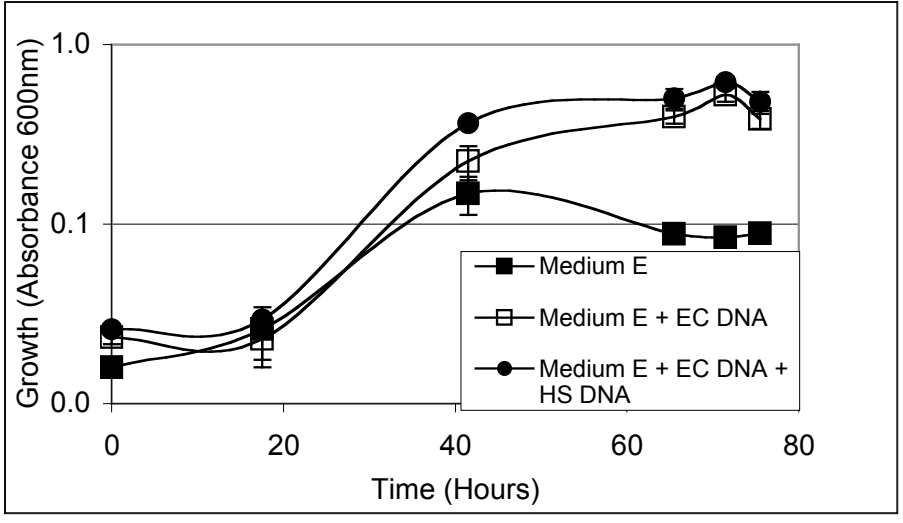

Figure 2.12. The effect of E. coli DNA on anaerobic growth of Bacillus mojavensis JF-2. $\mathrm{EC}$ DNA $=1 \mathrm{~g} / 1 \mathrm{E}$. coli DNA, HS DNA $=1 \mathrm{~g} / 1$ herring sperm DNA.

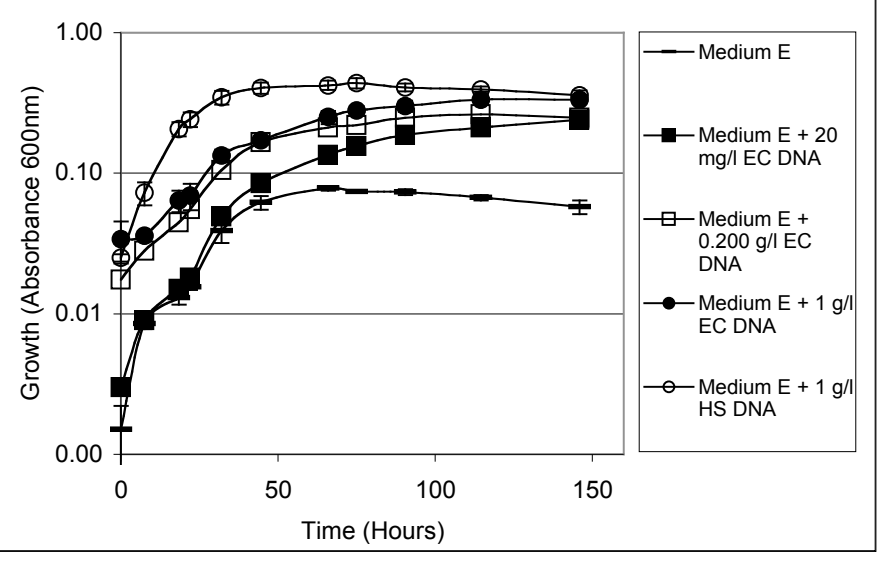

Figure 2.13. The effect of different concentrations of $E$. coli DNA on anaerobic growth of Bacillus mojavensis JF-2. EC DNA = E.coli DNA; HS DNA = herring sperm DNA. 


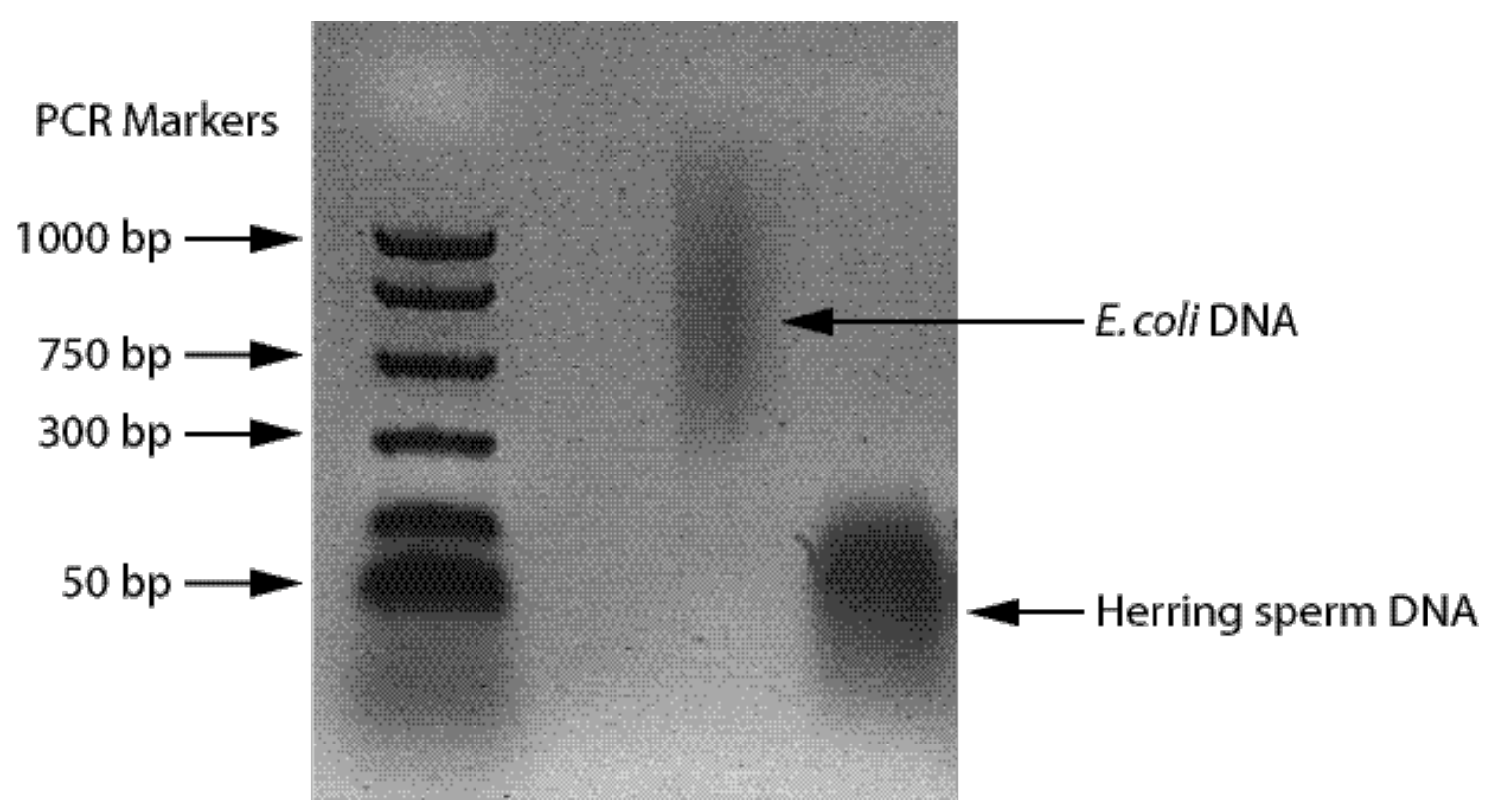

Figure 2.14. A polyacrylamide gel comparing the size of DNA fragments in herring sperm DNA and E. coli DNA.

Salmon sperm DNA, herring sperm DNA and E. coli DNA all consist of cellularly produced DNA extracted and purified by the Marmur procedure. It was possible that these preparations contained a compound that was the actual growthenhancing factor that was co-extracted with the DNA. To exclude this possibility, the ability of chemically synthesized DNA to support the anaerobic growth of B. mojavensis strain JF-2 was tested. From Figure 2.15, it is clear that synthetic DNA supported anaerobic growth of B. mojavensis strain JF-2 as did DNA purified from organisms. Both single stranded synthetic DNA and double stranded synthetic DNA supported growth.

Since the requirement for DNA for anaerobic growth has not been reported in any other prokaryotes, other strains of Bacillus were tested to see if they also required DNA for anaerobic growth. Both the type strain Bacillus mojavensis ${ }^{\mathrm{T}}$ (ABO21191) and a presumptive Bacillus mojavensis, strain ROB2, required DNA for anaerobic growth (Figures 2.16 and 2.17). 


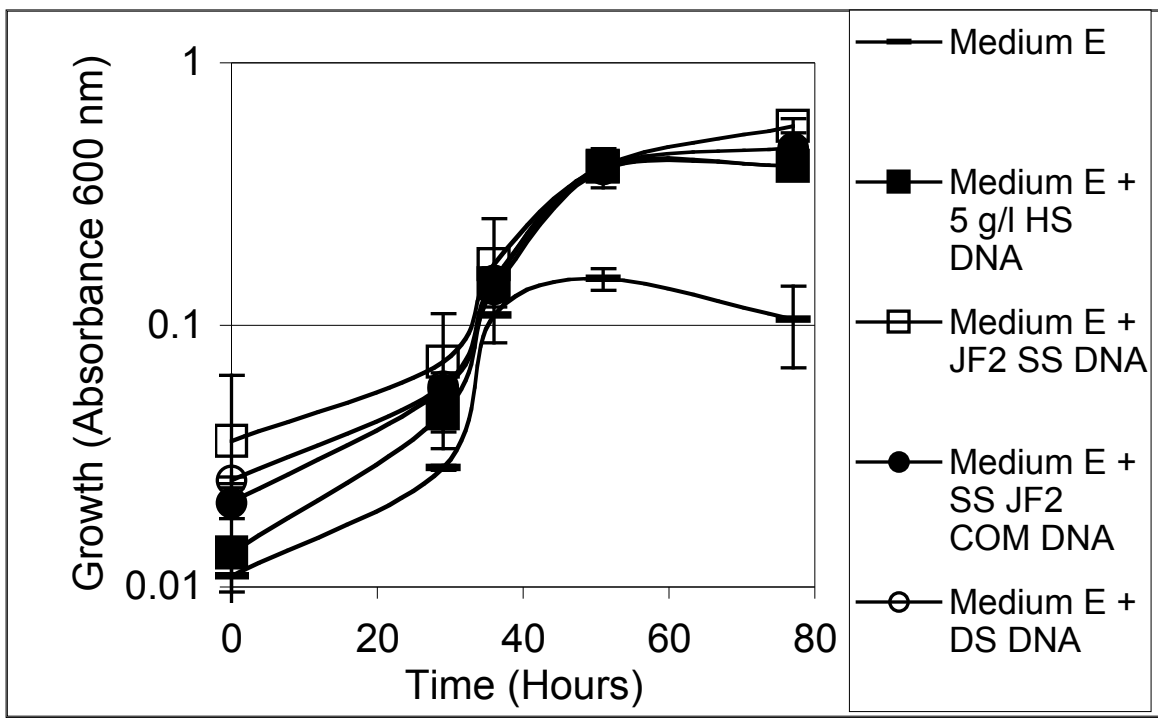

Figure 2.15. The effect of synthetic DNA on the growth of B. mojavensis JF-2 in anaerobic medium. JF2 SS DNA = single stranded DNA; SS JF2 COM = the complementary strand of JF2 SS single stranded DNA; DS DNA = both single strands together, resulting in double stranded DNA.

In addition to requiring DNA, ROB2 may require some other component since an absorbance greater than 1 was reached when Proteose peptone was included with the DNA compared to an absorbance of 0.4 in Medium E with just DNA

A presumptive Bacillus subtilus, ATCC 12332, also showed a requirement for DNA when growing anaerobically (Figure 2.18). The addition of Proteose peptone to the DNA supplemented medium further enhanced growth but not as dramatically as for ROB2. It is likely that this strain also requires some other component in addition to DNA for anaerobic growth. 


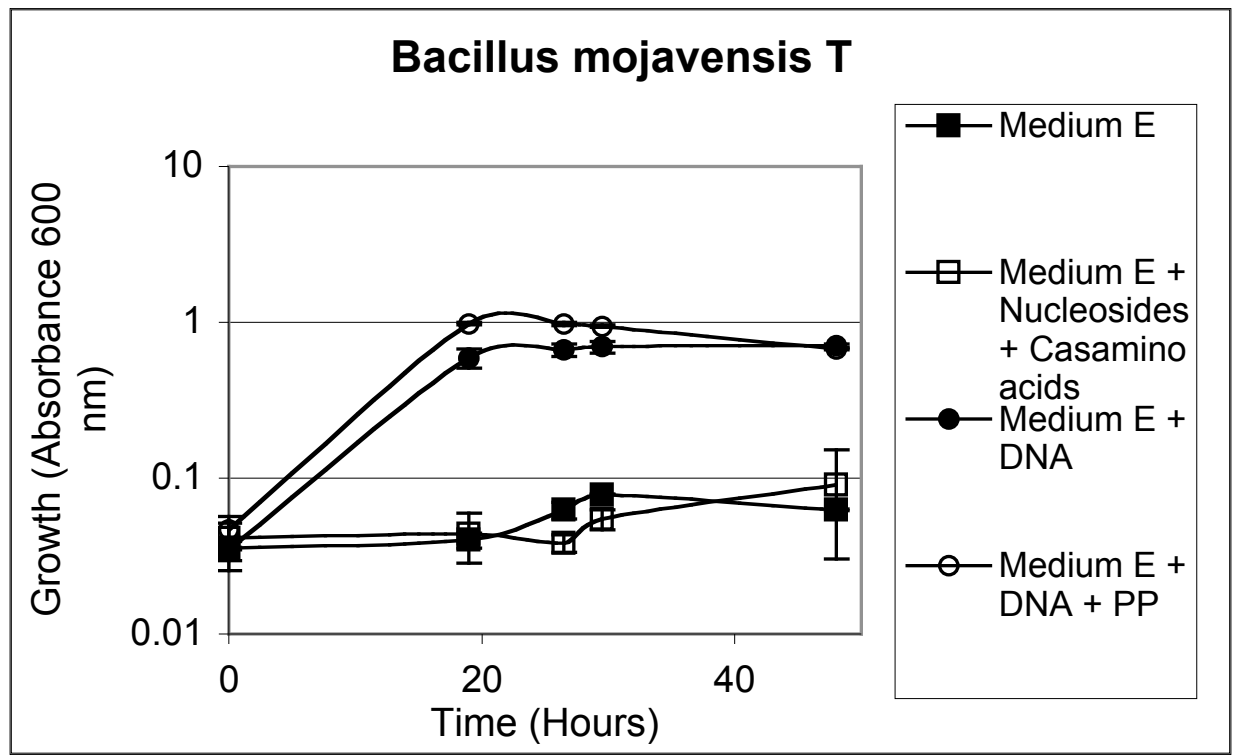

Figure 2.16. The effect of DNA on the anaerobic growth of Bacillus mojavensis ${ }^{\mathrm{T}}$ $(\mathrm{ABO} 21191) \mathrm{PP}=$ Proteose peptone

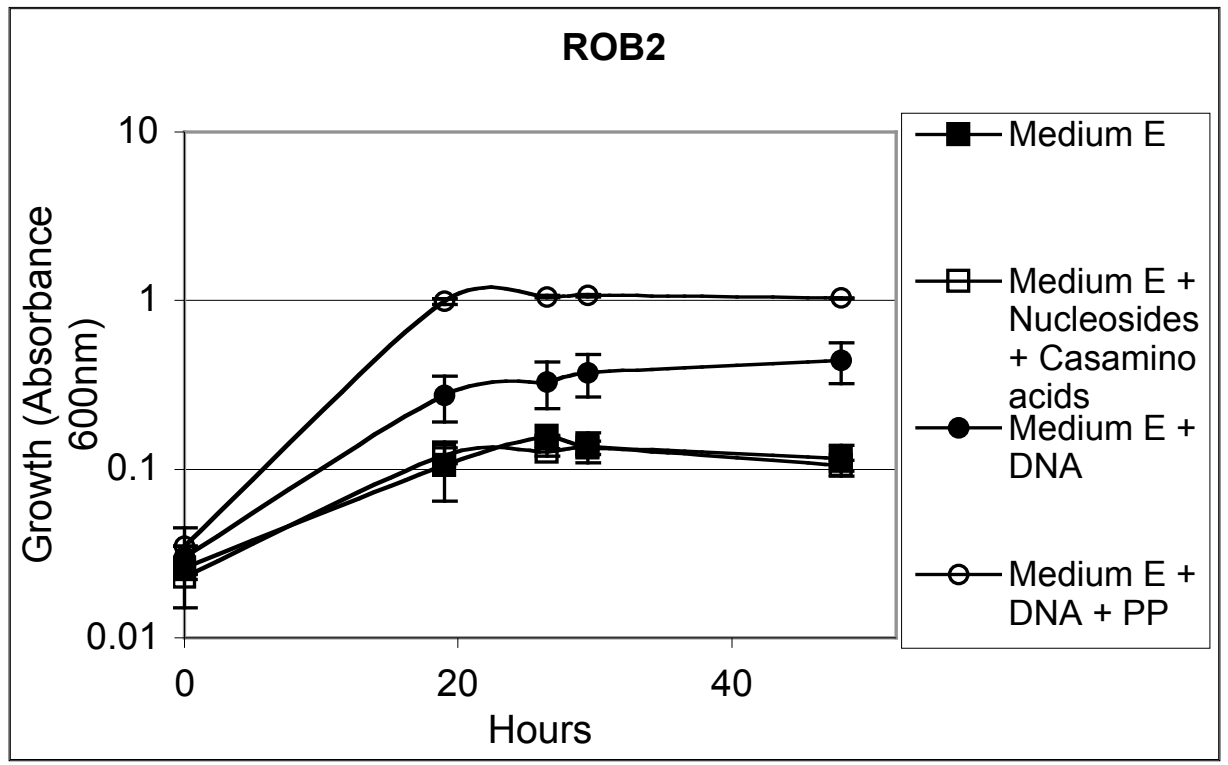

Figure 2.17. The effect of DNA on the anaerobic growth of a presumptive Bacillus mojavensis strain ROB2. DNA $=1 \mathrm{~g} / 1$ herring sperm DNA, PP $=1 \mathrm{~g} / 1$ Proteose peptone

Two strains of Bacillus licheniformis strains and two strains of Bacillus sonorensis were also tested. None of these strains required DNA for anaerobic growth. All grew similarly to the strain shown in Figure 2.19. The addition of DNA to Medium E did not enhance anaerobic growth of these four strains over that in unamended 
medium, but the addition of a mixture of Casamino acids and nucleosides to Medium $\mathrm{E}$ did enhance growth

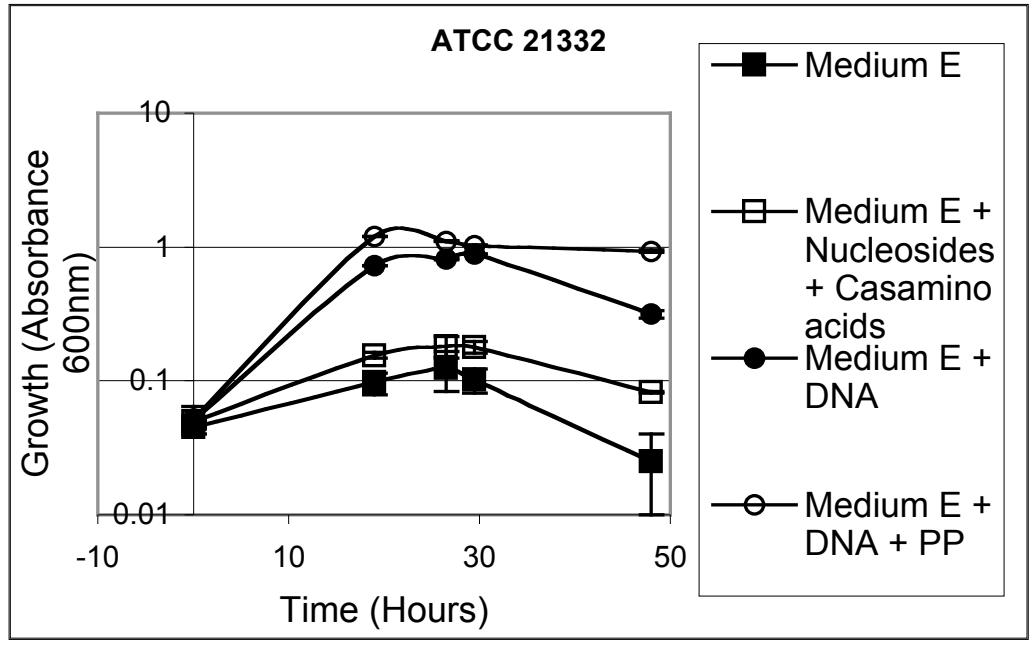

Figure 2.18. The effect of DNA on anaerobic growth of a presumptive Bacillus subtilus strain. DNA $=1 \mathrm{~g} / 1$ herring sperm DNA; $\mathrm{PP}=1 \mathrm{~g} / 1$ Proteose peptone

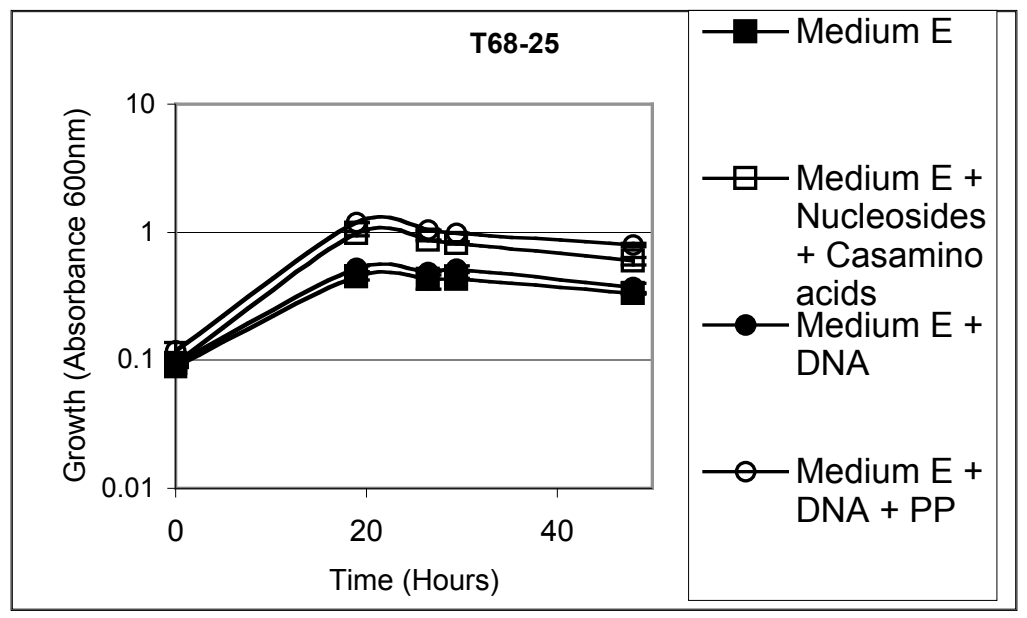

Figure 2.19. The effect of DNA on the anaerobic growth of a presumptive Bacillus licheniformis. DNA = $1 \mathrm{~g} / 1$ herring sperm DNA; $\mathrm{PP}=1 \mathrm{~g} / 1$ Proteose peptone

With the addition of $1 \mathrm{~g} / 1$ of DNA to Medium E, it was possible that the DNA was used as a carbon source and not simply a growth factor. However, as seen in Figure 2.20, DNA did not serve as a sole carbon or energy source for Bacillus mojavensis JF-2 in Medium E. No growth occurred when the medium lacked sucrose but had 1g/1 DNA. 


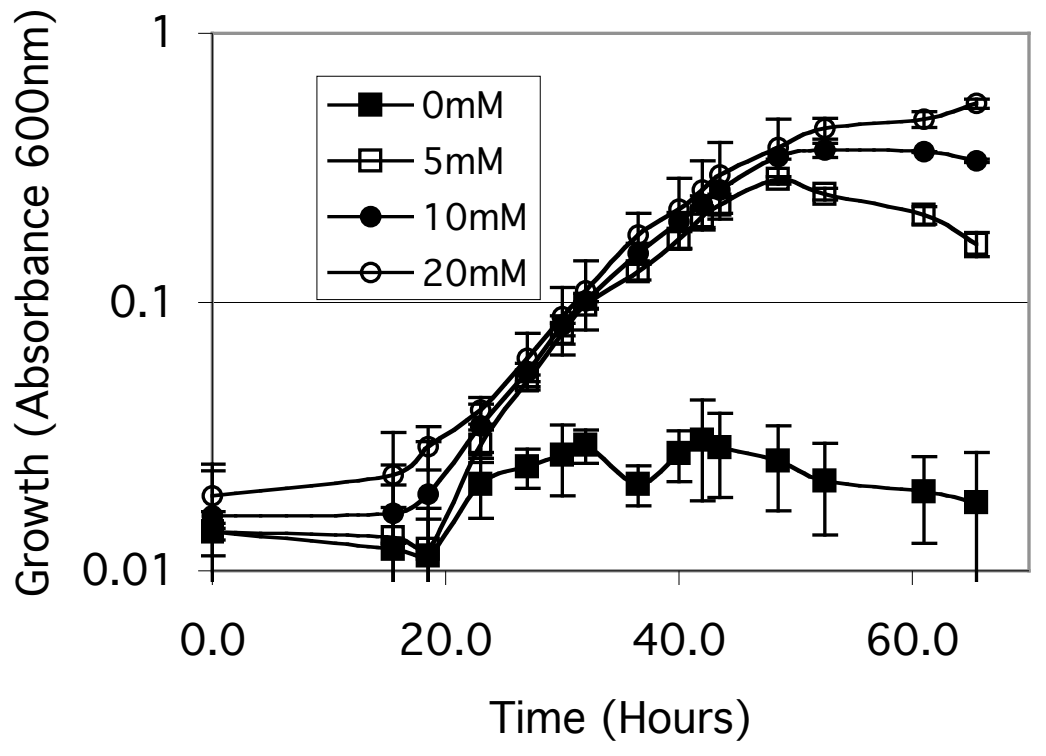

Figure 2.20. The effect of sucrose on the growth of $B$. mojavensis JF-2 in anaerobic medium supplemented with $1 \mathrm{~g} / 1 \mathrm{DNA}$.

Requirement for amino acids and vitamins of $\boldsymbol{B}$. mojavensis JF-2: Medium E contains $1 \mathrm{~g} / \mathrm{l}$ yeast extract that could supply a number of growth factors. These growth factors include nucleic acid bases, amino acids and vitamins. We then tested if any of these three growth factors might be additional anaerobic growth requirements of $B$. mojavensis JF-2.

Anaerobic growth of $B$. mojavensis strain JF-2 was not observed in DNA supplemented Medium E that lacked yeast extractor amino acids (Figure 2.21). Bases or 


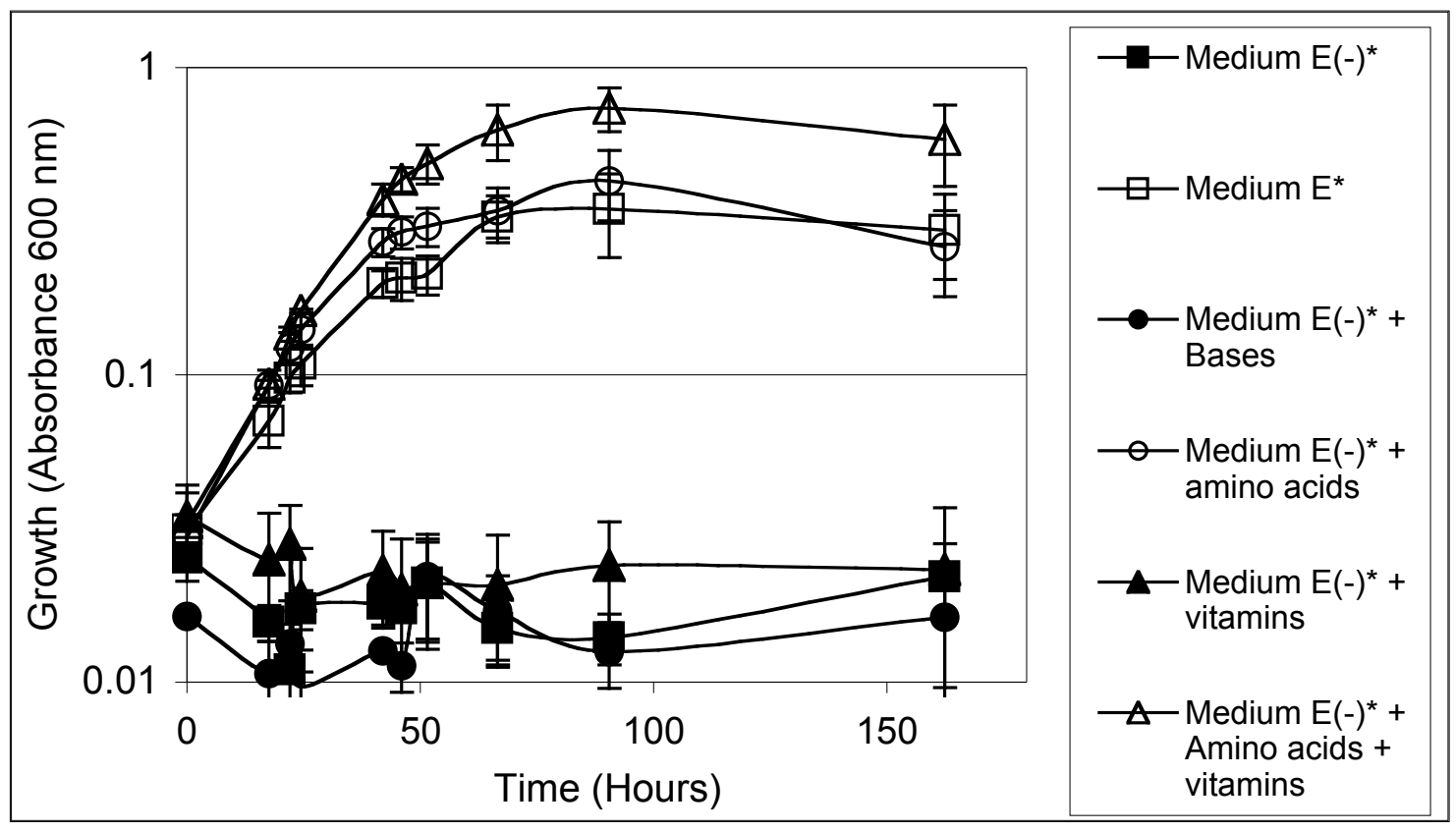

Figure 2.21. The effect of the removal of yeast extract from DNA supplemented Medium $\mathrm{E}$ and the addition of nucleic acid bases, amino acids and vitamins individually and in combination to DNA supplemented Medium E on the anaerobic growth of $B$. mojavensis JF-2. Medium E (-)* = DNA supplemented Medium E without yeast extract, Medium E* $=$ DNA supplemented Medium E, DNA $=1 \mathrm{~g} / 1$ herring sperm DNA, Bases $=1 \mathrm{~g} / 1$ each of nucleic acid bases, $\mathrm{AA}=1 \mathrm{~g} / \mathrm{l}$ Casamino acids.

vitamins alone did not replace yeast extract. The presence of amino acids in DNA supplemented Medium E did replace the requirement for yeast extract. Amino acid (plus DNA) supplemented Medium E supported a greater degree of growth $($ Absorbance $=0.9)$ than Medium E (plus DNA) supplemented with yeast extract (Absorbance $=0.5$ ). Medium E supplemented with DNA, amino acids, and vitamins supported the best growth.

Under aerobic conditions, no growth requirements were clearly identified. The addition of DNA to Medium E that lacked yeast extract did not improve growth under aerobic conditions (Figure 2.22). The presence of yeast extract in Medium E (without DNA) did improve growth but only very slightly (an absorbance of 0.33 without yeast 
extract vs. an absorbance of 0.47 with yeast extract) (Figure 2.22). However the addition of amino acids instead of yeast extract to Medium E did improve growth (an absorbance of 0.47 with yeast extract and an absorbance of 0.7 with amino acids) and the combination of amino acids with vitamins (as a replacement for yeast extract in Medium E) resulted in the best growth (an absorbance of 0.8) (Figure 2.23 and 2.24).

Requirement for small amounts of nitrate by B. mojavensis JF-2: It has been assumed that anaerobic growth of B. mojavensis JF-2 occurred as a result of nitrate respiration as this has been shown for B. subtilus (11). However B. mojavensis JF-2 did not require the stochiometric amounts of nitrate needed for the complete oxidation of sucrose to carbon dioxide for anaerobic growth (Figure 2.25). In anaerobic Medium E with $30 \mathrm{~g} / 1$ Proteose peptone and $1 \mathrm{~g} / 1(12 \mathrm{mM})$ of sodium nitrate, about $10 \mathrm{mM}$ of sucrose was consumed. The complete oxidation of $10 \mathrm{mM}$ of sucrose to carbon dioxide would require about $96 \mathrm{mM}$ nitrate. The actual requirement for nitrate for anaerobic growth of B. mojavensis JF-2 was as low as $6 \mathrm{mM}$ nitrate, which would be insufficient for the oxidation of $10 \mathrm{mM}$ sucrose. The actual minimal requirement for nitrate for $B$. mojavensis JF-2 when grown under anaerobic conditions has yet to be determined. 


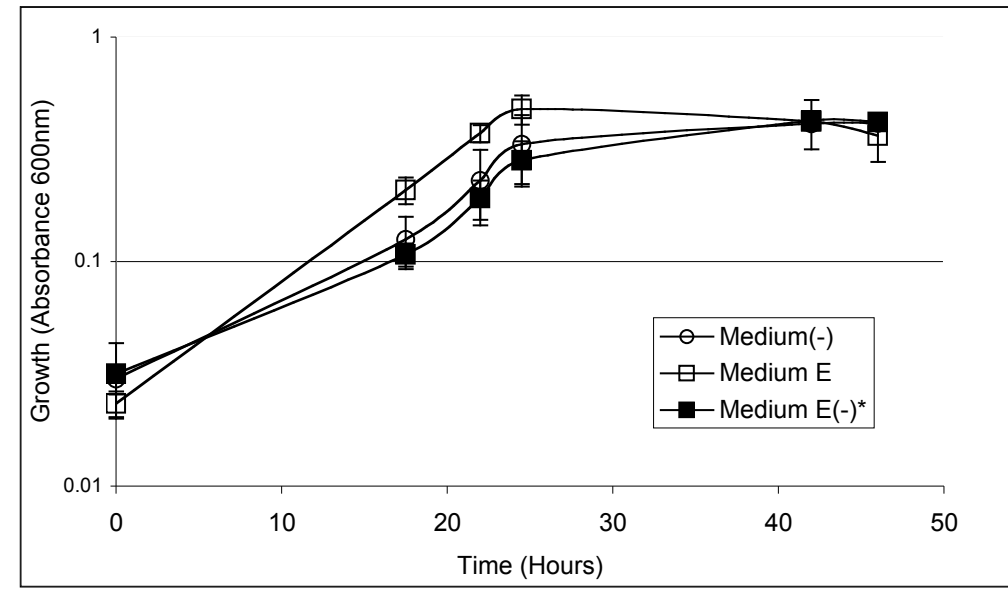

Figure 2.22. The effect of yeast extract and DNA on the aerobic growth of $B$. mojavensis JF-2. Medium E (-)* = DNA supplemented Medium E without yeast extract, Medium E* $=$ DNA supplemented Medium E, DNA= $1 \mathrm{~g} / 1$ herring sperm DNA.

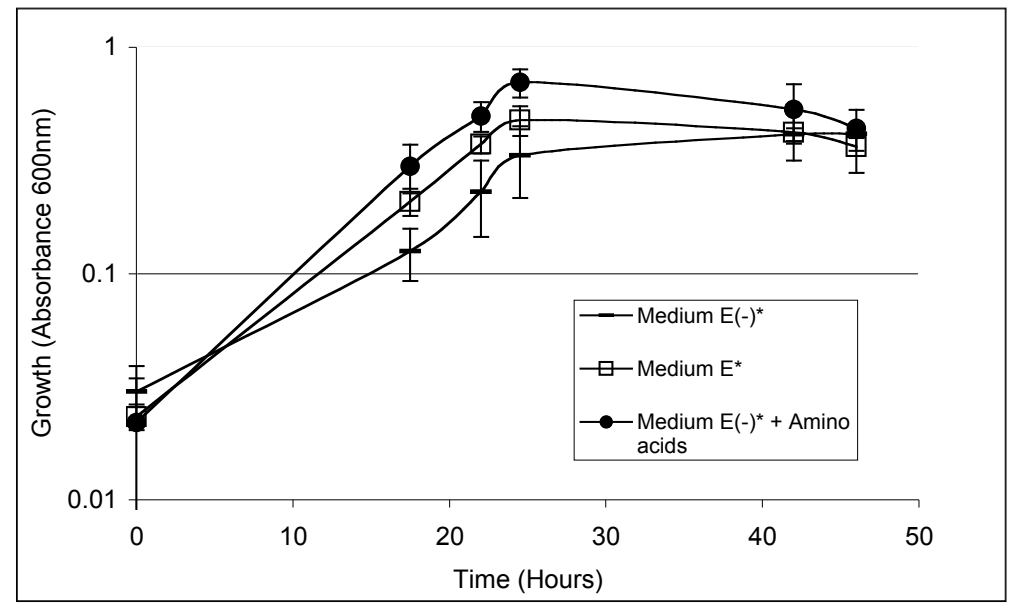

Figure 2.23. The effect of yeast extract and amino acids on the aerobic growth of $B$. mojavensis JF-2. Medium E (-)* = DNA supplemented Medium E without yeast extract, Medium $\mathrm{E}^{*}=$ DNA supplemented Medium E, DNA= $1 \mathrm{~g} / 1$ herring sperm DNA, Amino acids $=1 \mathrm{~g} / 1$ Casamino acids. 


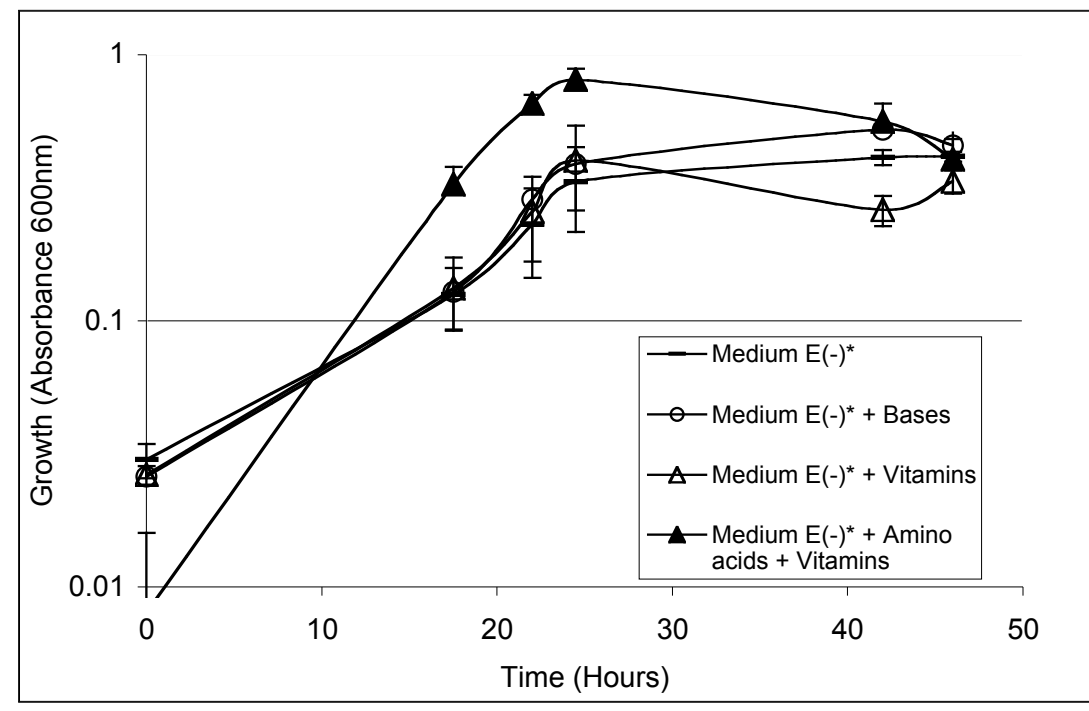

Figure 2.24. The effect of nucleic acid bases and vitamins on the aerobic growth of $B$. mojavensis JF-2 in DNA supplemented Medium E. Medium E (-)* = DNA supplemented Medium E without yeast extract, Medium $E^{*}=$ DNA supplemented Medium E, DNA=1 $\mathrm{g} / 1$ herring sperm DNA, Amino acids $=1 \mathrm{~g} / \mathrm{l}$ Casamino acids, nucleic acid bases $=1 \mathrm{~g} / \mathrm{l}$ each base, (for vitamin solution see methods and materials).

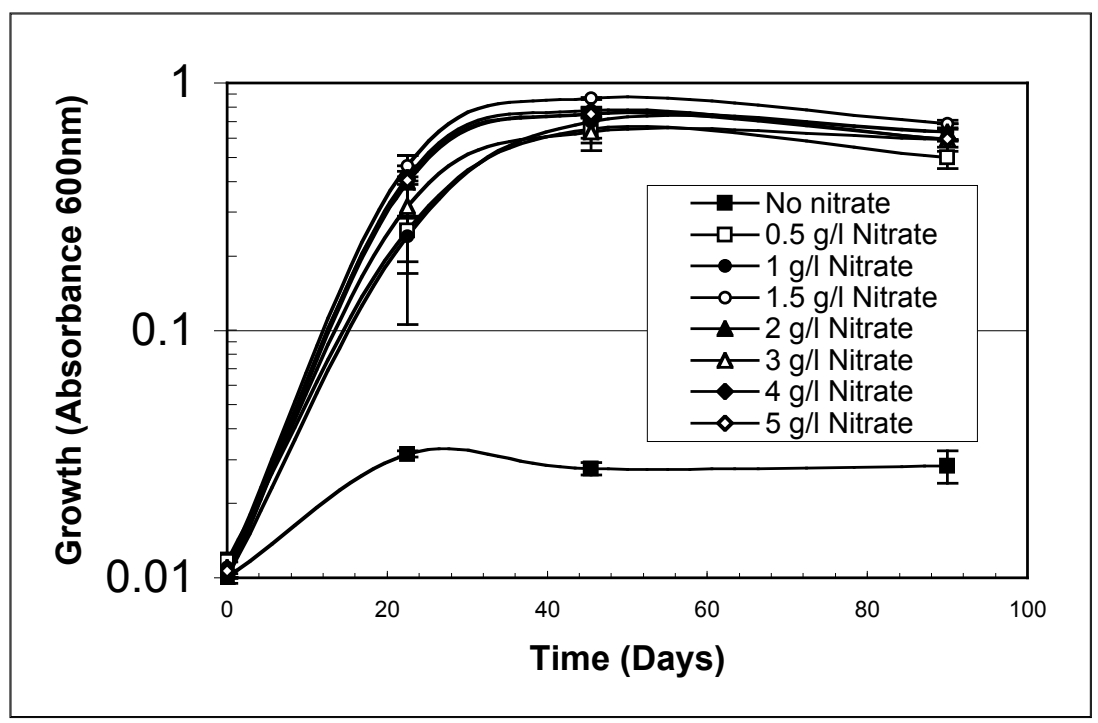

Figure 2.25. The effect of nitrate on the growth of $B$. mojavensis JF-2 in anaerobic medium supplemented with Proteose peptone.

\subsection{Discussion.}

Requirement for DNA: Proteose peptone is a complex source of nutrients both known and unknown. Its addition to Medium $\mathrm{E}$ was required for anaerobic growth of $B$. 
mojavensis JF-2 and also for biosurfactant production. However, the complexity of Proteose peptone restricts nutritional manipulation of the medium components since it is not possible to vary the amount of nitrogen, carbon, metals or other components that may result in improved biosurfactant production. However, we have now identified that DNA is one of the components that is required by B. mojavensis strain JF-2 and other strains of B. mojavensis and one strain of B. subtilis for anaerobic, but not aerobic growth. The replacement of Proteose peptone with DNA in anaerobic medium will allow us to manipulate the nutritional components of the medium to determine the optimal conditions for biosurfactant production. This will allow us to systematically vary not only the components of the medium, but also vary their concentrations to determine the optimal conditions for growth and biosurfactant production.

In addition to DNA, we found that Casamino acids and nitrate were required for anaerobic growth of B. mojavensis strain JF-2 and that the addition of Casamino acids and a vitamin solution containing $20 \square \mathrm{g} / \mathrm{l}$ each of $\mathrm{B}$ vitamins stimulated aerobic and anaerobic growth Figure 2.21 and 2.24). While B-vitamins clearly improved aerobic and anaerobic growth, it will be necessary to transfer the bacterium in vitamin-free medium several times to determine if vitamins are actually required or merely stimulate growth. These experiments are currently in progress. Vitamins may also impact biosurfactant production, but this has yet to be determined. The requirement for DNA for anaerobic growth is unusual and has not been previously demonstrated for any other organism. This requirement is especially unusual since the requirement does not exist during aerobic growth. Generally, microorganisms synthesize the components needed for the synthesis of nucleic acids from their carbon/energy source while some microorganisms 
may require either the addition of one or more nucleic acid base(s) or entire nucleosides themselves in the medium for growth (11).

It is not yet clear why B. mojavensis requires DNA for anaerobic growth. However, a possible explanation for the requirement for DNA under anaerobic growth conditions and not under aerobic conditions may be due to the absence of a Class II or Class III enzyme ribonucleotide reductase. The Class I ribonucleotide reductase only functions under aerobic conditions, since it requires oxygen to generate the tyrosyl radical needed to make the deoxyribonucleotide for DNA synthesis (5). The Class II enzyme will function under anaerobic conditions and the Class III is will only function under anaerobic conditions (5). If B. mojavensis has only the Class I ribonucleotide reductase and does not have either Class II or Class III, then it would be unable to reduce the ribonucleotide to the deoxyribonucleotide under anaerobic conditions, thus unable to make DNA.

It is evident that the source of DNA is not critical. Both eukaryotic DNA and prokaryotic DNA will suffice. Long strands of DNA are not necessary and may even be less favorable than short strands of DNA since better growth of B. mojavensis strain JF-2 was observed when herring sperm DNA that had shorter strands of DNA was used compared to E. coli DNA that had longer strands of DNA. Single-stranded DNA is just as effective as double-stranded DNA (2.15). Small pieces of DNA such as these are likely to be found many environments, and thus it may not be necessary to supply DNA for in situ growth. As a result, the requirement for Proteose peptone (and its high cost) very likely can be eliminated. 
It is interesting to note that the addition of nucleosides to medium with DNA caused an extended lag phase of B. mojavensis under anaerobic conditions. The reason for this is not yet known, but may have been due to a disruption in the balance of cell building material with both nucleosides and DNA present or the nucleosides may interfere with the uptake of DNA.

The fact that other Bacilli also have this requirement for DNA under anaerobic growth conditions indicates that this novel physiology is not limited to B. mojavensis JF2. It is possible that this requirement could be the phenotypic characteristic of $B$. mojavensis.

The fact that stochiometric quantities of nitrate are not required suggests that $B$. mojavensis is not growing by nitrate respiration. If $\mathrm{JF}-2$ were growing by nitrate respiration as shown in the equation below,

$$
\text { Sucrose }+9.6 \mathrm{NO}_{3}{ }^{-}+9.6 \mathrm{H}^{+} \rightarrow 12 \mathrm{CO}_{2}+4.8 \mathrm{~N}_{2}+15.8 \mathrm{H}_{2} \mathrm{O}
$$

$96 \mathrm{mM}$ nitrate would be required to completely oxidize $10 \mathrm{mM}$ sucrose. However, only 5 $\mathrm{mM}$ or less of nitrate is required for anaerobic growth. Clearly, B. mojavensis JF-2 is not respiring nitrate. The fermentative products such as 2,3-butanediol, acetate, and lactate have been detected in the medium after growth and, although a fermentation balance has not yet been completed, their presence indicates a fermentative metabolism.

Effect of amino acids and vitamins on growth of B. mojavensis JF: Our results show that yeast extract is not necessary for aerobic or anaerobic growth of B. mojavensis strain JF-2 if Casamino acids are supplied. Amino acids were required for anaerobic growth but not for aerobic growth and growth was improved with the addition of vitamins. The effect of these additions on biosurfactant production has yet to be tested. 
The effect of different sources of amino acids (other than Casamino acids) on growth and biosurfactant production has yet to be tested also.

Overall, it would appear that B. mojavensis JF-2 has numerous growth requirements, resulting in a relatively rich medium to support growth. However, it is quite common that bacteria require diverse organic growth factors (2). The growth requirements of a bacterium in pure culture reflect the environmental conditions under which is grows in natural environments. Thus, it is likely that DNA, amino acids and vitamins are naturally present in the environment where JF-2 was isolated. Since JF-s was isolated from oil field brine, this suggests that the organism must have had access to these nutrients in order to grow. If this is so, then it would not be necessary to supply them so long as B. mojavensis strain JF-2 can acquire these nutrients from other microorganisms that are present in the oil reservoir.

\subsection{Conclusion.}

By eliminating the Proteose peptone a major production cost has been eliminated and new possibilities for enhancing biosurfactant production through the manipulation of the medium components are now possible. We can now test the effect of the concentration of different medium components such as amino acids and the type of amino acid on biosurfactant production. Our work also represents an important advance in our knowledge of the biology of microorganisms. Almost all ecosystems have very diverse microbial populations and we know very little about the microorganisms that inhabit these ecosystems. The discovery of a DNA requirement for anaerobic growth may 
allow us to develop approaches to isolate and culture bacteria that so far have not been successfully cultured in a laboratory environment.

\subsection{References}

1. Balch, W. E., and R. S. Wolfe. 1976. New approach to the cultivation of methanogenic bacteria: 2-mercaptoethanesulfonic acid (HS-CoM)-dependent growth of Methanobacterium ruminantium in a pressurized atmosphere. Appl. Environ. Microbiol. 32:781-791.

2. Bryant, M. P. 1973. Nutritional requirements of the predominant rumen cellulolytic bacteria. Federation Proceedings 32:1809-13.

3. E. Wolin, M. W., R. Wolfe. 1963. Formation of methane in bacterial extracts. J. Bio. Chem. 238:2882-2886.

4. Javaheri, M., G. E. Jenneman, M. J. McInerney, and R. M. Knapp. 1985. Anaerobic production of a biosurfactant by Bacillus licheniformis JF-2. Appl. Environ. Microbiol. 50:698-700.

5. Jordan, A., P. Reichard. 1998. Ribonucleotide Reductases. Annu. Rev. Biochem. 67:71-98.

6. Lin, S. C., M. A. Minton, M. M. Sharma, and G. Georgiou. 1994. Structural and immunological characterization of a biosurfactant produced by Bacillus licheniformis JF-2. Appl. Environ. Microbiol. 60:31-38.

7. Marmur, J. A. 1961. A procedure for the isolation of deoxyribonucleic acid from microorganisms. J. Mol. Biol. 3:208-218.

8. Marsh, T. L., X. Zhang, R. M. Knapp, M. J. McInerney, P. K. Sharma, and B. E. Jackson. 1995. Mechanisms of microbial oil recovery by Clostridium 
acetobutylicum and Bacillus strain JF-2., p. 593-610. In R. S. Bryant and K. L. Sublette (ed.), The Fifth International Conference on Microbial Enhanced Oil Recovery and Related Problems for Solving Environmental Problems. Office of Scientific and Technical Information, CONF-9509173.

9. McInerney, M. J., S. O. Han, S. Maudgalya, H. Mouttaki, M. Folmsbee, R. Knapp, D. Nagle, B. Jackson, M. Staudt, and W. Frey. 2001. Development of more effective biosurfactants for enhanced oil recovery. Final Technical Report for DOE DE-AC26-98BC15113. University of Oklahoma.

10. McInerney, M. J., M. Javaheri, and D. P. Nagle. 1990. Properties of the biosurfactant produced by Bacillus licheniformis strain JF-2. J. Indust. Microbiol. 5:95-102.

11. Sonenshein, A. L., James A. Hoch, Richard Losick. 1993. Bacillus subtilus and Other Gram-positive Bacteria. ASM, Washington D.C.

12. Tanner, R. S. 1989. Monitoring sulfate-reducing bacteria: comparison of enumeration media. J. Microbiol. Methods. J. Microbiol. Methods 10:83-89.

13. Thomas, C. P., G. A. Bala, and M. L. Duvall. 1993. Surfactant-based enhanced oil recovery mediated by naturally occurring microorganisms. Soc. Petrol. Eng. Reservoir Eng. 11:285-291. 


\section{Chapter 3. Screening, selection, and genetic manipulation of biosurfactant-producing Bacillus strains.}

\subsection{Abstract.}

Microorganisms produce a wide range of biosurfactants with diverse chemical structures. Their ability to partition at the water-oil interface makes them ideal candidates for MEOR. In this year of the project, 157 bacterial strains were screened for biosurfactant production under both aerobic and anaerobic conditions. These data were compared to the amount of biosurfactant produced by Bacillus mojavensis JF-2, a model biosurfactant-producing microorganism that has been extensively applied in MEOR. Several methods were used to screen for biosurfactant production. The oil spreading technique and high performance liquid chromatography (HPLC) were used as quantitative measures of biosurfactant activity. The ability of the strains to reduce surface tension was measured by using ring tensiometer. A hundred and forty seven strains produced either equal or higher amounts of biosurfactant compared to JF-2 and the 10 best strains were chosen for further study. In an attempt to increase biosurfactant production, a genetic recombination experiment was conducted by mixing germinating spores of four of the best strains with JF-2. Biosurfactant production was higher with the

mixed spore culture than in the co-cultures containing JF-2 and each of the other 4 strains or in a mixed culture containing all five strains that had not undergone genetic exchange. Four isolates were obtained from the mixed spores culture that gave higher biosurfactant production than any of the original strains. Repetitive sequence-based polymerase chain 
reaction (REP-PCR) analysis showed differences in the band pattern for these strains compared to the parent strains, suggesting the occurrence of genetic recombination.

\subsection{Introduction.}

Biosurfactants are a diverse group of surface-active chemical compounds produced by a wide variety of microorganisms [1]. Members of the genera Arthrobacter, Bacillus, Candida, Pseudomonas, and Rhodococcus are known to produce biosurfactants of diverse chemical structures $[1,3]$. Biosurfactants have been investigated as replacements for synthetic surfactants since they are environmentally friendly and biodegradable. They are less sensitive to extreme conditions of temperature, salt concentration, and pressure than synthetic surfactants. Since biosurfactants have very low critical micelle concentration $(\mathrm{mg} / \mathrm{l})$, they are considered to be more economical to use than synthetic surfactants [2]. Biosurfactants are amphiphilic molecules with both hydrophilic and hydrophobic domains, which allow them to partition at the interface of two fluids with differing polarities such as oil-water or water-air interfaces [1, 3, 4]. They are thus capable of reducing the interfacial and/or surface tension. Such properties make them good candidates for enhanced oil recovery.

Candidate microorganisms for microbially enhanced oil recovery (MEOR) should be able to grow and produce their biosurfactants at high temperatures (about $50^{\circ} \mathrm{C}$ ) and high salt concentrations (around 5\%) and under anaerobic conditions with minimal nutrient requirements. The bacteria should be able to maintain their biosurfactant production over a long period of time. The lipopeptide biosurfactant produced by Bacillus mojavenesis strain $J F-2$ isolated from oil well produced waters 
has been used in MEOR due to its stability at high temperatures and high salinities [5]. The JF-2 biosurfactant reduces oil- brine interfacial tension to less than $0.01 \mathrm{mN} / \mathrm{m}$ and has a low critical micellar concentration (CMC) of 10-25 mg/L. However, anaerobic growth and biosurfactant production by JF-2 require the addition of growth factors as proteose peptone and yeast extract. Also, the activity of biosurfactant produced decreases over time [5].

Since genetic recombination is known to occur between mixed germinating spores of Bacillus species [6, 7], we hypothesized that Bacillus strains with improved biosurfactant producing ability could be obtained by mixing germinating spores of JF-2 and those of other Bacillus species. Our aim is to obtain strains that produce higher amount of biosurfactants than JF-2, are able to grow anaerobically with minimal nutrient requirements, and can maintain their biosurfactant activity over long periods of time. We screened a large number of Bacillus strains for anaerobic growth and biosurfactant production, selected the most promising strains, and attempted to increase biosurfactant production through genetic recombination.

\subsection{Materials and Methods.}

Bacterial strains: The following strains were used in our study:

Bacillus mojavensis strains: ROB-2, ROG-4, ROQQ-2, ROH-1, TG2-42, TG3-41, TG6-33, and T89-14.

Bacillus subtilis subsp. subtilis: T89-43, T89-44, T89-46, T89-47, T89-48, T89-49, T89-50, T89-51, T89-42, TG6-27, T89-8, TG4-19, T89-2, TF-32, TF-34, TG1-11, TG2-5, TG5-13, T88-13, T89-1, T89-10, T89-13, T89-15, T89-17, and T89-18. 
Bacillus subtilis subsp. spizizensis: T88-8, T88-9, T88-10, T88-11, T88-12, T8819, T88-20, T88-39, T89-3, T89-4, T89-5, T89-6, T89-7, T89-9, T89-12, T89-16, T89-52, T89-53, T89-55, T89-56, TG1-16, TT1-48, TT1-33, TT1-23, TG3-43, TG6-19, TG6-11, TG2-31, TG1-44, TG1-24, T89-26, T89-27, T89-28, T89-29, T89-30, T89-31, T89-34, T89-36, T89-37, T89-54.

Bacillus licheniformis and sonorensis: TE-46, TG8-8, T88-15, T89-40, T89-38, TE-50, T89-32, TE-11, TE-45, TE-48, TG8-25, RF-1, T89-33, T89-11, T89-39, TE-12, TG2-32, TG1-15, TG3-38, and T88-14.

The above strains were isolated by Dr. K. Duncan from the Sonoran desert, Arizona [8].

Oil well isolates with unknown taxonomic affiliation from our culture collection were also used. These strains are designated: $39,40,41,42,44,45,46,47,48,49,50,51$, $52,53,54,55,56,57,58,59,61,62,63,64,65,66,67,68,69,70,71,72,73,74,78,79$, $80,83,84,87,88,92,93,96,102,103,104$.

Media. All cultures were grown aerobically in liquid medium E $\left(\mathrm{KH}_{2} \mathrm{PO}_{4}, 2.7 \mathrm{~g} / \mathrm{l}\right.$; $\mathrm{K}_{2} \mathrm{HPO}_{4}, 13.9 \mathrm{~g} / \mathrm{l} ;$ sucrose, $10 \mathrm{~g} / \mathrm{l} ; \mathrm{NaCl}, 50 \mathrm{~g} / \mathrm{l} ;$ yeast extract, $0.5 \mathrm{~g} / 1 ; \mathrm{NaNO}_{3}, 1 \mathrm{~g} / \mathrm{l} ; \mathrm{pH}$ 6.86). This was autoclaved and after cooling $10 \mathrm{ml} / \mathrm{l}$ of each of the following solutions was added: $\mathrm{MgSO}_{4}, 2.5 \mathrm{~g} \%$; $\left(\mathrm{NH}_{4}\right)_{2} \mathrm{SO}_{4}, 10 \mathrm{~g} \%$; Wolin's trace metals solution containing (EDTA, $0.5 \mathrm{~g} / \mathrm{l} ; \mathrm{MnSO}_{4} \cdot \mathrm{H}_{2} \mathrm{O}, 3 \mathrm{~g} / \mathrm{l} ; \mathrm{NaCl}, 1 \mathrm{~g} / \mathrm{l} ; \mathrm{CaCl}_{2} \cdot 2 \mathrm{H}_{2} \mathrm{O}, 0.1 \mathrm{~g} / \mathrm{l} ; \mathrm{ZnSO}_{4} \cdot 7 \mathrm{H}_{2} \mathrm{O}, 0.1 \mathrm{~g} / \mathrm{l}$; $\mathrm{FeSO}_{4} \cdot 7 \mathrm{H}_{2} \mathrm{O}, 0.1 \mathrm{~g} / \mathrm{l} ; \mathrm{CuSO}_{4} \cdot 5 \mathrm{H}_{2} \mathrm{O}, 0.01 \mathrm{~g} / 1 ; \mathrm{AlK}\left(\mathrm{SO}_{4}\right)_{2}, 0.01 \mathrm{~g} / 1 ; \mathrm{Na}_{2} \mathrm{MoO}_{4} \cdot 2 \mathrm{H}_{2} \mathrm{O}, 0.01$ g/l; boric acid, $\left.0.01 \mathrm{~g} / 1 ; \mathrm{Na}_{2} \mathrm{SeO}_{4}, 0.005 \mathrm{~g} / 1 ; \mathrm{NiCl}_{2} \cdot 6 \mathrm{H}_{2} \mathrm{O}, 0.003 \mathrm{~g} / \mathrm{l}\right)$.

For anaerobic growth, anaerobic medium $\mathrm{E}$ with $15 \mathrm{~g} / \mathrm{l}$ proteose peptone, $10 \mathrm{ml} / \mathrm{l}$ of Woiln's trace metal solution containing $3 \mathrm{~g} / 1 \mathrm{MgSO}_{4} \cdot 7 \mathrm{H}_{2} \mathrm{O}$ ), and $0.1 \mathrm{mg} / \mathrm{l}$ resazurin as 
redox indicator was used. The medium was boiled under $100 \% \mathrm{~N}_{2}$ gas, allowed to cool under a stream of $100 \% \mathrm{~N}_{2}$, and then dispensed in serum tubes $(10 \mathrm{ml} /$ tube $)$ with $100 \%$ $\mathrm{N}_{2}$ headspace. The tubes were then stoppered and $0.2 \mathrm{ml}$ of cysteine $\mathrm{HCl}$ (a $25 \mathrm{~g} / \mathrm{l}$ solution) was added to each tube [9]. All media and solutions were sterilized by autoclaving at $121^{\circ} \mathrm{C}$ for $15 \mathrm{~min}$.

Spores were prepared on AK sporulation agar (Becton Dickinson, Sparks MD) plates.

Blood agar plates [blood agar base (Becton Dickinson, Sparks MD), 40 g/l; sheep blood (Brown laboratory, Topeka KA), $50 \mathrm{ml} / \mathrm{l}$ ] were used for screening of biosurfactant production.

Methods to screen for biosurfactant production. Strains were streaked on blood agar plates, incubated for 48 hours at $37^{\circ} \mathrm{C}$. The plates were then visually inspected for zones of clearing around colonies, indicative of biosurfactant production. The diameters of the clearing zones are known to increase with increasing the concentration of the biosurfactant. The diameters of clearing zones were compared to those obtained with strain JF-2, which was used as a positive control. Strain JF-2 mutant strain, which does not produce biosurfactant, was used as the negative control of the experiment [10].

In the drop-collapse method, two microliters of mineral oil were added to each well on a 96-microtiter plate lid. The lid was equilibrated for 1 hour, and then $5 \mu 1$ of a culture grown in liquid medium E for 24 hours at $37^{\circ} \mathrm{c}$ was added to the surface of oil. The shape of the drop on the surface of oil was inspected after 1 minute. Biosurfactantproducing cultures gave flat drops while those that did not produce biosurfactant gave 
rounded drops. Strain $J F-2$ was used as positive control while strain $J F-2$ mutant or water was used as negative controls $[10,11]$.

For the oil spreading technique, fifty milliliters of distilled water were added to a large Petri dish (25 $\mathrm{cm}$ in diameter) followed by the addition of $20 \mu 1$ of crude oil to the surface of the water. Ten microliters of a culture grown in liquid medium E for 24 hours at $37^{\circ} \mathrm{C}$ was added to the surface of oil. The area of the clear zones on the oil surface was measured and related to the concentration of biosurfactant by using a standard curve prepared with the commercially available biosurfactant, surfactin (Sigma chemicals co., St. Louis, MO)[12].

Surface tension was measured using a Du Nouy ring tensiometer [9]. Pure water and a soap solution were used to standardize the tensiometer. Two milliliters of the sample were used for measurement.

The amount of biosurfactant was quantified by high pressure liquid chromatography (HPLC). A C-18 column was used with an isocratic mobile phase of $73 \%$ methanol and $27 \% 10 \mathrm{mM}$ phosphate buffer at a $\mathrm{pH}$ of 6.5 . The flow rate was 1 $\mathrm{ml} / \mathrm{min}$ and the injection volume was $20 \mu \mathrm{l}$. A variable-wavelength UV absorbance detector at $210 \mathrm{~nm}$ was used to detect biosurfactant. Samples for HPLC analysis were prepared by centrifuging $10 \mathrm{ml}$ of culture at $17,300 \mathrm{xg}$ for 10 minutes at $4^{\circ} \mathrm{C}$ and the supernatant was collected. Acidification of the supernatant was done by adding $1 \mathrm{~N} \mathrm{HCl}$ until a $\mathrm{pH}$ of 2 was reached. The acidified supernatant was placed at $4^{\circ} \mathrm{C}$ for 24 hours and then centrifuged at $10,000 \mathrm{xg}$ for 30 minutes at $4^{\circ} \mathrm{C}$. The pellet was washed with $2 \mathrm{ml}$ of methanol for 1 minute, and then centrifuged at 15,000 xg for $5 \mathrm{~min}$. The supernatant was carefully decanted and used for analysis. 
Genetic recombination. Genetic recombination experiment was conducted using 5 Bacillus mojavensis strains: $J F-2, R O B-2, R O G-4, R O Q Q-2$, and T89-14. Spores were prepared from each of these strains by using AK sporulation medium. Plates of the solid AK medium were streaked with each of the strains ( 5 plates per strain) and incubated at room temperature for 1 week. Growth was then scraped off the plates and collected in 5 $\mathrm{ml}$ of sterile distilled water. To germinate the spores, each spore preparation was heated at $85^{\circ} \mathrm{C}$ for 20 minutes.

Approximately $10^{7}$ colony forming units (CFU) of heat-treated spores of $J F-2$ and one of each of the other 4 strains were placed onto the surface of a plate of plate count agar (PCA) (Difco, Inc. Detroit, MI), mixed, and then allowed to grow for 24 hours at $37^{\circ} \mathrm{C}$. A mixture containing spores of all 5 strains was also prepared as described above. This incubation would provide an opportunity for genetic exchange to occur between the different strains. As a control, germinating spores were grown separately on PCA plates for 24 hours at $37^{\circ} \mathrm{C}$ followed by scraping off the growth into separate liquid medium E. After 24 hours of incubation cultures were combined. This control would account for differences in biosurfactant activity due to the presence of two or more biosurfactants. Higher biosurfactant activity observed with the mixed spore preparation where all five strains were allowed to germinate on the same plate compared to the control where the five strains were combined after germination and growth indicates that genetic recombination took place.

Biosurfactant activity in cultures of each of the single strains, mixed spores, and combined cultures was followed over a period of 14 days by using the oil spreading technique. 
The above experiment was repeated where the incubation time for germinating spores was increased to 48 hours to test the effect of the incubation time on the occurrence of genetic recombination and biosurfactant activity.

Methods used to test for the occurrence of genetic recombination. Acid precipitated biosurfactant was prepared from pure cultures of $J F-2, R O B-2$, cultures inoculated with mixed spores of both strains, and a co-culture of both strains where each organism was inoculated into the same culture. The cultures were grown in 1-liter volumes in medium $\mathrm{E}$ for 48 hours. After growth, the cells were removed by centrifugation at $17,300 \mathrm{xg}$ for 15 minutes at $4^{\circ} \mathrm{C}$. The $\mathrm{pH}$ of the supernatant was adjusted to 2 by the addition of concentrated $\mathrm{HCl}$ and the acidified culture was kept overnight at $4^{\circ} \mathrm{C}$. The acidified culture fluid was centrifuged at $10,000 \mathrm{xg}$ for 30 minutes at $4^{\circ} \mathrm{C}$ and the pellet containing the biosurfactant was collected. The acid-precipitated biosurfactant was dissolved in water and the $\mathrm{pH}$ was adjusted to 7 with the addition of $1 \mathrm{~N} \mathrm{NaOH}$ [13].

Thin layer chromatography plates were prepared by applying a $5 \mu$ l-sample from each culture onto silica gel plates previously heated at $110^{\circ} \mathrm{C}$ for 1 hour. Each plate received $5 \mu$ of surfactin as the positive control. After drying the plates were placed in a chamber and resolved using a solvent that contained $\mathrm{CHCl}_{3}$ : $\mathrm{CH}_{3} \mathrm{OH}(2: 1)$ for 10 minutes. Next, the plates were resolved with acetone: $\mathrm{NH}_{4} \mathrm{OH}(9: 1)$ [14]. When the solvent reached the top of the plate, the plate was removed from the chamber and dried. To visualize the resolved spots, two reagents were used. Ninhydrin $0.2 \%$ in ethanol (Sigma spray reagent, cat. No. N-0757) gives reddish-purple spots with amino groups when the plate is heated at $110^{\circ} \mathrm{C}$ for 10 min. Rhodamine $0.25 \mathrm{~g} \%$ in absolute ethanol 
gives yellow or blue violet spot against pink-red background with lipids when the plate is exposed to UV light at $270 \mathrm{~nm}$ [15].

In order to obtain rifampicin resistance strains of $J F-2$ and $R O B-2$, plate count agar (PCA) plates with $10 \mathrm{mg} / 1$ rifampicin were prepared and streaked heavily with JF-2 or ROB-2. The plates were incubated at $37^{\circ} \mathrm{C}$ for 48 hours or until colonies started to appear. The colonies were restreaked 3 times to obtain a pure culture. The rifampicinresistant strain was used for DNA extraction.

A single colony was used to inoculate $10 \mathrm{ml}$ of antibiotic medium 3 (Difco, Detroit, MI), which was shaken at $37^{\circ} \mathrm{C}$ until turbid. Two $\mathrm{ml}$ of this culture was then used to inoculate $100 \mathrm{ml}$ of the same medium, which was incubated at $37^{\circ} \mathrm{C}$ for 6 hours. The cells were pelleted by centrifugation at $5000 x g$ for 15 minutes at $4^{\circ} \mathrm{C}$. The pellet was resuspended in $5 \mathrm{ml}$ of $50 \mathrm{mM}$ Tris (tri hydroxymethyl amino methane)-HCl- EDTA (ethylene diamine tetra-acetic acid) (TE buffer) $(\mathrm{pH} 8)$ and $100 \mathrm{mg}$ of lysozyme was added to lyse the cells. The lysozyme mixture was incubated at $37^{\circ} \mathrm{C}$ for 50 minutes with occasional shaking. To hydrolyze RNA, $1 \mu 1$ of RNAse ONE (Invitrogen) was added for each $3 \mathrm{ml}$ of cell suspension, which was then incubated at $37^{\circ} \mathrm{C}$ for 60 minutes. Next, the cell suspension received adding $0.1 \mathrm{ml}$ of $10 \%$ sodium dodecyl sulfate (SDS) and $0.25 \mathrm{ml}$ of $1 \mathrm{mg} / \mathrm{ml}$ proteinase $\mathrm{K}$ and was incubated at $37^{\circ} \mathrm{C}$ overnight with shaking to hydrolyze proteins. To purify and extract the DNA, an equal volume of Tris-buffered phenol was added and the tube was inverted several times for mixing then centrifuged at $10000 \mathrm{xg}$ for $5 \mathrm{~min}$ at room temperature. The aqueous layer was then extracted several times by adding an equal volume of chloroform: isoamyl alcohol (24:1) and centrifuging as above. The DNA was then precipitated by adding 0.1 volume of $3 \mathrm{M}$ sodium acetate $(\mathrm{pH}$ 5.2) 
and 3 volumes of pure ethanol. The precipitated DNA was then spooled unto a glass pipette, rinsed in $70 \%$ and $100 \%$ ethanol, and left to dry at room temperature. DNA was then redissolved in TE buffer and the DNA concentration was determined by measuring the absorbance at $260 \mathrm{~nm}$.

To obtain transformants, $10^{7} \mathrm{CFU}$ of $J F-2$ germinating spores and $2.5 \mu \mathrm{g}$ of rifampicin-resistant, $R O B-2$ DNA were mixed on plate count agar (PCA) plate and incubated for 24 hours at $37^{\circ} \mathrm{C}$. Similarly, $10^{7} \mathrm{CFU}$ of $R O B-2$ germinating spores and 2.5 $\mu \mathrm{g}$ of rifampicin resistant, $J F-2$ DNA were mixed on PCA plate and incubated for 24 hours at $37^{\circ} \mathrm{C}$. As controls, germinating spores of either strain were grown on plates individually without DNA added. After incubation, growth on the plate was scraped off and mixed with aerobic, liquid medium E. The cell suspension was serially 10-fold diluted and the dilutions were inoculated to PCA plates with $10 \mathrm{mg} / \mathrm{l}$ of rifampicin and PCA plates without rifampicin. The DNA was also streaked on PCA plates and PCA with $10 \mathrm{mg} / \mathrm{l}$ rifampicin to check for contamination. Appearance of colonies on the rifampicin plates would suggest DNA uptake by the germinating spores.

Isolation of improved biosurfactant-producing strains. The mixed spore preparation containing the five Bacillus mojavensis strains that were allowed to germinate on the same plate (see above) was used. The growth from the initial germination plate was scrapped off and mixed with liquid medium E. After 24 hours of incubation at $37^{\circ} \mathrm{C}$, a PCA plate was streaked from the liquid culture and 90 colonies were picked to individual wells of a 96-microtiter plate each containing $1 \mathrm{ml}$ medium E. The microtiter plate was incubated for 24 hours at $37^{\circ} \mathrm{C}$ and biosurfactant production was monitored by using the drop collapse method. Wells that gave positive results from the 
drop collapse methods were further tested by the oil spreading technique and compared to the values obtained with cultures of 5 original strains.

REP-PCR reaction. In an attempt to determine whether the isolated strains from the mixed spore culture were genetic recombinants, REP-PCR was utilized. This technique relies on the fact that some of the non-coding regions in prokaryotic genomes are highly repetitive and conserved within a strain so the technique can be used to show genetic difference between different strains [16].

The PCR reaction was conducted with purified DNA for each of the parent strains and the new isolates according to the protocol shown in Table 3.1.

Table 3.1: Components of the master mix for the REP-PCR reaction:

\begin{tabular}{|c|c|}
\hline Components & Volume added $(\mu 1)^{*}$ \\
\hline PCR water & 8.8875 \\
$25 \mathrm{mM} \mathrm{MgCl} 2$ & 2 \\
$10 \mathrm{x}$ PCR buffer & 2.5 \\
$10 \mathrm{mM}$ dNTP's & 0.5 \\
BOX AIR primer & 1 \\
Taq polymerase $(5 \mathrm{U} / \mu \mathrm{l})$ & 0.125 \\
\hline
\end{tabular}

*Total reaction volume was $15 \mu 1$.

A hundred nanograms of DNA from each of the species was added to a PCR tube followed by the addition of $15 \mu \mathrm{l}$ of the master mix (Table 3.1) and mixing by inverting the tube several times. REP-PCR program used a protocol involving initial denaturation of the DNA for 4 minutes at $94^{\circ} \mathrm{C}, 35$ cycles of $94^{\circ} \mathrm{C}$ for 1 minute, $50^{\circ} \mathrm{C}$ for 1 minute, and 
$72^{\circ} \mathrm{C}$ for 8 minutes, followed by a final extension at $72^{\circ} \mathrm{C}$ for 8 minutes. Negative controls contained PCR water without DNA present.

Agarose gel electrophoresis was used to visualize the products of the REP-PCR reaction. Agarose gels were prepared as $1.5 \mathrm{~g} \%$ in Tris Borate EDTA (TBE) buffer $\mathrm{pH}$ 8.3 (Eppendorf, Westbury, NY). Each gel was run at 40 volts for 5 hours. To better visualize the bands, polyacrylamide gel electrophoresis (PAGE) was used. PAGE gels were prepared as 5\% in Tris Acetate EDTA (TAE) buffer pH 8.3 (Eppendorf, Westbury, NY). Each gel was run at 35 volts for 17 hours at room temperature to examine the difference in pattern between the 4 new colonies compared to the original strains.

Selection of biosurfactant-producing strains. To select for biosurfactantproducing strains, medium E was modified to contain Inipol (Atofina chemicals, Philadelphia, PA). Medium E was modified by the deletion of nitrate and the addition of $1 \mathrm{~g} / \mathrm{l}$ Inipol. Inipol is a compound that has nitrogen in the form of urea completely enclosed in a lipid membrane. Biosurfactant-producing strains would be able to emulsify the lipid membrane making the urea available for the organism for growth.

Aerobic medium E containing inipol was prepared and inoculated with a loopful of a culture of $J F-2, J F-2$ mutant, $R O B-2$, mixed spores of $J F-2$ and $R O B-2$, and coculture of both grown aerobically in liquid medium E. Then, $0.1 \mathrm{ml}$ of the aerobic cultures grown in medium with inipol was used as an inoculum for the anaerobic medium E with inipol and proteose peptone. Growth was determined visually and biosurfactant production was followed over a period of 1 week by using the oil spreading technique. 


\subsection{Results}

Comparison different methods for screening of biosurfactant production.

Table 3.2 shows the total number of strains that were screened and the number of positive results obtained with each of the different screening methods.

Table 3.2: Comparison of different methods used for screening of biosurfactant production.

Number of strains screened

Number of strains positive with the oil spreading technique

Number of strains positive with the drop collapse method

Number of strains positive with blood agar plates
157

147

142

123

Lysis of blood agar has been recommended as a method to screen for biosurfactant activity. This method is useful in predicting the promising strains regarding biosurfactant production since, in most cases, the degree of lysis of red blood cells is directly proportional to the concentration of biosurfactant production. However, it has not been determined that all kinds of biosurfactants have a hemolytic activity and microorganisms may produce chemicals other than biosurfactants that can cause hemolysis. We found that a number of strains did not have hemolytic activity but did have biosurfactant activity when measured by the drop collapse method (19/142), or by the oil spreading technique (24/147). Drop collapse method is only semi-quantitative, but only gave 5 false negatives compared to the oil spreading technique. The drop collapse method may not be sensitive enough to detect small concentrations of biosurfactant. The oil spreading technique gave the highest number of positive results compared to the other two screening methods. It is also quantitative and reproducible, and is easy and cheap to 
use. Surface tension measurement can always be used to confirm biosurfactant activity by measuring the decrease in surface tension caused by biosurfactants regardless of their chemical structure.

Optimization of the oil spreading technique. Table 3.3 shows the concentration of biosurfactant present in a series of culture dilutions of both JF-2 and ROB-2 liquid cultures. Each strain was inoculated in $100 \mathrm{ml}$ liquid medium E and incubated aerobically for 24 hours at $37^{\circ} \mathrm{C}$.

Table 3.3: Effect of dilution on biosurfactant activity when measured by the oil spreading technique.

\begin{tabular}{llll}
\hline Strain & Dilution & $\begin{array}{l}\text { Average diameter } \\
(\mathrm{cm})\end{array}$ & $\begin{array}{l}\text { Concentration } \\
(\mathrm{mg} / \mathrm{ml})\end{array}$ \\
\hline JF-2 (liquid culture) & $1: 32$ & 0 & 0 \\
& $1: 16$ & 0.3 & 0.30 \\
& $1: 8$ & 0.5 & 0.37 \\
& $1: 4$ & 0.6 & 0.42 \\
& $1: 2$ & 0.8 & 0.60 \\
& 1 & 1.2 & 1.0 \\
ROB-2 (liquid culture) & $1: 32$ & 0.5 & 0.37 \\
& $1: 16$ & 0.7 & 0.50 \\
& $1: 8$ & 0.9 & 0.64 \\
& $1: 4$ & 1.2 & 1.0 \\
& $1: 2$ & 1.5 & 1.3 \\
& 1 & 1.8 & 1.8 \\
\hline
\end{tabular}


Figure 3.1: Linearity of response of the oil spreading technique to concentration

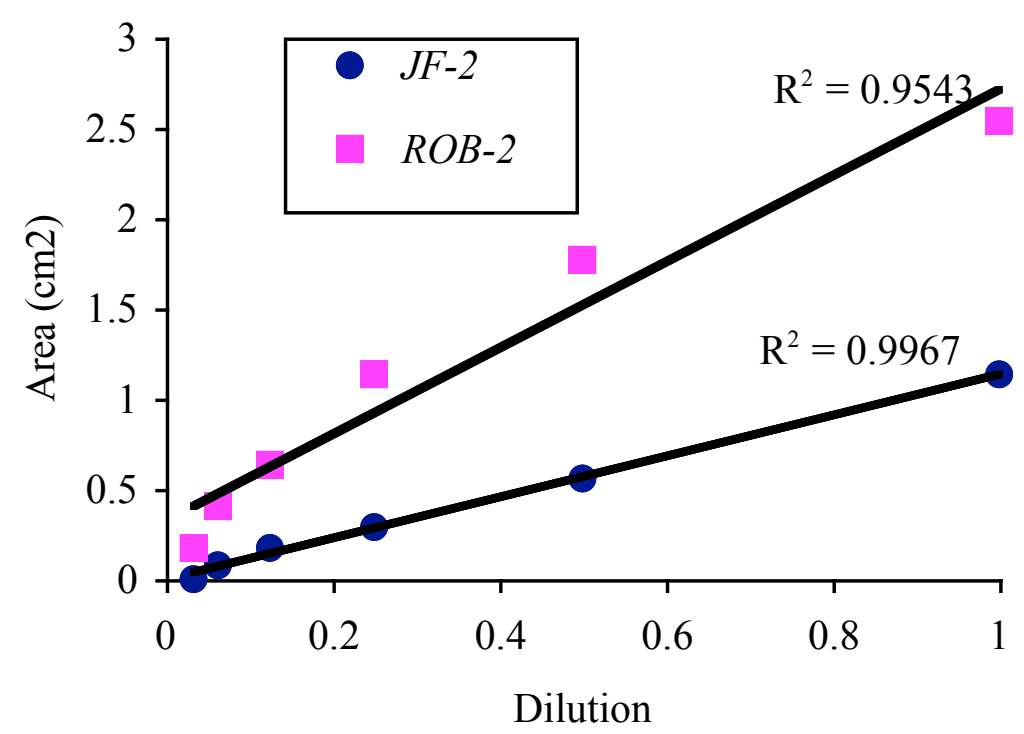

Figure 3.1 shows the effect of dilution on the oil spreading technique. The linear response indicates that the biosurfactant activity as measured by the diameter of the clear zone on the oil-water surface decreases proportionally with a decrease in concentration of the biosurfactant. Thus, the oil spreading technique is a quantitative measure of biosurfactant activity.

Effect of acid precipitation. Table 3.4 shows the concentration of biosurfactant, as calculated by oil spreading technique before and after acid precipitation. These results show that some of the biosurfactant produced by these strains is lost during the acidification-precipitation procedure as evidenced by the lower amount (in mg) obtained with the acid precipitated preparation as compared to that of liquid culture. The low recovery of the biosurfactant activity present in the ROB-2 culture may suggest that ROB-2 produces several kinds of biosurfactants 
Table 3.4: Effect of acid precipitation on biosurfactant activity

\begin{tabular}{llllll}
\hline Strain & Fraction & $\begin{array}{l}\text { Concentration } \\
(\mathrm{mg} / \mathrm{ml})\end{array}$ & $\begin{array}{l}\text { Final } \\
\text { volume } \\
(\mathrm{ml})\end{array}$ & $\begin{array}{l}\text { Total Amount } \\
(\mathrm{mg})\end{array}$ & $\begin{array}{l}\text { Percentage } \\
\text { recovery }\end{array}$ \\
\hline \multirow{2}{*}{ JF-2 } & Culture & 0.95 & $100 \mathrm{ml}$ & 95.0 & 80.8 \\
& Acid ppt. & 11 & $7 \mathrm{ml}$ & 76.8 & 22.5 \\
ROB-2 & Culture & 1.8 & $100 \mathrm{ml}$ & 182.3 & \\
& Acid ppt. & 5.9 & $7 \mathrm{ml}$ & 41.0 & \\
\hline
\end{tabular}

Screening Bacillus strains for growth and biosurfactant production. Table 3.5

shows the results obtained when the oil spreading technique was done for aerobic cultures of some promising Bacillus strains grown in liquid medium E and incubated at $37^{\circ} \mathrm{C}$ for 24 hours. These cultures were able to produce either equal or higher amounts of biosurfactant as compared to the amount produced by JF-2. 
Table 3.5: Biosurfactant production by various Bacillus strains measured by the oil spreading technique.

\begin{tabular}{|c|c|c|c|}
\hline Bacillus species & Strain & $\begin{array}{l}\text { Ave. } \\
\text { Diameter } \\
(\mathrm{cm})\end{array}$ & $\begin{array}{l}\text { Concentration } \\
(\mathrm{mg} / \mathrm{ml})\end{array}$ \\
\hline \multirow[t]{4}{*}{ B. mojavensis } & ROB-2 & $2.5 \pm 0$ & 3.3 \\
\hline & ROG-4 & $2 \pm 0$ & 2.2 \\
\hline & ROQQ-2 & $1.8 \pm 0$ & 1.7 \\
\hline & T89-14 & $1.2 \pm 0$ & 0.95 \\
\hline \multirow[t]{6}{*}{$\begin{array}{l}\text { B. subtilis subsp. } \\
\text { subtilis }\end{array}$} & T89-44 & $1.8 \pm 0.17$ & 1.7 \\
\hline & T89-49 & $1.8 \pm 0.17$ & 1.7 \\
\hline & T89-2 & $1.3 \pm 0.1$ & 1.1 \\
\hline & TG4-19 & $4.2 \pm 0.17$ & 8.8 \\
\hline & T89-42 & $5 \pm 0$ & 12.4 \\
\hline & TG6-27 & $3.2 \pm 0.17$ & 5.2 \\
\hline \multirow[t]{12}{*}{$\begin{array}{l}\text { B. subtilis subsp. } \\
\text { spizizensis }\end{array}$} & T88-8 & $2.4 \pm 0.17$ & 2.8 \\
\hline & T88-9 & $1.8 \pm 0.17$ & 1.7 \\
\hline & T88-11 & $3 \pm 0.17$ & 4.6 \\
\hline & T88-12 & $1.8 \pm 0.17$ & 1.7 \\
\hline & T88-19 & $3 \pm 0$ & 4.6 \\
\hline & Т88-19 & $1.8 \pm 0$ & 1.7 \\
\hline & T88-39 & $3 \pm 0$ & 4.6 \\
\hline & T89-3 & $3 \pm 0.17$ & 4.6 \\
\hline & T89-6 & $1.8 \pm 0$ & 1.7 \\
\hline & T89-16 & $1.8 \pm 0.17$ & 1.7 \\
\hline & T89-52 & $1.5 \pm 0$ & 1.3 \\
\hline & T89-53 & $1.8 \pm 0$ & 1.7 \\
\hline \multirow[t]{2}{*}{ Oil well isolates } & 45 & $1.8 \pm 0$ & 1.7 \\
\hline & 53 & $1.8 \pm 0.17$ & 1.7 \\
\hline
\end{tabular}




\begin{tabular}{llll}
57 & $2.1 \pm 0.17$ & 2.0 \\
58 & $1.8 \pm 0.17$ & 1.7 \\
61 & $1.8 \pm 0.17$ & 1.7 \\
62 & $1.5 \pm 0$ & 1.3 \\
& 64 & $1.8 \pm 0.17$ & 1.7 \\
& 69 & $2.4 \pm 0.17$ & 2.8 \\
B. mojavensis & 70 & $1.8 \pm 0.17$ & 1.7 \\
& 74 & $2.1 \pm 0.17$ & 2.0 \\
& $\mathrm{JF}-2$ & $1.2 \pm 0.12$ & 0.95 \\
\hline
\end{tabular}

Figure 3.1-A shows the diameters obtained when the oil spreading technique was done with 10 of the best biosurfactant-producing strains. These strains have biosurfactant activity that is at least twice that produced by JF-2. All these strains were grown aerobically in liquid medium $\mathrm{E}$ at $37^{\circ} \mathrm{C}$ for 24 hours. However, they were unable to produce biosurfactant when grown anaerobically in medium $\mathrm{E}$ at $37^{\circ} \mathrm{C}$ for 24 hours.

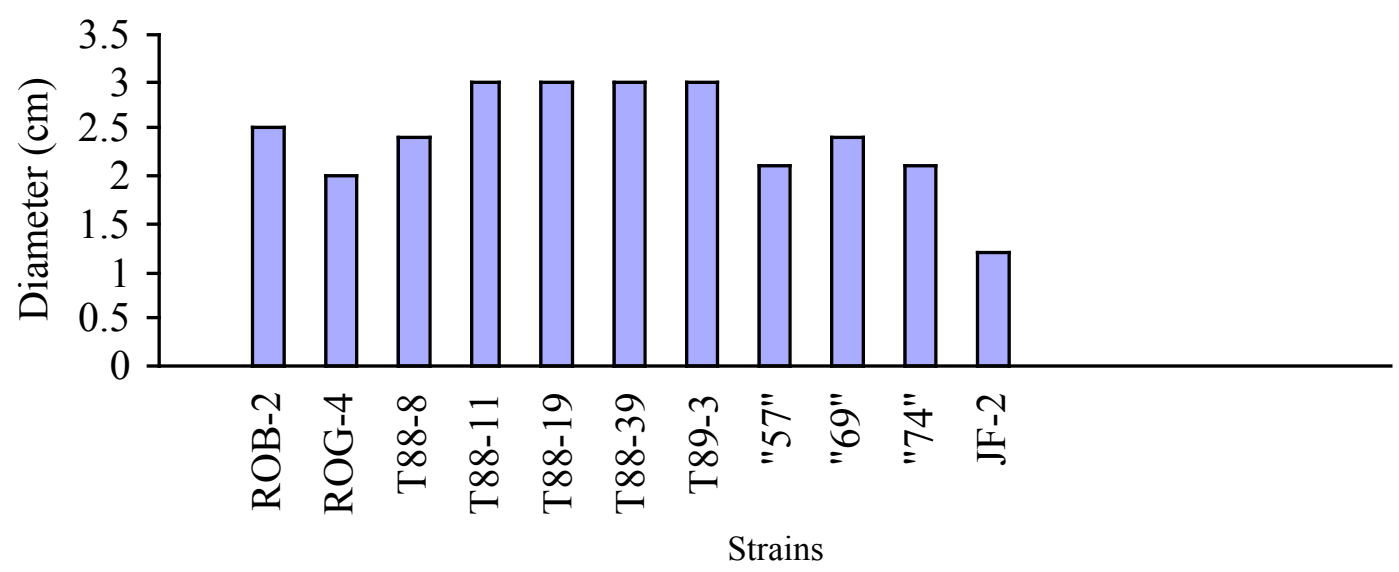

Figure 3.1-A. Biosurfactant activity by the 10 best biosurfactant-producing strains as measured by the oil spreading technique. 
Table 3.6 summarizes the growth properties and biosurfactant production by all of the strains that were screened. Bacillus mojavensis strains were able to grow under both aerobic and anaerobic conditions (in presence of Proteose peptone) with $50 \mathrm{~g} / \mathrm{l}$ of $\mathrm{NaCl}$. However, they were only able to produce biosurfactant under aerobic conditions with 50 $\mathrm{g} / \mathrm{l}$ of $\mathrm{NaCl}$. Out of the 8 strains of Bacillus mojavensis screened, only 4 were able to produce equal or higher amount of biosurfactant than JF-2.

Bacillus subtilis subspecies subtilis strains were able to grow under both aerobic and anaerobic conditions (in presence of proteose peptone) with $50 \mathrm{~g} / 1$ of $\mathrm{NaCl}$. However, they were able to produce biosurfactant only under aerobic conditions with 50 $\mathrm{g} / 1$ of $\mathrm{NaCl}$. Out of the 30 strains of Bacillus subtilis subspecies subtilis screened, 7 were able to produce equal or higher amount of biosurfactant compared to JF-2, with 4 strains producing more than double the amount produced by JF-2.

Bacillus subtilis subspecies spizizensis strains were able to grow under both aerobic and anaerobic conditions (in presence of proteose peptone) with $50 \mathrm{~g} / \mathrm{l}$ of $\mathrm{NaCl}$. However, they were only able to produce biosurfactant under aerobic conditions with 50 $\mathrm{g} / \mathrm{l}$ of $\mathrm{NaCl}$. Out of the 40 strains of Bacillus subtilis subspecies spizizensis screened, 13 were able to produce equal or higher amount of biosurfactant than JF-2 with 5 strains producing more than double the amount produced by JF-2.

Bacillus licheniformis and sonorensis strains were able to grow under both aerobic and anaerobic conditions (in absence of proteose peptone) with $50 \mathrm{~g} / 1$ of $\mathrm{NaCl}$. However, they were not able to produce biosurfactant under either aerobic or anaerobic conditions with 5\% salt. The strains that grew anaerobically in high salt medium without proteose peptone are candidates for our genetic recombination experiments. We hope to 
be able to transfer the genes required for anaerobic growth to strain JF-2 so Proteose peptone is no longer required.

Table 3.6: Summary of growth and biosurfactant properties of strains that have been analyzed to date.

\begin{tabular}{llllll}
\hline \multicolumn{1}{c}{ Strains } & $\begin{array}{l}\text { No. of } \\
\text { strains }\end{array}$ & $\begin{array}{l}\text { Biosurfactant } \\
\text { production } \\
(>0.95 \\
\mathrm{mg} / \mathrm{ml})\end{array}$ & $\begin{array}{l}\text { Anaerobic } \\
\text { biosurfactant } \\
\text { production }\end{array}$ & $\begin{array}{l}\text { Anaerobic } \\
\text { growth } \\
\text { with P.P.* }\end{array}$ & $\begin{array}{l}\text { Anaerobic } \\
\text { growth }\end{array}$ \\
without P.P.*
\end{tabular}

*Abbreviation: P.P. proteose peptone

Genetic recombination experiment. Table 3.7 and Figure 3.2 show the concentrations of biosurfactant $(\mathrm{mg} / \mathrm{ml})$ obtained when germinating spores of JF-2 were mixed with those of other Bacillus mojavensis strains for 24 hours. The highest concentrations were obtained when JF-2 germinating spores were mixed with those of ROB-2 and when the germinating spores of all the five Bacillus mojavensis strains were mixed together. The amount of biosurfactant produced did not decrease over time in case 
of mixed spore preparation of JF-2 and ROB-2. This suggests that mixing germinating spores lead to the production of larger amounts of biosurfactants compared to the amounts produced by strain JF-2. Some of the biosurfactants produced are stable over a period of 14 days while that produced by strain JF-2 decreased dramatically by the end of the 14 days.

Table 3.7: Biosurfactant production by 24-hour mixed spore preparations (The amounts of biosurfactants are shown in $\mathrm{mg} / \mathrm{ml}$. Biosurfactant production was measured by the oil spreading technique.)

\begin{tabular}{lllllll}
\hline Days & JF-2 & $\begin{array}{l}\text { JF-2 } \\
+ \text { ROG-4 }\end{array}$ & $\begin{array}{l}\text { JF-2 } \\
+ \text { ROB-2 }\end{array}$ & $\begin{array}{l}\text { JF-2 } \\
+ \text { ROQQ-2 }\end{array}$ & $\begin{array}{l}\text { JF-2 } \\
+ \text { T89-14 }\end{array}$ & \begin{tabular}{l} 
All** \\
\hline 1
\end{tabular} \\
\hline & 0.95 & 1.34 & 3.28 & 0.74 & 0.95 & 6.2 \\
3 & 0.43 & 1.34 & 3.28 & 0.56 & 0.4 & 5.22 \\
5 & 0.43 & 1.34 & 3.28 & 0.56 & 0.4 & 5.22 \\
8 & 0.33 & 1.34 & 3.28 & 0.4 & 0.4 & 4.62 \\
9 & 0.33 & 1.2 & 3.28 & 0.4 & 0.3 & 4.62 \\
14 & 0.33 & 1.2 & 3.28 & 0.4 & 0.3 & 3.79 \\
\hline
\end{tabular}

**All: mixed spore preparation containing all five strains. 
Figure 3.2: Biosurfactant production by 24-hour mixed spore preparation:

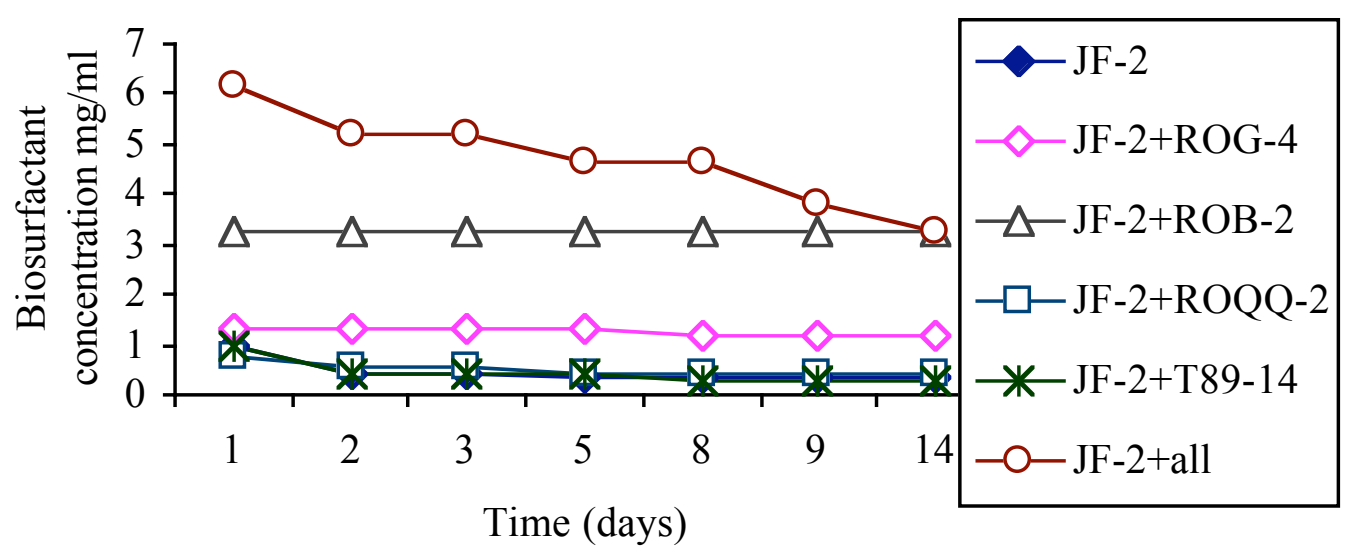

Table 3.8 and Figure 3.3 show the concentrations of biosurfactant $(\mathrm{mg} / \mathrm{ml})$ obtained when germinating spores of JF-2 were mixed with those of other Bacillus mojavensis strains for 48 hours. The highest concentrations were obtained when JF-2 germinating spores were mixed with those of ROB-2 and when the germinating spores of all five Bacillus mojavensis strains were mixed together. However, the amount of biosurfactant produced decrease over time in all cases. 
Table 3.8: Biosurfactant production by 48-hour mixed spore preparations (The amounts of biosurfactants are shown in $\mathrm{mg} / \mathrm{ml}$. Biosurfactant production was measured by the oil spreading technique.)

\begin{tabular}{lllllll}
\hline Days & JF-2 & $\begin{array}{l}\text { JF-2 } \\
+ \text { ROG-4 }\end{array}$ & $\begin{array}{l}\text { JF-2 } \\
+ \text { ROB-2 }\end{array}$ & $\begin{array}{l}\text { JF-2 } \\
+ \text { ROQQ-2 }\end{array}$ & $\begin{array}{l}\text { JF-2 } \\
+ \text { T89-14 }\end{array}$ & All** \\
\hline 1 & 0.95 & 2.19 & 2.6 & 1.34 & 0.95 & 6.2 \\
2 & 0.4 & 2.19 & 1.82 & 1.34 & 0.95 & 6.2 \\
4 & 0.4 & 2.19 & 1.82 & 0.74 & 0.4 & 5.22 \\
7 & 0.3 & 1.34 & 1.82 & 0.74 & 0.37 & 3.28 \\
8 & 0.3 & 0.95 & 1.82 & 0.74 & 0.29 & 2.19 \\
13 & 0.3 & 0.69 & 1.82 & 0.49 & 0.29 & 1.82 \\
\hline
\end{tabular}

**All: mixed spore preparation containing all five strains.

Comparison of the results between Tables 3.7 and 3.8 suggests that when spores were mixed on plates for 48 hours, biosurfactant production was higher as compared to mixing them for 24 hours. However, in case of the mixture of JF-2 with ROG-4 or ROB2 , or the mixed spore preparation containing all five strains, the amount of biosurfactant at the end of the 14 days was about one half of that observed when the spores were incubated for 24 hours. These experiments will be repeated in order to obtain a preparation that consistently give high biosurfactant activity over long incubation times. 
Figure 3.3: Biosurfactant production by the 48-hour mixed spore preparation

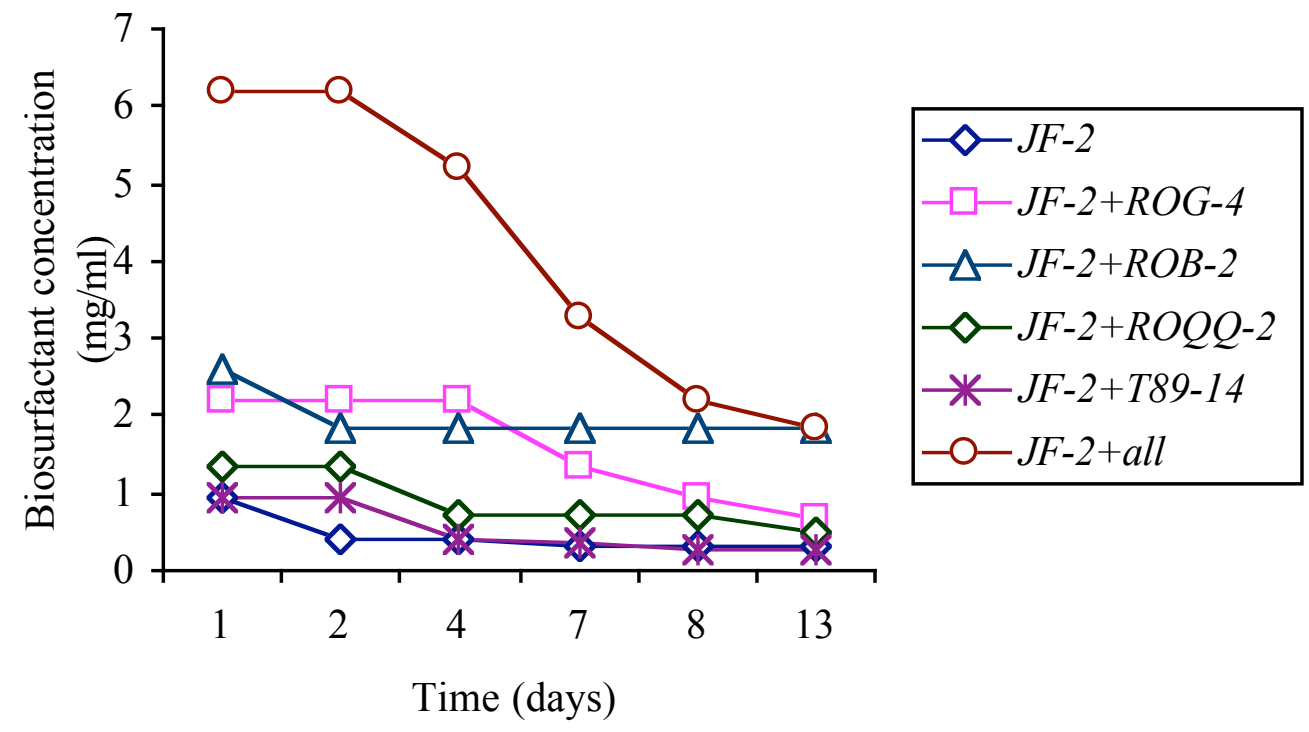

Table 3.9 shows the concentration of biosurfactants $(\mathrm{mg} / \mathrm{ml})$ produced by pure cultures of the five Bacillus mojavensis strains, the mixed spores preparation of JF-2 with each of the other 4 strains (ROB-2, ROG-4, ROQQ-2, T89-14), the mixed spore preparation containing all five strains, co-cultures of JF-2 with each of the other 4 strains, and a mixed culture containing all 5 strains. Co-cultures and the mixed cultures were used as a control since DNA exchange did not occur in these cultures. 
Table 3.9: Biosurfactant production $(\mathrm{mg} / \mathrm{ml})$ by various combinations of Bacillus mojavensis strains that were (mixed spore preparations) and were not (co-cultures and mixed cultures) allowed to exchange DNA as measured by using the oil spreading technique.

\begin{tabular}{|c|c|c|c|c|}
\hline Days & Strain & $\begin{array}{l}\text { Single } \\
\text { strain }\end{array}$ & $\begin{array}{l}\text { Mixed spores } \\
\text { with JF-2 }\end{array}$ & $\begin{array}{l}\text { Co-culture with } \\
\text { JF-2 }\end{array}$ \\
\hline 1 & ROB-2 & 3.28 & 3.28 & 0.95 \\
\hline 2 & & 3.28 & 3.28 & 0.74 \\
\hline 3 & & 3.05 & 3.28 & 0.74 \\
\hline 5 & & 3.05 & 3.28 & 0.74 \\
\hline 7 & & 3.05 & 3.28 & 0.74 \\
\hline 8 & & 3.05 & 3.28 & 0.74 \\
\hline 9 & & 3.05 & 3.28 & 0.74 \\
\hline 14 & & 3.05 & 3.28 & 0.74 \\
\hline 1 & ROG-4 & 2.19 & 1.34 & 0.56 \\
\hline 2 & & 2.19 & 1.34 & 0.56 \\
\hline 3 & & 1.82 & 1.34 & 0.56 \\
\hline 5 & & 1.82 & 1.34 & 0.56 \\
\hline 7 & & 1.34 & 1.34 & 0.43 \\
\hline 8 & & 1.34 & 1.2 & 0.43 \\
\hline 9 & & 1.34 & 1.2 & 0.43 \\
\hline 14 & & 1.34 & 1.2 & 0.37 \\
\hline 1 & ROQQ-2 & 1.82 & 0.74 & 0.43 \\
\hline 2 & & 1.82 & 0.56 & 0.43 \\
\hline 3 & & 1.2 & 0.56 & 0.43 \\
\hline 5 & & 1.2 & 0.43 & 0.43 \\
\hline 7 & & 0.95 & 0.43 & 0.33 \\
\hline 8 & & 0.95 & 0.43 & 0.33 \\
\hline 9 & & 0.74 & 0.43 & 0.33 \\
\hline 14 & & 0.74 & 0.43 & 0.33 \\
\hline 1 & T89-14 & 0.95 & 0.95 & 0.56 \\
\hline 2 & & 0.95 & 0.42 & 0.56 \\
\hline 3 & & 0.95 & 0.42 & 0.56 \\
\hline 5 & & 0.95 & 0.42 & 0.56 \\
\hline 7 & & 0.74 & 0.42 & 0.56 \\
\hline 8 & & 0.74 & 0.33 & 0.56 \\
\hline
\end{tabular}




\begin{tabular}{|c|c|c|c|c|}
\hline 9 & & 0.74 & 0.33 & 0.42 \\
\hline 14 & & 0.74 & 0.33 & 0.33 \\
\hline 1 & All & & 6.2 & 2.60 \\
\hline 2 & & & 5.2 & 2.60 \\
\hline 3 & & & 5.2 & 2.2 \\
\hline 5 & & & 4.62 & 2.2 \\
\hline 7 & & & 4.62 & 1.82 \\
\hline 8 & & & 4.62 & 1.82 \\
\hline 9 & & & 3.79 & 1.82 \\
\hline 14 & & & 3.05 & 1.34 \\
\hline
\end{tabular}

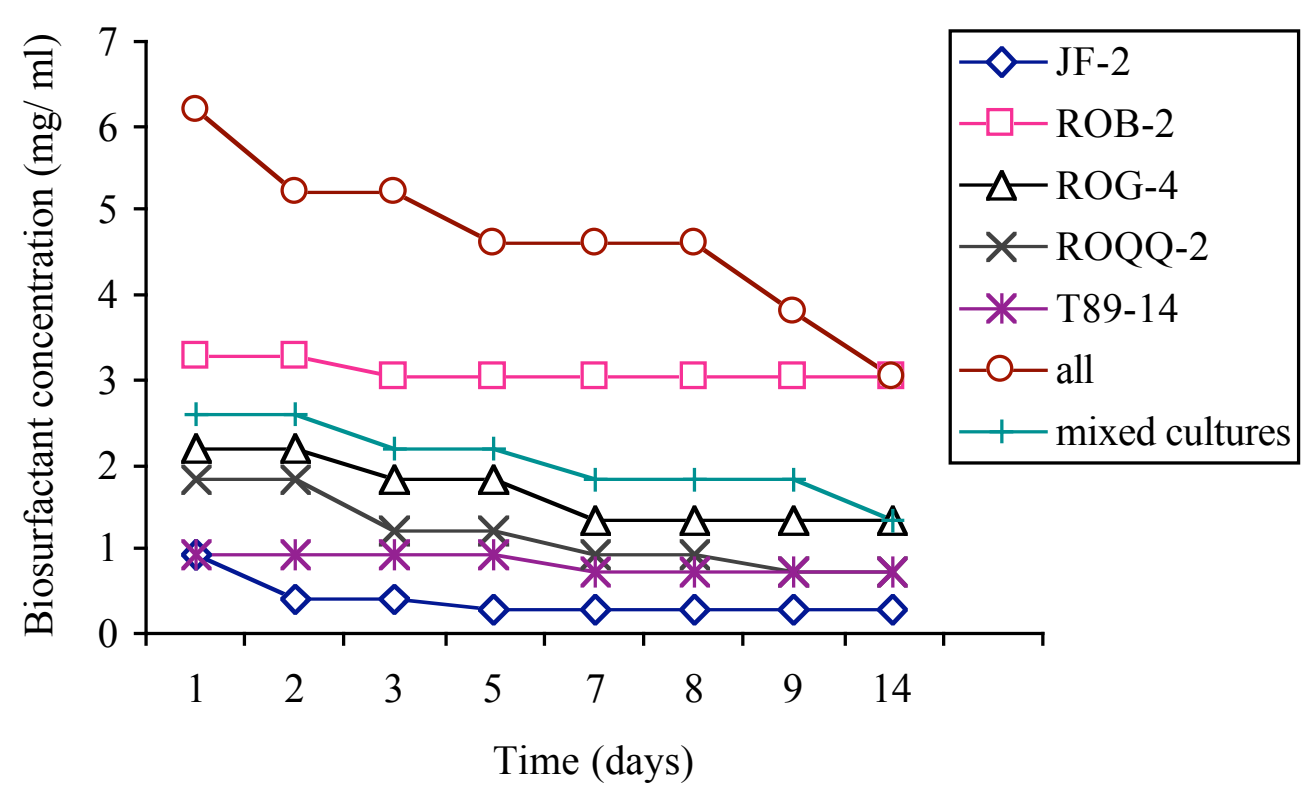

Figure 3.4: Stability of the biosurfactant produced by each of the 5 Bacillus mojavensis strains, their mixed spore preparation, and their mixed cultures over a period of 14 days.

Figure 3.4 shows that the amount of biosurfactant produced by mixed spores of all 5 strains was higher than that produced by any of the original strains. The amount of 
biosurfactant produced by mixed germinating spores of all five strains was higher compared to the control where each strain was present in the mixed culture. This might suggest the occurrence of genetic recombination between mixed germinating spores.

Testing for the occurrence of genetic recombination. Thin layer chromatography was used to determine if different biosurfactants were made after mixing germinating spores of different strains. This would suggest the occurrence of genetic recombination. No spots were obtained upon spraying the plates with Ninhydrin possibly because the there is no free amino group in the structure of the cyclic lipopeptide biosurfactant. The results upon spraying with Rhodamine were not decisive since all the spots migrated to the same $R_{f}$ value.

In order to verify that genetic recombination occurred between mixed sores of different strains, DNA with rifampicin resistance genes was mixed with germinating spores that lack the genes for rifampicin resistance. Appearance of colonies on PCA plates with rifampicin would suggest that DNA exchange occurred.

No colonies were obtained on rifampicin plates upon mixing the germinating spores with the rifampicin-resistant DNA. The transformation of cells with exogenous DNA is a random process that requires optimization of conditions in order to detect the event. Thus, the absence of detectable transformation does not exclude the possibility that DNA exchange occurred with germinating spores. Further characterization of the strains were required (see below).

Another attempt to verify genetic recombination was to isolate individual strains from the mixed spore preparation and determine whether they produced greater amounts of biosurfactant than any of the original strains. Using the drop collapse method, 21 out 
of the 90 colonies picked to wells of a 96-microtiter plate, gave positive results where the drop completely spread over the oil surface. Using the oil spreading technique to quantify the concentration of biosurfactant produced by these 21 cultures, only 4 out of the 21 cultures produced higher amounts of biosurfactant compared to that produced by any of the original 5 strains. These 4 cultures (C8, C9, E10, and F2) also had different colony morphologies than any of the 5 original strains. Table 3.10 and Figure 3.5 show the diameters obtained on the oil/water surface by the 5 original and the 4 new strains when using the oil spreading technique.

Table 3.10: The average diameter $(\mathrm{cm})$ and the concentration of biosurfactant $(\mathrm{mg} / \mathrm{ml})$ obtained when oil spreading technique was done for aerobic cultures of the 5 original strains and the 4 putative recombinant strains.

\begin{tabular}{lll}
\hline Strain & Average diameter $(\mathrm{cm})$ & $\begin{array}{l}\text { Concentration } \\
\text { (mamen }\end{array}$ \\
\hline$J F-2$ & $1.2 \pm 0.12$ & 1.0 \\
ROB-2 & $2.4 \pm 0$ & 3.1 \\
ROG-4 & $2 \pm 0$ & 2.2 \\
ROQQ-2 & $1.8 \pm 0.12$ & 1.8 \\
T89-14 & $1.2 \pm 0.12$ & 1.0 \\
$C 8$ & $3.6 \pm 0$ & 6.5 \\
C9 & $3.6 \pm 0$ & 6.5 \\
E10 & $3.6 \pm 0.17$ & 6.5 \\
F2 & $3 \pm 0$ & 4.6 \\
\hline
\end{tabular}

The values obtained for biosurfactant concentrations were higher for the 4 new isolates compared to the concentrations obtained with the 5 original strains. This may suggest that genetic recombination occurred by mixing the germinating spores of the 5 original strains. 


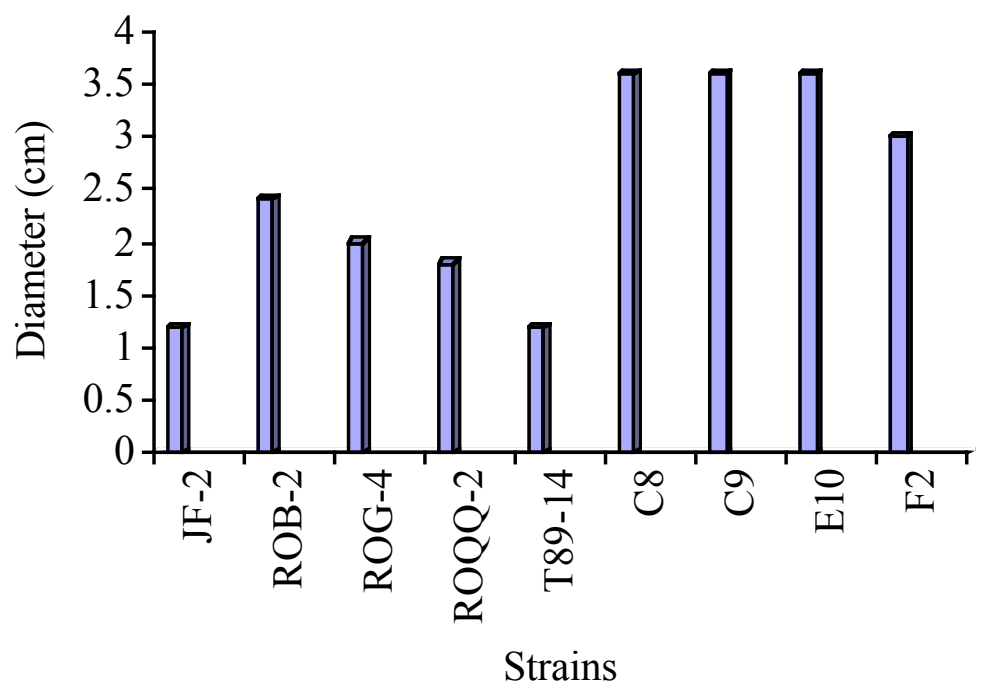

Figure 3.4: The average diameter obtained when the oil spreading technique was done for aerobic cultures of the 5 original strains and the 4 new isolates.

In order to determine the stability of biosurfactant produced by the new isolates, the 4 new cultures and the 5 parent strains were sub-cultured in liquid medium $\mathrm{E}$ and incubated at $37^{\circ} \mathrm{C}$ for 7 days. The amount of biosurfactant produced by the 9 strains was measured over the period of the 7 days by using the oil spreading technique. Table 3.11 shows the concentration of biosurfactant produced by the 9 strains over the 7 -day period.

Table 3.11: Biosurfactant concentration in $\mathrm{mg} / \mathrm{ml}$ obtained when oil spreading technique was done for aerobic cultures of the 5 original Bacillus mojavensis strains and the 4 new isolates.

\begin{tabular}{llllllllll}
\hline Days & JF-2 & ROB-2 & ROG-4 & ROQQ-2 & T89-14 & C8 & C9 & E10 & F2 \\
\hline 1 & 1.0 & 3.0 & 2.2 & 1.8 & 1.0 & 6.54 & 6.54 & 5.54 & 4.62 \\
2 & 1.0 & 3.0 & 2.2 & 1.8 & 1.0 & 6.54 & 6.54 & 5.54 & 4.62 \\
3 & 0.60 & 3.0 & 1.8 & 1.2 & 0.74 & 6.54 & 6.54 & 4.62 & 4.62 \\
7 & 0.37 & 3.0 & 1.3 & 1.0 & 0.74 & 3.05 & 6.54 & 1.82 & 3.8 \\
\hline
\end{tabular}


Figure 3.6 shows the time course of biosurfactant production by the 5 original and the 4 new strains over a 7-day period. Only C9 continued to produce the same amount of biosurfactant over the period of 7 days.

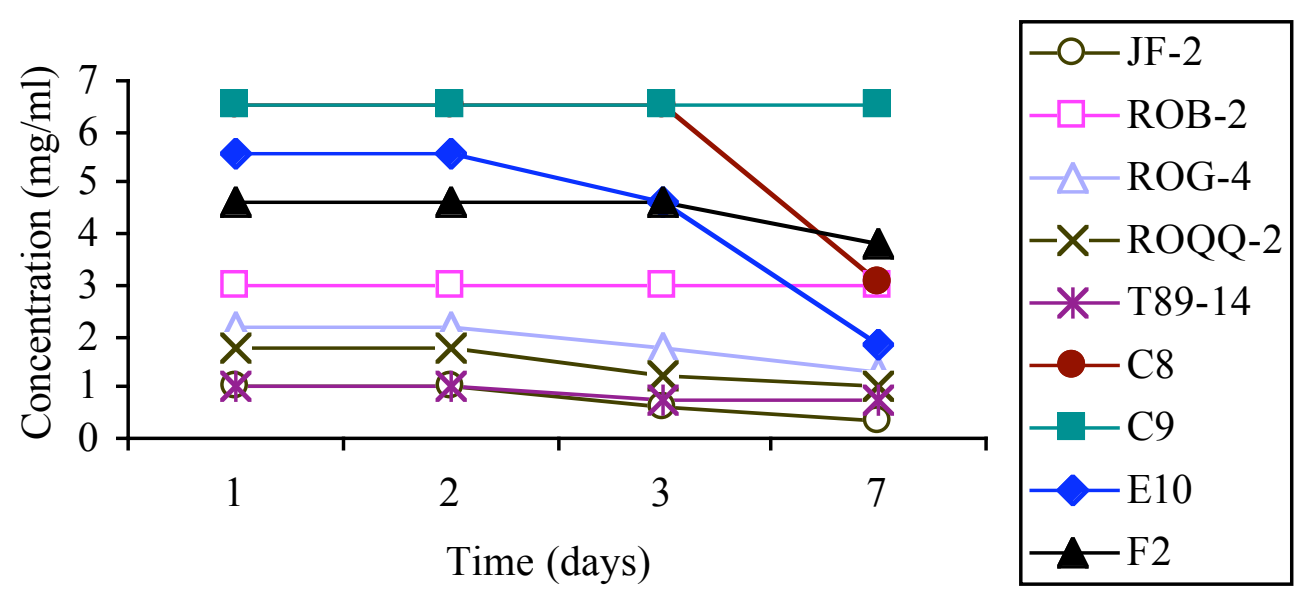

Figure 3.6: Stability of biosurfactant production over a period of 7 days

REP-PCR. The purpose of the REP-PCR experiment was to determine whether genetic differences exist between the 5 original Bacillus mojavensis strains and the 4 new isolates to determine whether the genetic recombination occurred. The agarose gel for the REP-PCR products in Figure 3.7 shows that the band pattern of the new isolates is similar to that of ROG-4, one of the original Bacillus mojavensis strains. This suggests that ROG-4 might be the recipient strain in the process of genetic transformation. To show the minor differences between the 4 strains and ROG-4 a PAGE gel was run and the results are shown in Figure 3.8. One of the bands of ROG-4 (shown) is absent in C8 and C9. This supports the assumption that C8 and C9 are actually different from the 5 original strains and that they might have developed from the genetic recombination experiment with ROG-4 being the recipient strain. 


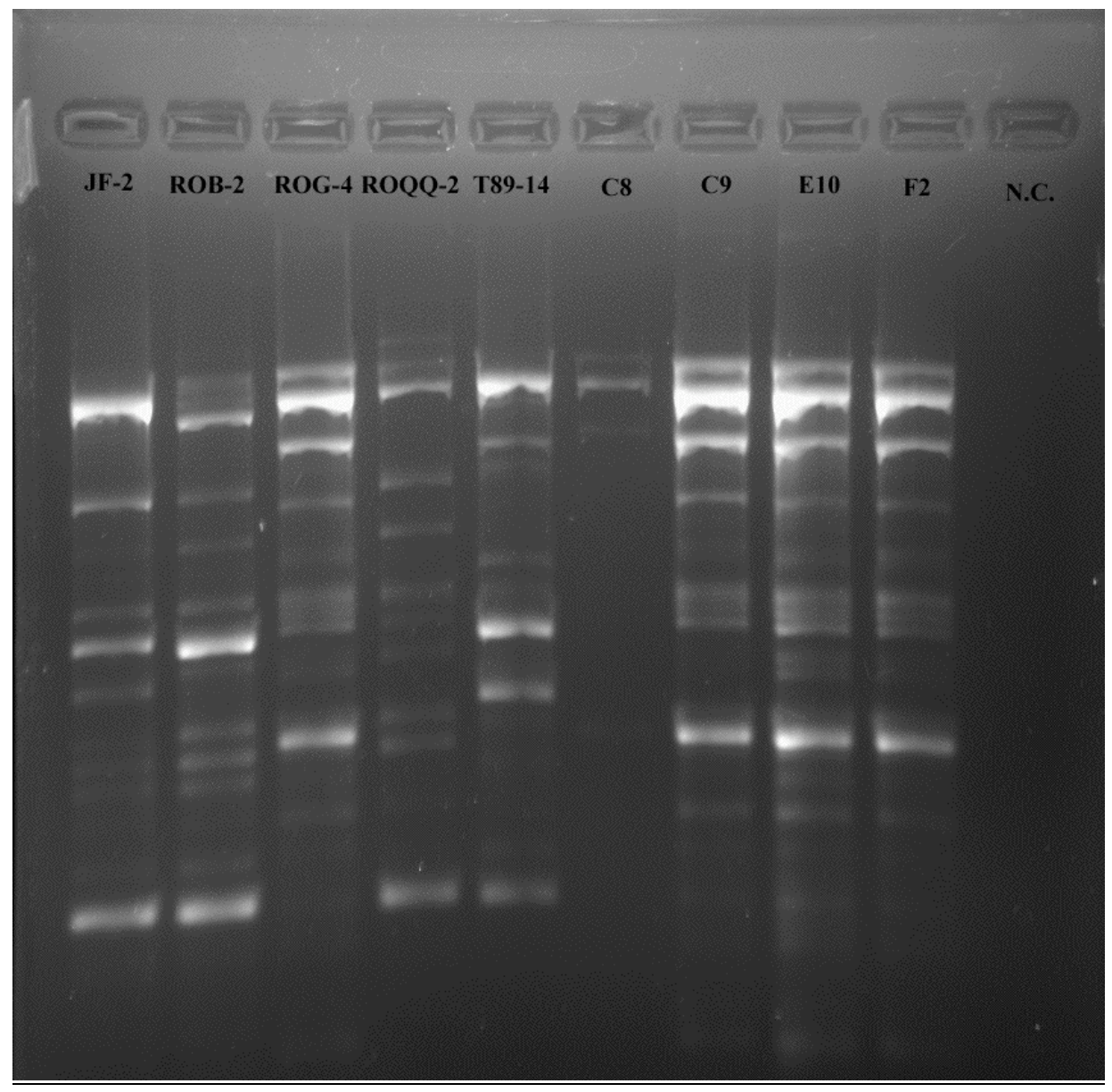

Figure 3.7: The agarose gel run for the products of the REP-PCR reaction done for the 5 original Bacillus mojavensis strains (JF-2, ROB-2, ROG-4, ROQQ-2, T89-14) and the 4 new isolates (C8, C9, E10, F2). (N.C. is the negative control). 


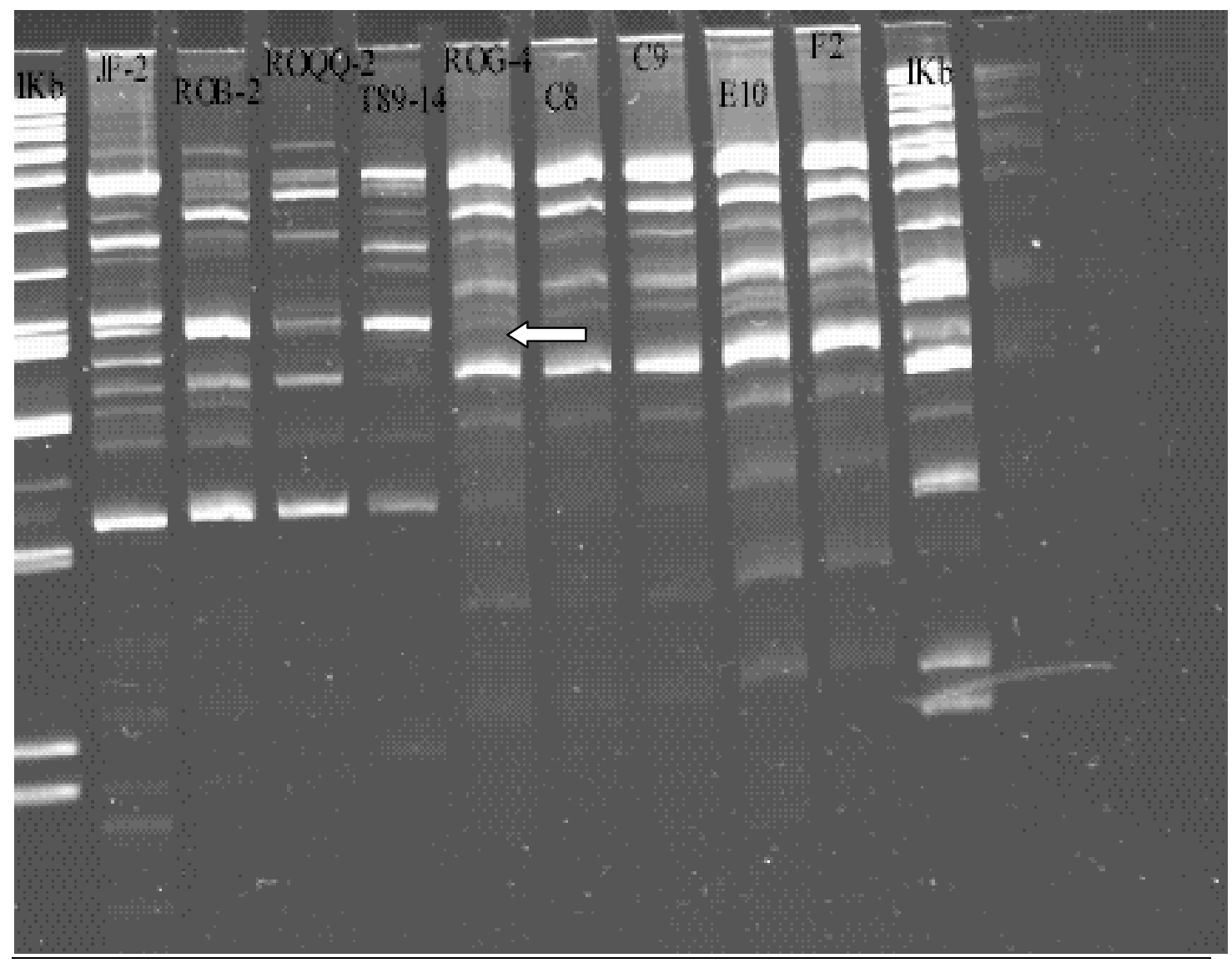

Figure 3.8: The PAGE gel elecrophoresis showing the products of the REP-PCR reaction done for the 5 original Bacillus mojavensis strains (JF-2, ROB-2, ROG-4, ROQQ-2, T8914) and the 4 new isolates $(\mathrm{C} 8, \mathrm{C} 9, \mathrm{E} 10, \mathrm{~F} 2)$. (The arrow points to the band that is present in ROG-4, absent in C8 and C9).

Selection of biosurfactant-producing Bacillus strains. JF-2 mutant strain (which is known not to produce biosurfactant) was able to grow aerobically at $37^{\circ} \mathrm{C}$ in the presence of inipol and absence of nitrate as nitrogen source. The medium still contains ammonium sulfate and yeast extract, which has other nitrogen sources that allow growth of the mutant. This suggests that inipol cannot be used for selection of biosurfactant producers unless all other nitrogen sources are removed from the medium.

Table 3.12 shows the diameters $(\mathrm{cm})$ and biosurfactant concentrations $(\mu \mathrm{g} / \mathrm{ml})$ obtained when oil spreading technique was done over a 7-day period for both aerobic and 
anaerobic cultures of JF-2, ROB-2, mixed spores of both, and co-cultures of both in medium $\mathrm{E}$ with inipol instead of the nitrate. It was observed that in the aerobic medium prepared with inipol instead of the nitrate, the amount of biosurfactant produced with any of the strains (JF-2, ROB-2, mixed spores of both, and co-culture of both) decreased steadily over a period of 7 days. While in case of anaerobic medium with inipol instead of nitrate, there was an increase in the amount of biosurfactant production after 2 days. Biosurfactant activity then decreases on the third day. Biosurfactant activity was higher under anaerobic conditions when medium E with inipol (without nitrate) was used compared to medium $\mathrm{E}$ with nitrate (without inipol). In the latter case, the maximum amount of biosurfactant produced was between $200-300 \mu \mathrm{g} / \mathrm{ml}$ for JF-2. 
Table 3.12: The diameters $(\mathrm{cm})$ and biosurfactant concentration $(\mathrm{mg} / \mathrm{ml})$ measured by the oil spreading technique for aerobic and anaerobic samples of JF-2, ROB-2, mixed spores of both, and co-culture of both in medium $\mathrm{E}$ with inipol instead of the nitrate.

\begin{tabular}{llllllll}
\hline Anaerobic & & \multicolumn{5}{c}{ Aerobic } \\
\hline Strain & Days & Diameter & Conc. & Strain & Days & Diameter & Conc. \\
& 1 & 2.1 & 2.4 & JF-2 & 1 & 3.9 & 7.6 \\
& 2 & 4.25 & 9.0 & & 2 & 2.35 & 2.9 \\
& 3 & 3 & 4.6 & & 3 & 2.5 & 3.3 \\
& 6 & 1 & 0.74 & & 6 & 1.8 & 1.8 \\
ROB-2 & 1 & 2.7 & 3.8 & ROB-2 & 1 & 3.9 & 7.6 \\
& 2 & 4 & 8.0 & & 2 & 3 & 4.6 \\
& 3 & 3 & 4.6 & & 3 & 2.5 & 3.3 \\
& 6 & 1.2 & 0.95 & & 6 & 2.4 & 3.05 \\
Mixed & 1 & 6.9 & 23.4 & Mixed & 1 & 3 & 4.6 \\
& 2 & 8 & 31.3 & spores & 2 & 2 & 2.2 \\
& 3 & 5.25 & 13.6 & & 3 & 2 & 2.2 \\
& 6 & 1.8 & 1.8 & & 6.7 & 2.4 & 3.05 \\
Co- & 1 & 2.7 & 3.8 & Co- & 1 & 3.3 & 5.54 \\
culture & 2 & 4.75 & 11.2 & culture & 2 & 3.25 & 5.4 \\
& 3 & 4.5 & 10.1 & & 3 & 1.5 & 1.3 \\
& 6 & 1 & 0.74 & & 6 & 1.8 & 1.8 \\
\hline
\end{tabular}


Figure 3.9: Stability of the biosurfactant produced aerobically in medium E with inipol over 1 week period.

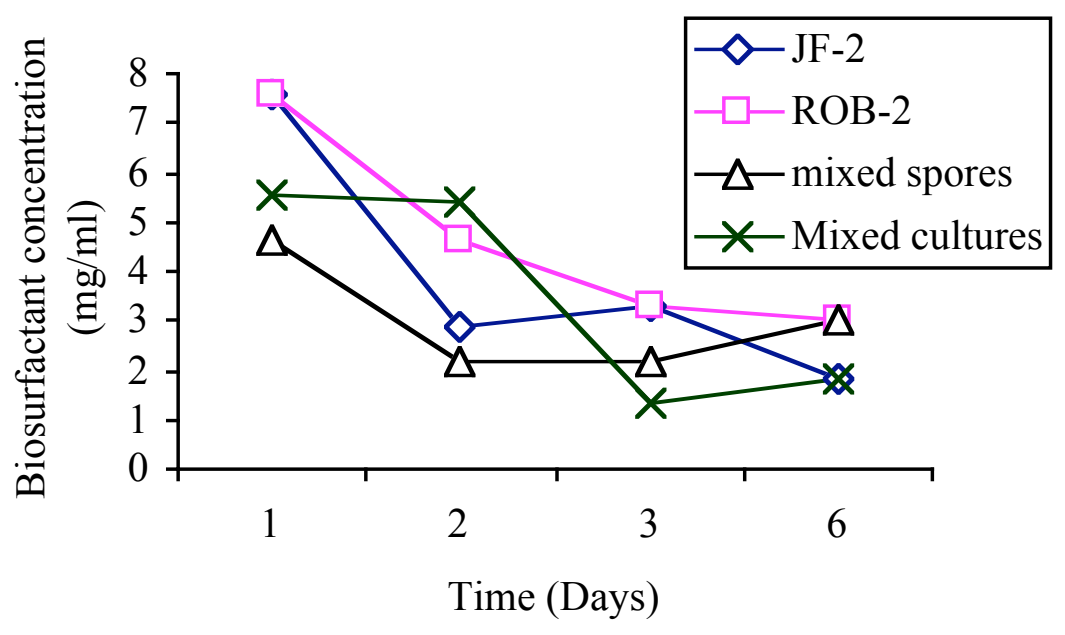

Figure 3.10: Stability of the biosurfactant produced anaerobically in medium E with inipol over 1 week period.

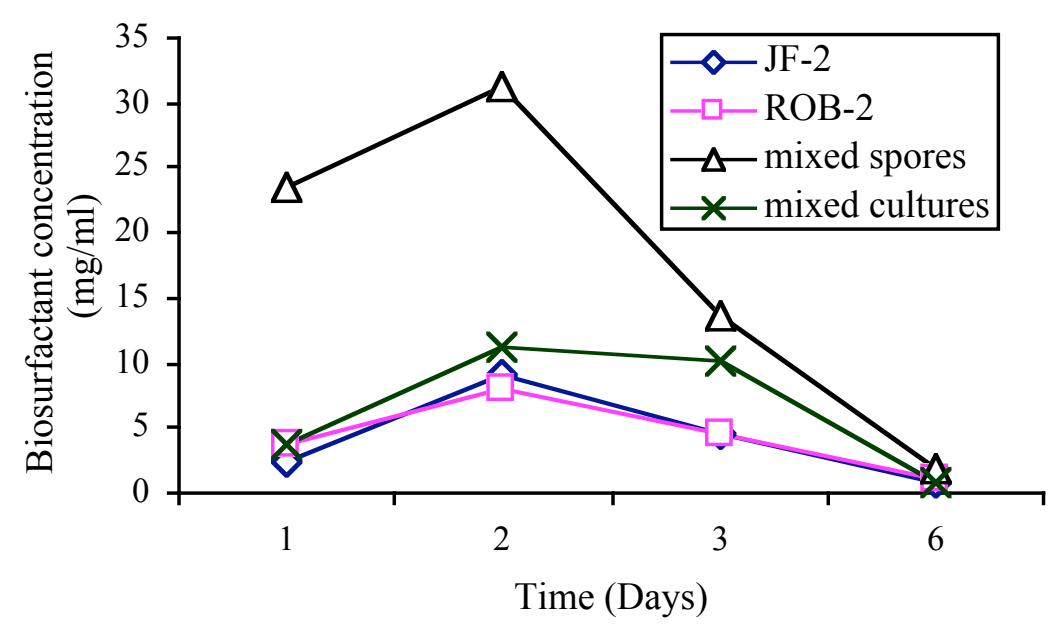

Figures 3.9 and 3.10 show the amount of biosurfactant produced over a 7-day period by JF-2, ROB-2, mixed spores of both, and co-cultures of both when they were grown in medium $\mathrm{E}$ with inipol under aerobic and anaerobic conditions respectively. 


\subsection{Discussion.}

In this work, we combined traditional screening of naturally occurring Bacillus isolates and genetic recombination of Bacillus spores to obtain cultures capable of efficient biosurfactant production under various environmental conditions. The work clearly highlights the potential for biosurfactant production among natural Bacillus isolates, and also indicates the usefulness of genetic recombination to achieve the same goal. We also utilized the screening effort to compare various existing methods for biosurfactant screening, and highlight the advantages and disadvantages of each.

It has been known that genetic recombination can occur between mixed germinating spores of Bacillus species [6,7]. This was tried successfully between members of Bacillus subtilis and Bacillus licheniformis [6]. We applied genetic recombination on biosurfactant-producing Bacillus mojavensis by mixing germinating spores preparation of five different Bacillus mojavensis strains. Our aim was to obtain Bacillus strains with better or improved biosurfactant-producing ability. The results showed that a more biosurfactant was produced by the mixed spore preparation compared to the amount produced by any of the individual strains or by the mixed culture controls. These results suggest that genetic recombination might have occurred between the 5 original strains. Isolation of 4 new isolates from the mixed spore preparation with a biosurfactant-producing ability better than any of the original strains in amount and stability, and differences in the band pattern of the REP-PCR reaction products between the 4 new isolates and the 5 original strains further support the contention that genetic recombination occurred. 
The ability to obtain recombinant strains by mixing germinating spores of the parent strains is not only useful in improving biosurfactant-producing ability. It can be also applied to get strains that are capable of producing biosurfactant under anaerobic condition, or that do not require expensive nutrients for growth and biosurfactant production such as Proteose peptone (Chapter 2). The latter application would markedly reduce costs for in situ applications of microbially-mediated oil recovery. Biosurfactants produced by these new strains could also be useful in aspects other than MEOR depending on their chemical structure. Some biosurfactants are known to have therapeutic application as antibiotics, antimicrobial agents, antifungals, or antivirals. Biosurfactants can also be used in bioremediation processes of soil or sand, or in the cleanup of hydrocarbon contaminants in groundwater [17].

Screening 157 Bacillus strains for growth and biosurfactant production showed that 147 strains were capable of producing biosurfactant under aerobic conditions. Thirty three of these produced biosurfactants in amounts that were at least twice the amount produced by JF-2 with members of Bacillus subtilis subspecies subtilis being the most promising strains. In contrast to JF-2, some of the strains were able to maintain their biosurfactant production over a period of 7-14 days. Members of B. licheniformis and $B$. sonorensis did not require proteose peptone for growth under anaerobic conditions. Thus, we have a number of promising strains, either because of the amount of biosurfactant produced, the stability of biosurfactant production over time, or the capability of anaerobic growth without proteose peptone, that can be used in genetic recombination experiments with JF-2 in the future to obtain recombinant strains that have improved 
properties for MEOR. This approach should allow us to obtain strains that do not have the technical problems that have been encountered with JF-2.

Several methods were used for screening of biosurfactant production. However, the oil spreading technique proved to be a quantitative and reproducible method for determining the activity of biosurfactant produced by different Bacillus strains. The principal of the method depends on the decrease in water-oil interfacial tension caused by the biosurfactant regardless of its structure [12]. Other quantitative approaches such as HPLC are effective. However, the chromatographic conditions have to be optimized for each class of biosurfactants, thus, making it difficult to use it as a general screening method to detect biosurfactants of unknown composition in diverse bacteria. The drop collapse method is only semi-quantitative and is not sensitive enough to detect slight differences in biosurfactant activity. However, it can be used for rapid screening of a large number of strains at the same time (96 strains per microtiter dish). The blood agar plate method is a useful preliminary approach in screening to detect biosurfactant production. However, it can give both false positive (hemolytic agents other than biosurfactants) and false negative (biosurfactants with non-hemolytic activity) results, which can only be discerned upon further testing.

\subsection{References.}

1. Banat I. M. 1995. Characterization of biosurfactants and their use in pollution removal-state of the art. Acta Biotechnologica 15, 251-267.

2. Sullivan E. R. 1998. Molecular genetics of biosurfactant production. Current opinion in biotechnology 9; 263-269. 
3. Banat I.M., Makkar R.S., and Cameotra S.S. 2000. Potential commercial applications of microbial surfactants. Applied microbiology and biotechnology 53, 495-508.

4. Georgiou G., Lin S., and Sharma M. M. 1992. Surface-active compounds from microorganisms. Biotechnology 10, 60-65.

5. Lin S., Minton M.A., Sharma M.M., and Georgio G. 1994. Structural and immunological characterization of a biosurfactant produced by Bacillus licheniformis JF-2. Applied and environmental microbiology 60(1);

6. Duncan K.E., Istock C. A., Graham J. B., Ferguson N. 1989. Genetic exchange between Bacillus subtilis and Bacillus licheniformis: variable hybrid stability and the nature of bacterial species. Evolution 43(8); 1585-1609.

7. Orrego C., Arnaud M., and Halvorson H.O. 1978. Bacillus subtilis 168 genetic transformation mediated by outgrowing spores: necessity for cell contact. Journal of bacteriology 134(4); 973-981.

8. Duncan K. E., Ferguson N., Kimura K., Zhou X., and Istock C.A. 1994.Fine-scale genetic and phenotypic structure in natural populations of Bacillus subtilus and Bacillus licheniformis: implications for bacterial evolution and speciation. Evolution 48(6); 2002-2025.

9. Javaheri M., Jenneman G.E., Mcinerney M. J. and Knapp R.M. 1985. Anaerobic production of a biosurfactant by Bacillus licheniformis JF-2. Applied and environmental microbiology 50: 698-700.

10. Bodour A. A., and Miller-Maier R.M. 1998. Application of a modified drop collapse technique for surfactant quantitation and screening of biosurfactant- 
producing microorganisms. Journal of microbiological methods 32, 273-280.

11. Jain D. K., Collins-Thompson, D. L.; Lee, H.; and Trevors, J. T. 1991. A drop-collapsing test for screening surfactant-producing microorganisms. Journal of microbiological methods 13, 271-279.

12. Morikawa M., Hirata Y., and Imanaka T. 2000. A study on the structure-function relationship of lipopeptide biosurfactants. Biochimica et Biophysica Acta 1488(3); 211-218.

13. McInerney MJ, Javaheri M, Nagle DP Jr. 1990. Properties of the biosurfactant produced by Bacillus licheniformis strain JF-2. Journal of Industrial Microbiology 5(2-3): 95-101.

14. Matsuyama T., Sogawa M., and Yano I. 1987. Direct colony thin layer chromatography and rapid characterization of Serratia marcescens mutants defective in production of wetting agents. Applied and environmental microbiology 53(5); 1186-1188.

15. Stahl, E. 1969. Thin-layer chromatography. A laboratory handbook. Second edition, fully revised and expanded. Berlin, Heidelberg, New York, Springer.

16. Versalovic J., Schneider M., De Bruijn F. J., and Lupski J. R. 1994. Genomic fingerprinting of bacteria using repetitive sequence-based polymerase chain reaction. Methods in molecular and cellular biology 5:25-40.

17. Ron E. Z., and Rosenburg E. 2001. Natural roles of biosurfactants. Environmental microbiology `3(4); 229-236. 


\section{Chapter 4. Interfacial Tension Measurements}

\subsection{Abstract}

Interfacial tensions (IFT) between crude oil and water in the presence of varying concentrations of the biosurfactant produced by Bacillus mojavensis JF-2 bio-surfactant were determined. Effects of salinity and co-surfactant 2,3-butanediol were also studied. The biosurfactant lowered IFT by nearly 2 orders of magnitude compared to typical values of $28-29 \mathrm{mN} / \mathrm{m}$. Increasing the salinity increased the IFT with or without 2,3-butanediol present. The lowest interfacial tension observed was $0.1 \mathrm{mN} / \mathrm{m}$.

\subsection{Introduction}

In Chapter 4, we found that the JF-2 biosurfactant in the presence of a viscosifying agent and a co-surfactant, 2,3-butanediol, could recover significant amounts of residual oil. The recovery of residual oil depends on the generation of low interfacial tensions in order to release oil that is entrapped in small pores. The data in Chapter 4 suggested that the JF-2 biosurfactant could significantly lower the interfacial tension. This study was conducted to test whether the JF-2 biosurfactant does generate low interfacial tensions. The presence of a cosurfactant, 2,3-butanediol was shown to improve oil recoveries (Maudgalya, 2002) possibly by changing the optimal salinity concentration of the formulation. For this reason, we also tested the effect of 2,3-butanediol on interfacial tension.

\subsection{Methods}


Procedures for the growth of Bacillus mojavensis strain JF-2, preparation of cell-free culture fluids, and quantitation of the JF-2 biosurfactant are described in Chapter 2 of this report. Bacillus mojavensis strain JF-2 was grown aerobically in medium E in 300-ml cultures. The medium was inoculated with $B$. mojavensis strain JF-2 (1\% by volume) and incubated at $37^{\circ} \mathrm{C}$ without shaking for 24 hours. The culture was then centrifuged to remove the cells and the concentration of the JF-2 biosurfactant in the cell-free culture fluid was determined by high-pressure liquid chromatography. The cell-free culture fluid was used immediately for analysis.

The effect of the biosurfactant concentration, salinity and the presence of 2,3-butanediol, a co-surfactant, on interfacial tension was determined. Cell-free culture fluid containing of the JF-2 biosurfactant was diluted two-fold and five-fold to give three aliquots of the original culture that contained 11,28 or $57 \mathrm{mg} / 1$ of the JF-2 biosurfactant. The dilutions were preformed with uninoculated, sterile medium $E$ in order to maintain the same salinity and chemical composition as the original culture. Each aliquot representing a different biosurfactant concentration was then split into three portions. Enough solid $\mathrm{NaCl}$ was added to one of the portions to give a final $\mathrm{NaCl}$ concentration of $75 \mathrm{~g} / 1$; another portion received enough $\mathrm{NaCl}$ to give a final $\mathrm{NaCl}$ concentration of $100 \mathrm{~g} / 1$. The remaining portion did not received additional $\mathrm{NaCl}$ and had a $\mathrm{NaCl}$ concentration of $50 \mathrm{~g} / 1$, which is the $\mathrm{NaCl}$ concentration of medium $\mathrm{E}$.

In another experiment, the effect of the presence of a co-solvent, 2,3-butanediol, was studied along with studying the effects of biosurfactant concentration and salinity. The experiment was conducted in a similar fashion as described above using two different cultures of $B$. mojavensis strain JF-2 that contained 54.0 and $58.0 \mathrm{mg} / 1$ of the biosurfactant. Each culture was split into equal volumes and to one portion enough solid 2,3-butanediol was added to give a final concentration of $10 \mathrm{mM}$. Each portion (e. g., with and without 2,3- 
butanediol) was then two- and five-fold diluted as described above. After dilution, the concentration of the JF-2 biosurfactant from one culture was 54,27 and $11 \mathrm{mg} / 1$ while that of the other culture was 58,29 and $12 \mathrm{mg} / 1$.

Interfacial tension (IFT) was measured by using a spinning drop tensiometer. Duplicate measurements were conducted for each of the above treatments. The capillary tube of the tensiometer was filled with the biosurfactant solution or the sterile medium E. A drop of $44^{\circ}$ API crude oil was then introduced into the aqueous phase by using a syringe and needle. IFT's were measured as the tube rotated at high speeds. The IFT value was recorded after the diameter of the drop did not change with time.

\subsection{Results}

The biosurfactant concentrations of three replicate cultures of $B$. mojavensis strain JF-2 grown at different times with different inocula were 57,54 and $58 \mathrm{mg} / 1$ to give a mean and standard deviation of $56.3 \pm$ 2.1. The coefficient of variation was $3.7 \%$, indicating a high degree of reproducibility in biosurfactant concentration among cultures grown at different times and with different inocula.

Table 4.1 summarizes the effects of biosurfactant concentration, salinity and the presence of 2,3-butanediol on the interfacial tension between culture medium and crude oil. 
Table 4.1. Summary of interfacial tension measurements at different biosurfactant concentrations, salinities with and without 2,3-butanediol.

\begin{tabular}{lllll}
\hline $\begin{array}{l}\text { Biosurfactant } \begin{array}{l}\text { concentration } \\
(\mathrm{mg} / \mathrm{l})\end{array} \\
\text { 56 }\end{array}$ & Additions & \multicolumn{2}{l}{$\begin{array}{l}\text { Interfacial tension }(\mathrm{mN} / \mathrm{M}) \text { at different } \mathrm{NaCl} \\
\text { concentrations. }\end{array}$} \\
\cline { 2 - 5 } & $50 \mathrm{~g} / \mathrm{l}$ & $75 \mathrm{~g} / \mathrm{l}$ & $100 \mathrm{~g} / 1$ \\
\hline \multirow{2}{*}{23} & None & $0.2(0.15)^{*}$ & $0.7(0.7)^{*}$ & $3.5(0.8)^{*}$ \\
& Butanediol & $0.2(0.08)$ & $1.5(0.2)$ & $2.0(0.8)$ \\
11 & None & $0.8(0.7)$ & $1.1(0.2)$ & $2.6(1.9)$ \\
& Butanediol & $0.4(0.2)$ & $2.4(0.4)$ & $2.2(0.7)$ \\
& None & $1.6(1.0)$ & $3.2(0.8)$ & $3.8(0.7)$ \\
& Butanediol & $2.0(1.2)$ & $2.0(0.4)$ & $3.6(1.0)$ \\
\hline
\end{tabular}

*Values are means with the standard deviation given in parentheses.

The lowest interfacial tension measured was $0.1 \mathrm{mN} / \mathrm{m}$. This is two orders of magnitude lower than the typical IFT between crude oil and water of 29 to $32 \mathrm{mN} / \mathrm{m}$ as reported by Green and Willhite (1998). The interfacial tensions were lower at $50 \mathrm{~g} / 1 \mathrm{NaCl}$ than at the higher salinities regardless of the biosurfactant concentration.

Two-factor analysis of variance was used to determine whether the biosurfactant concentration and salinity significantly affected interfacial tension. Table 4.2 shows the means interfacial tensions of each treatment and Table 4.3 shows the results of the analysis of variance.

Table 4.2. Effect of salinity and biosurfactant concentration on interfacial tension between culture medium and crude oil without 2,3-butanediol.

\begin{tabular}{llll}
\hline $\begin{array}{l}\text { Biosurfactant } \\
\text { concentration } \\
(\mathrm{mg} / \mathrm{l})\end{array}$ & \multicolumn{3}{l}{ Mean interfacial tensions at different salinities } \\
\cline { 2 - 4 } & $50 \mathrm{~g} / \mathrm{l}$ & $75 \mathrm{~g} / \mathrm{l}$ & $100 \mathrm{~g} / \mathrm{l}$ \\
\hline 56 & 0.1 & 0.8 & 3.5 \\
23 & 1.0 & 1.2 & 2.8 \\
11 & 1.4 & 3.4 & 4.1 \\
\hline
\end{tabular}


Table 4.3. Two-factor analysis of variance summary table on the effects of salinity and biosurfactant concentration on interfacial tension between culture medium and crude oil.

\begin{tabular}{lllllll}
\hline $\begin{array}{l}\text { Source of } \\
\text { variance }\end{array}$ & $\begin{array}{l}\text { Sums of } \\
\text { squares }\end{array}$ & $\begin{array}{l}\text { Degrees } \\
\text { of } \\
\text { freedom }\end{array}$ & $\begin{array}{l}\text { Mean } \\
\text { squared } \\
\text { deviation } \\
\text { from the } \\
\text { mean }\end{array}$ & F value & P value & F critical \\
\hline Concentration & 16.3 & 2 & 8.1 & 7.953 & 0.00192 & 3.354 \\
Salinity & 43.1 & 2 & 21.6 & 21.05 & $3.1 \mathrm{E}-06$ & 3.354 \\
Interaction & 6.6 & 4 & 1.7 & 1.622 & 0.19753 & 2.728 \\
Within cells & 27.7 & 27 & 1.0 & & & \\
Total & 93.7 & 35 & & & & \\
\hline
\end{tabular}

The analysis of variance shows that there were significant differences among all of the treatments $(\mathrm{P}<0.05)$. Both the biosurfactant concentration and the $\mathrm{NaCl}$ concentration affected the interfacial tension. Increasing the $\mathrm{NaCl}$ concentration significantly increased the interfacial tension as did decreasing the biosurfactant concentration. There was no significant interaction between these two factors.

A second two-factor analysis of variance was conducted to assess the effect of 2,3-butanediol on interfacial tension. For this analysis, only data at a biosurfactant concentration of $23 \mathrm{mg} / \mathrm{l}$ was used since it was not possible to obtain interfacial tension measurements at all salt concentrations at the other two biosurfactant concentrations. The mean values obtained from this analysis are shown in Table 4.4 and the summary statistics are shown in Table 4.5 . 
Table 4.4. Effect of the presence of 2,3-butanediol on interfacial tension between culture medium and crude oil at a biosurfactant concentration of $26 \mathrm{mg} / \mathrm{l}$.

\begin{tabular}{llll}
\hline Additions & \multicolumn{3}{l}{ Mean interfacial tensions at salinities $(\mathrm{g} / \mathrm{l})$ of } \\
\cline { 2 - 4 } & 50 & 75 & 100 \\
\hline None & 0.4 & 0.75 & 1.2 \\
2,3-Butanediol & 0.4 & 2.5 & 2.2 \\
\hline
\end{tabular}

Table 4.5. Two factor analysis of variance summary table on the effect of the presence of 2,3-butanediol on interfacial tension between culture medium and crude oil.

\begin{tabular}{lllllll}
\hline $\begin{array}{l}\text { Source of } \\
\text { variance }\end{array}$ & $\begin{array}{l}\text { Sums of } \\
\text { squares }\end{array}$ & $\begin{array}{l}\text { Degrees of } \\
\text { freedom }\end{array}$ & $\begin{array}{l}\text { Mean } \\
\text { squared } \\
\text { deviation } \\
\text { from the } \\
\text { mean }\end{array}$ & F value & P value & F critical \\
\hline Butanediol & 5.0 & 1 & 5.0 & 24.9 & $9 \mathrm{E}-5$ & 4.41 \\
Salinity & 8.3 & 2 & 4.1 & 20.6 & $2 \mathrm{E}-5$ & 3.35 \\
$\begin{array}{l}\text { Interaction } \\
\text { Within }\end{array}$ & 2.9 & 2 & 1.4 & 7.24 & 0.005 & 3.35 \\
cells & 3.6 & 8 & 0.2 & & & \\
Total & 19.9 & 23 & & & & \\
\hline
\end{tabular}

Again, increasing salinity significantly affected the interfacial tension with the lowest values once again obtained at $50 \mathrm{~g} / 1$ salt. Interfacial tensions were higher in the presence of 2,3-butanediol compared to replicate treatments without 2,3-butanediol. The interaction between these two factors was also significant.

With $50 \mathrm{~g} / 1 \mathrm{NaCl}$, the presence of 2,3-butanediol had impact except at the lowest biosurfactant concentration (Figure 4.1). When the $\mathrm{NaCl}$ concentration was $75 \mathrm{~g} / 1$, the presence of 2,3 -butanediol raised the IFT compared to treatments without 2,3-butanediol, except when the 

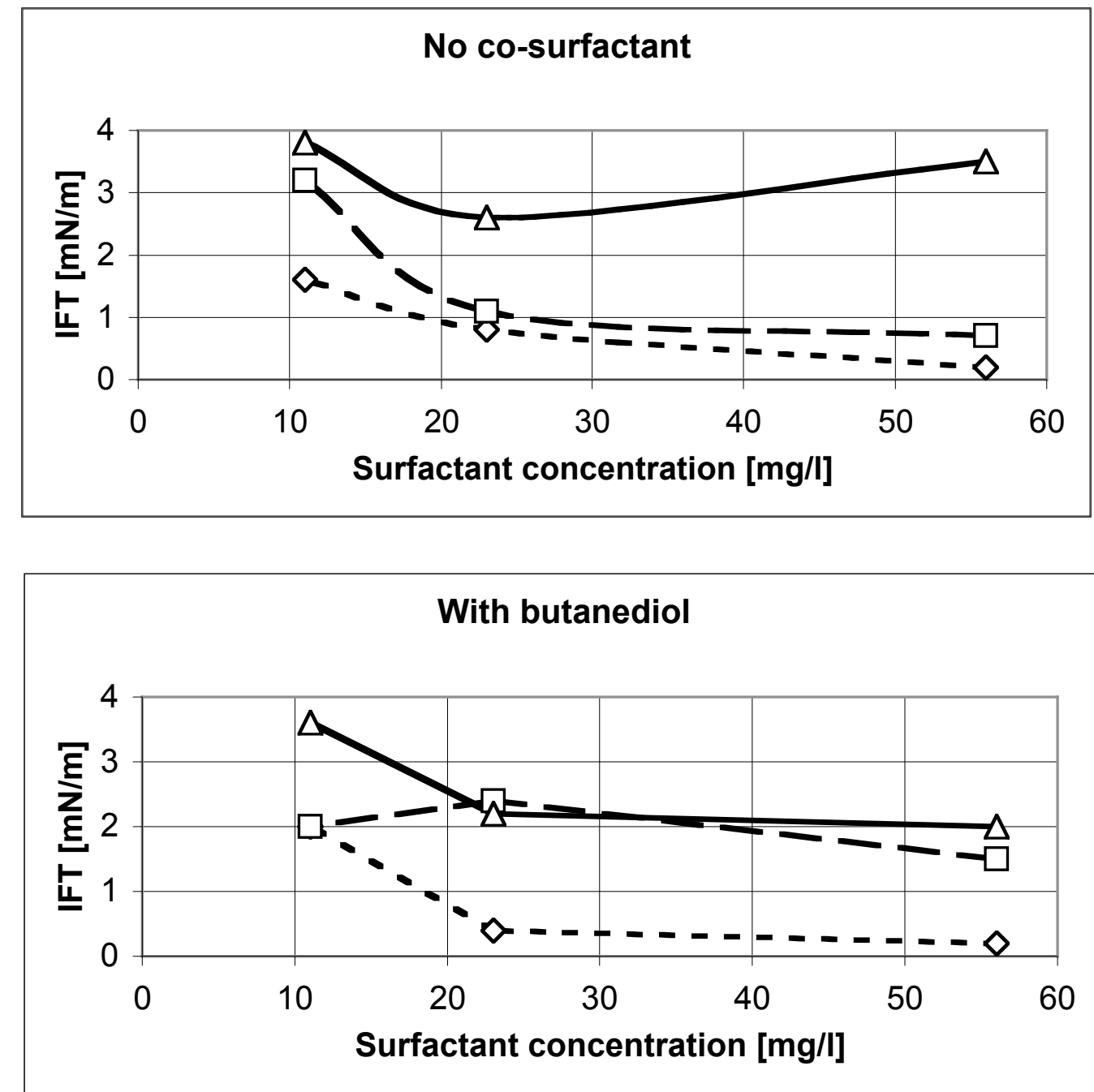

Figure 4.1. Effect of 2,3-butanediol on interfacial tension between crude oil and medium at different biosurfactant and $\mathrm{NaCl}$ concentrations. Symbols: diamonds, $50 \mathrm{~g} / \mathrm{l} \mathrm{NaCl}$; squares, $75 \mathrm{~g} / 1 \mathrm{NaCl}$; and triangles, $100 \mathrm{~g} / 1 \mathrm{NaCl}$.

biosurfactant concentration was $11 \mathrm{mg} / 1$. At $100 \mathrm{~g} / 1 \mathrm{NaCl}$ concentration, 2,3-butanediol lowered the IFT at all biosurfactant concentrations tested. With $56 \mathrm{mg} / 1$ of the biosurfactant and $100 \mathrm{~g} / 1 \mathrm{NaCl}$, the presence of 2,3butanediol lowered the IFT by $50 \%$ compared to similar treatments without 2,3-butanediol. 


\subsection{Discussion.}

The interfacial tension increases as biosurfactant concentration decreases because less biosurfactant is present at the interface between oil and water. Consequently, work done to bring the immiscible phases together results in higher interfacial tension. This is explained in detail by Rosen (1978). Healy et al. (1976) showed that salt ions repel biosurfactant molecules from the aqueous phase into the hydrocarbon phase as salinity increases. This results increases the IFT between the hydrocarbon and aqueous phases and explains the rise in IFT with increasing salinity

The increase in IFT in the presence of a co-surfactant such as 2,3butanediol may be because alcohols alter biosurfactant behavior and raise the optimal salinity of the biosurfactant. Optimal salinity is the salinity where the lowest IFT can be found. Hsieh and Shah (1977) and Wade et al.(1978) have shown that addition of water soluble alcohols raises the optimal salinity of a surfactant system and consequently, the IFT. It is to be noted that at high alcohol concentrations, the addition of more alcohol does not affect the optimal salinities or IFT of a formulation. An interesting observation was that the salinity effects were more pronounced at lower concentrations and the co-surfactant did not alter this sensitiveness to salinity.

\subsection{Conclusions:}

1. The bacteria Bacillus mojavensis JF- 2 produced a bio-surfactant that lowered interfacial tension between crude oil and water by two or more orders of magnitude.

2. Increasing salinity of the aqueous phase from $50 \mathrm{~g} / 1$ to $10 \mathrm{o} g / 1$ increased IFT with larger increases at lower bio-surfactant concentrations.

3. Addition of 2,3-butanediol caused an increase in IFT. 


\subsection{List of references}

1. Maudgalya, S.: "Development of a Bio-surfactant based Microbial Enhanced Oil Recovery Process", M.S Thesis, University of Oklahoma, 2002.

2. Green, D.W. and Willhite, G.P.: "Enhanced Oil Recovery", SPE Text Book Series Vol. 6,1998, pp. 239-300

3. Healy, R.N., Reed, R.L. and Stenmark, D.G.:"Multiphase Microemulsion Systems", SPEJ (June 1976), 147-160; Trans AIME 261 .

4. Rosen, M.J.: "Surfactants and Interfacial Phenomena", John Wiley and Sons Inc., New York City, 1978.

5. Hsieh, W.C. and Shah, D.O.: "The Effect of Chain Length of Oil and Alcohol as well as Surfactant to Alcohol ratio on the Solubilization, Phase Behavior and Interfacial tension of Oil-brineSurfactant- Alcohol Systems", SPE 6594, presented at the SPEAIME International Symposium on Oilfield and geothermal Chemistry, San Diego, CA, June 27-29, 1977.

6. Wade, W.H., Morgan, J.C., Schechter, R.S., Jacobson, J.K. and Salager, J.L.: “Interfacial tension and Phase behavior of Surfactant Systems", SPEJ 1978, pp 242-252. 